University of Louisville

ThinkIR: The University of Louisville's Institutional Repository

8-2012

\title{
Simulating and optimizing stormwater best management practices in University of Louisville watershed.
}

Mohammad Amin Zomorrodian

University of Louisville

Follow this and additional works at: https://ir.library.louisville.edu/etd

\section{Recommended Citation}

Zomorrodian, Mohammad Amin, "Simulating and optimizing stormwater best management practices in University of Louisville watershed." (2012). Electronic Theses and Dissertations. Paper 1653.

https://doi.org/10.18297/etd/1653

This Master's Thesis is brought to you for free and open access by ThinkIR: The University of Louisville's Institutional Repository. It has been accepted for inclusion in Electronic Theses and Dissertations by an authorized administrator of ThinkIR: The University of Louisville's Institutional Repository. This title appears here courtesy of the author, who has retained all other copyrights. For more information, please contact thinkir@louisville.edu. 


\title{
SIMULATING AND OPTIMIZING STORMWATER BEST MANAGEMENT PRACTICES IN UNIVERSITY OF LOUISVILLE WATERSHED
}

\author{
By \\ Mohammad Amin Zomorrodian \\ A Thesis \\ Submitted to the Faculty of the \\ J.B. Speed School of Engineering of the University of Louisville \\ In Partial Fulfillment of the Requirements \\ For the degree of

\section{Master of Science}

Department of Civil and Environmental Engineering

University of Louisville

Louisville, Kentucky

August 2012 
Copyright 2012 by Mohammad Amin Zomorrodian

All rights reserved 


\title{
SIMULATING AND OPTIMIZING STORMWATER BEST MANAGEMENT PRACTICES IN UNIVERSITY OF LOUISVILLE WATERSHED
}

\author{
By \\ Mohammad Amin Zomorrodian \\ BSCE, Ferdowsi University of Mashhad, 2010
}

A Thesis Approved on

July $18^{\text {th }}, 2012$

By the following Thesis Committee:

Dr. Thomas. D. Rockaway, Thesis Director

Dr. J. P. Mohsen

Mr. Robert. W. Forbes 


\section{DEDICATION}

To my parents 


\section{ACKNOWLEDGMENTS}

I would like to express my deep gratitude to my advisor, Dr. Thomas. D. Rockaway, for his guidance that he gave me throughout this research project. I would not have accomplished the project without his supervision and support. By his recommendations and daily encouragement he gave me the resolve to push forward with greatest confidence and I am grateful for this.

I would also like to thank the thesis committee, Dr. J. P. Mohsen and Mr. Robert W. Forbes, for providing their time and advice. A particular thanks to Josh. A. Rivard, for assisting and supporting me during this research.

Also many thanks to Dr. L. F. Cohn and Dr. N. R. Bhaskar for their help and support in various areas during the last two years. 


\begin{abstract}
SIMULATING AND OPTIMIZING STORMWATER BEST MANAGEMENT PRACTICES IN UNIVERSITY OF LOUISVILLE WATERSHED

Mohammad Amin Zomorrodian
\end{abstract}

July 18, 2012

Urbanization disrupts natural soil profiles and as watersheds are urbanized, their surfaces become impervious and this will result in reduction of infiltration. For this reason, Many cities are facing problems with treating runoff water. Best management practices ( BMPs ) consist of built systems designed to reduce and control the quality of runoff water in urban areas and help to control the direction of it. This system guides water to a structural soil retention area beneath the pavement where it is then temporary stored. BMPs are based of rainwater withholding (such as infiltration basins) or infiltration into the soil (such as permeable pavement). In this project we are to create a stormwater management model for campus using a modeling software for the purpose of guiding future BMP types and locations by predicting different scenarios' efficiency based on runoff water reduction. 


\section{TABLE OF CONTENTS}

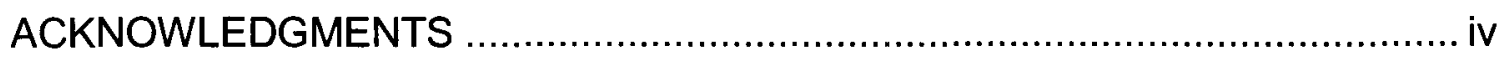

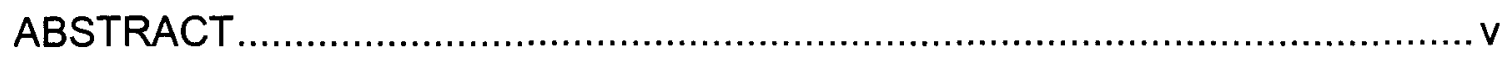

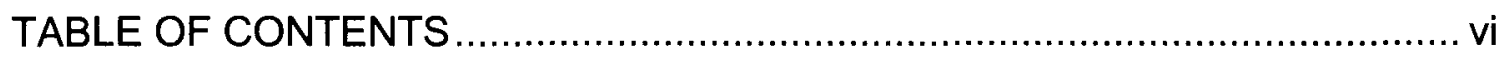

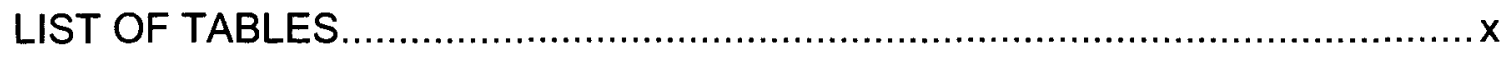

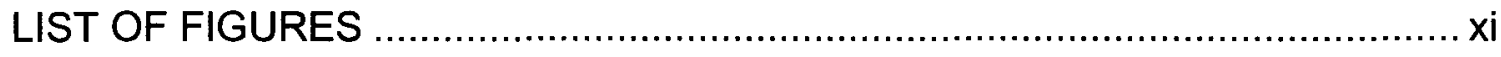

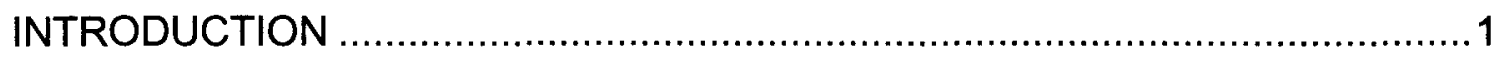

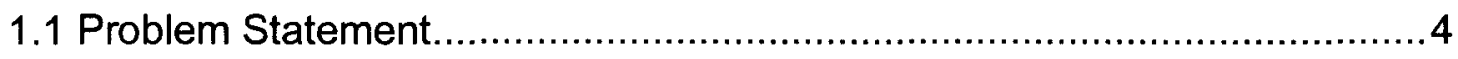

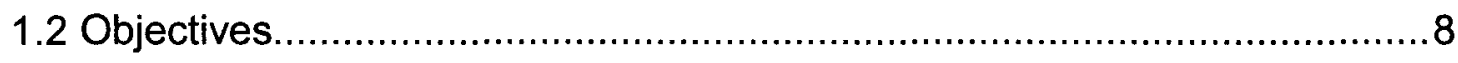

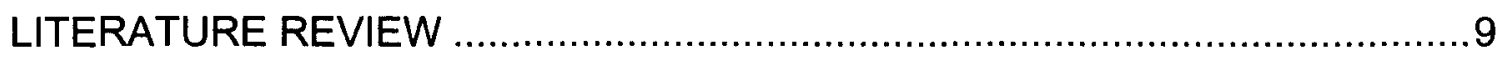

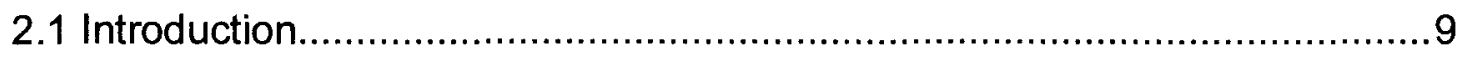

2.2 Previous studies ..................................................................... 19

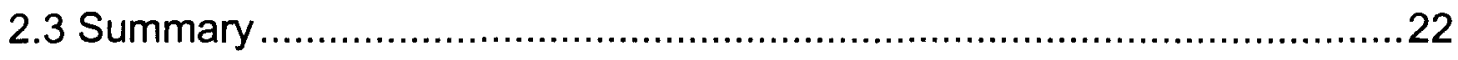

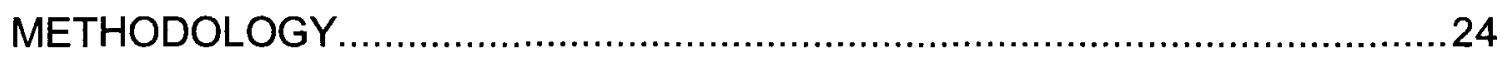

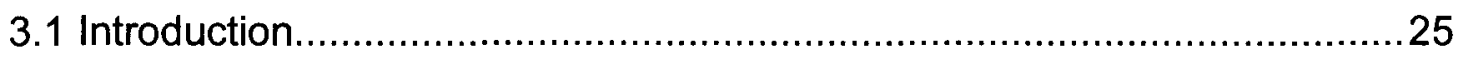

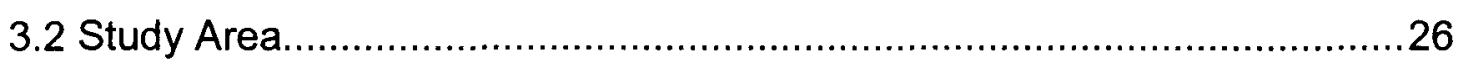

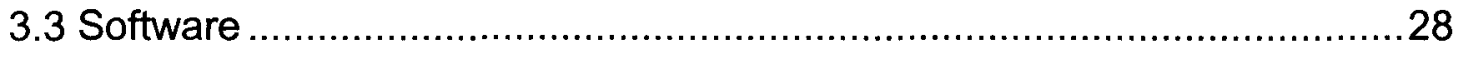




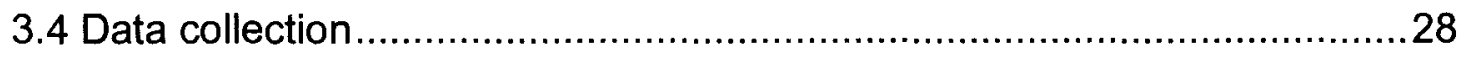

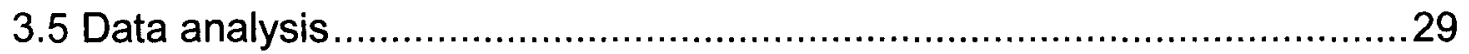

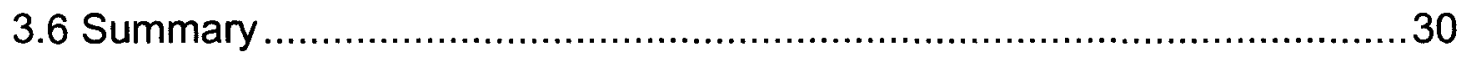

SOFTWARE

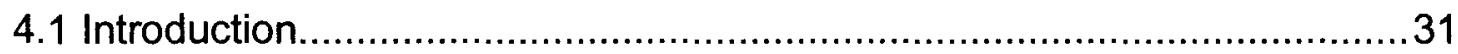

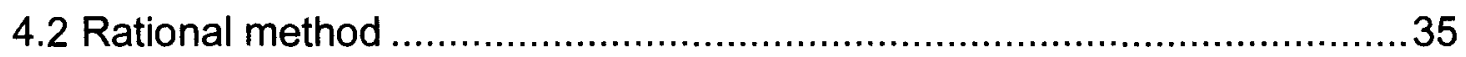

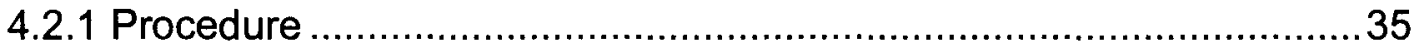

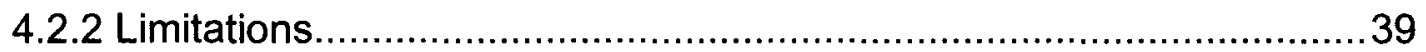

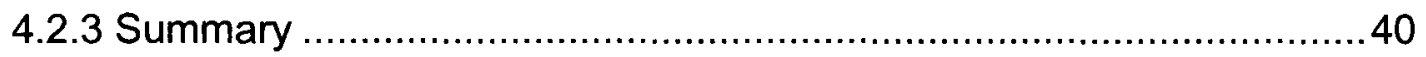

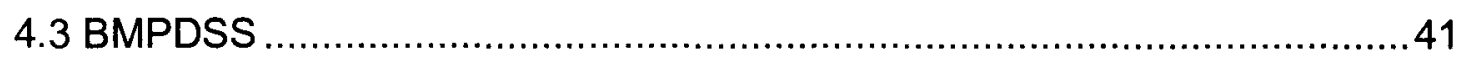

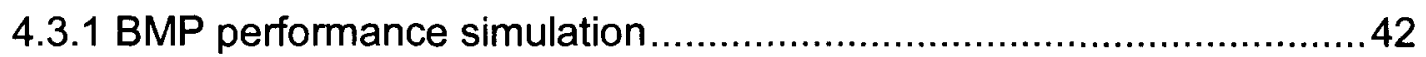

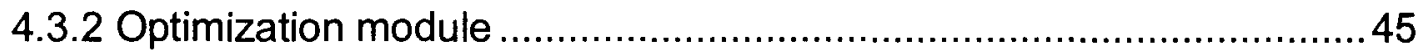

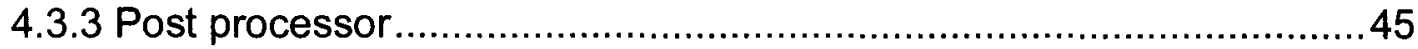

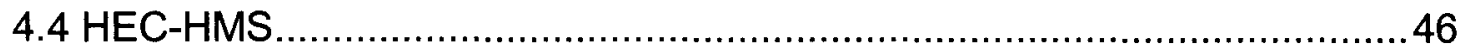

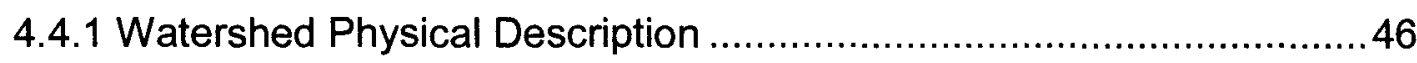

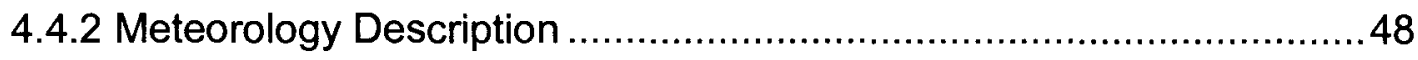

4.4.3 BMP and Hydrologic Simulation ................................................. 49

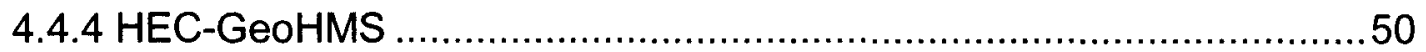

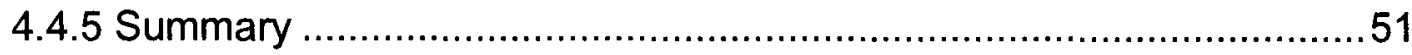

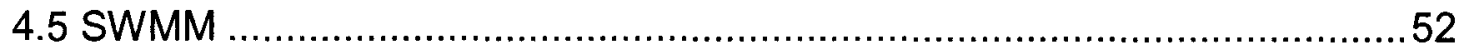




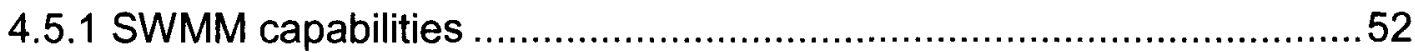

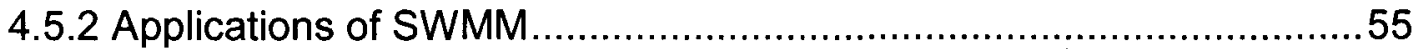

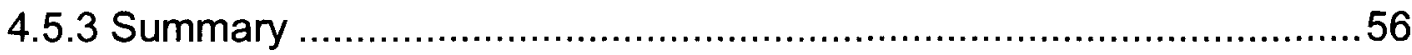

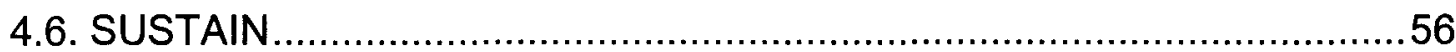

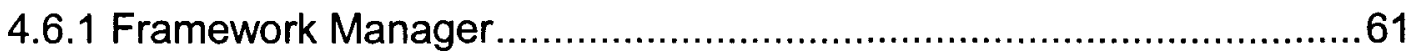

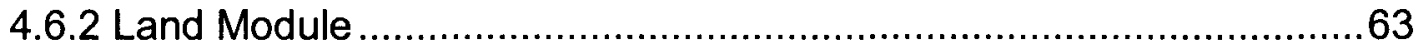

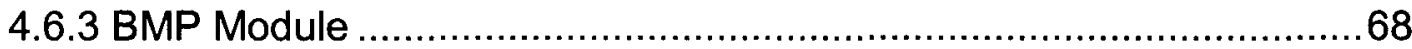

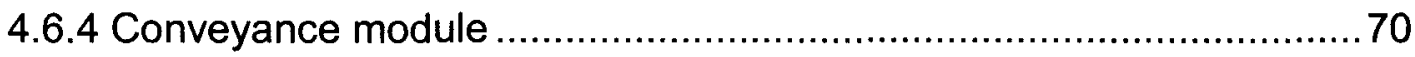

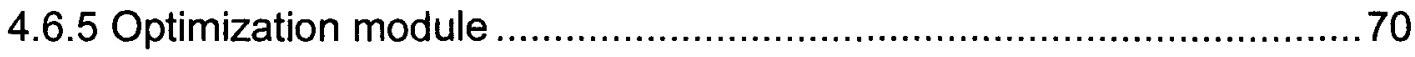

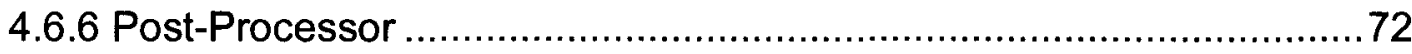

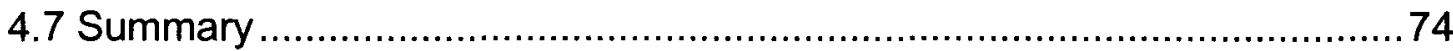

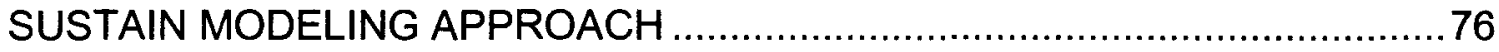

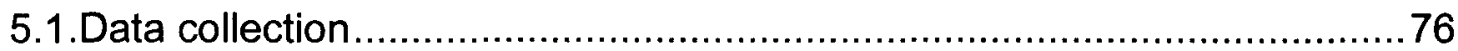

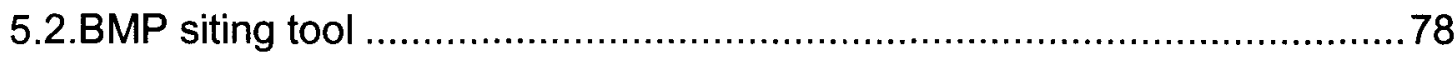

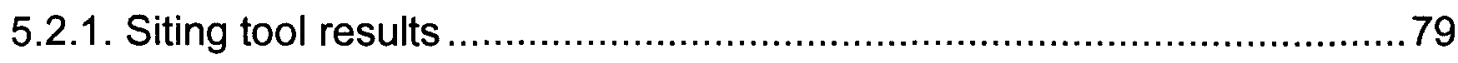

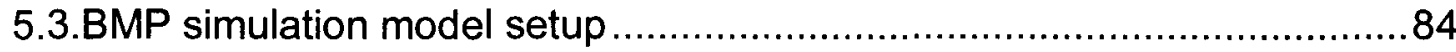

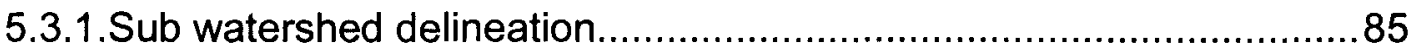

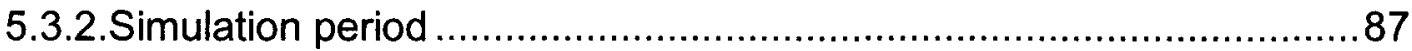

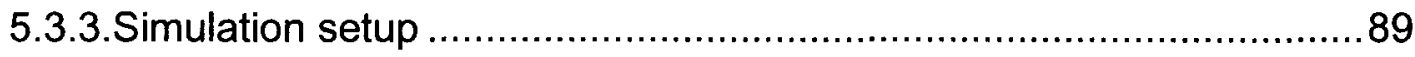

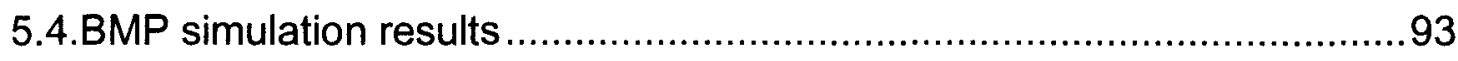




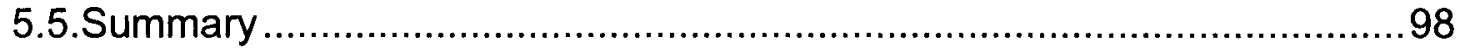

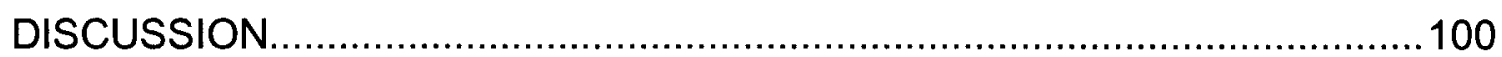

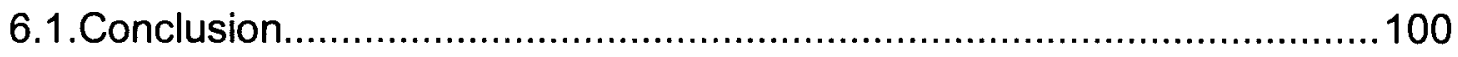

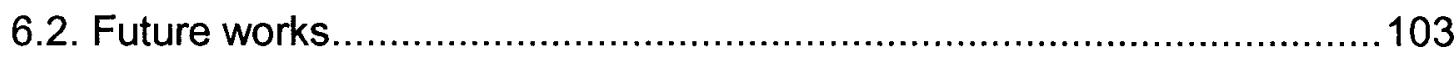

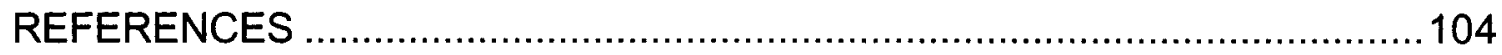

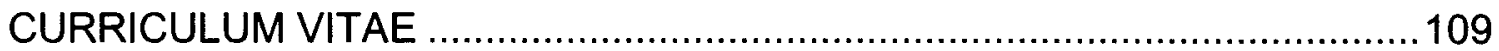




\section{LIST OF TABLES}

Table

Page

4.1 Runoff coefficients for the Rational method.

.37

4.2 Runoff Coefficient Adjustment factors.......................................................

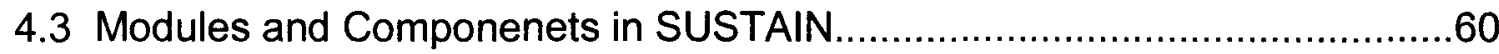

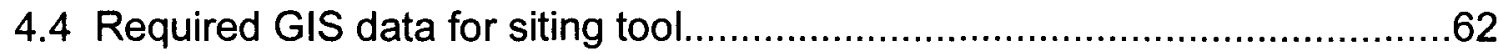

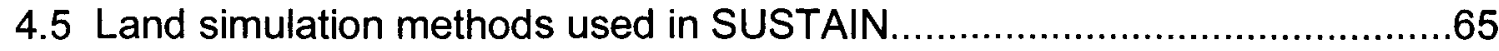

4.6 Representative BMPs and recommended simulation methods in

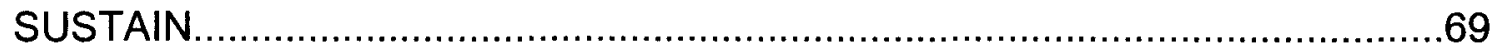

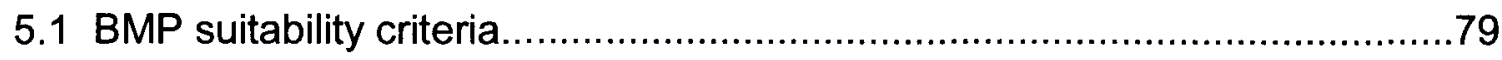

5.2 Characteristics of twelve delineated sub watersheds in University of

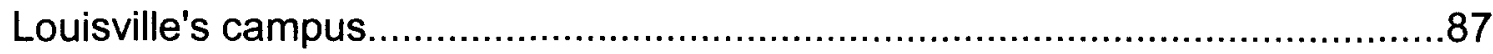

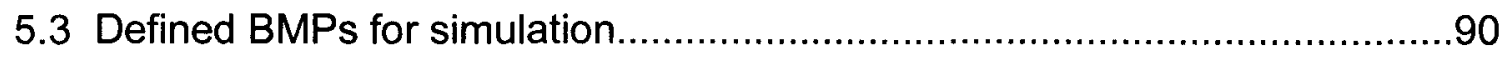

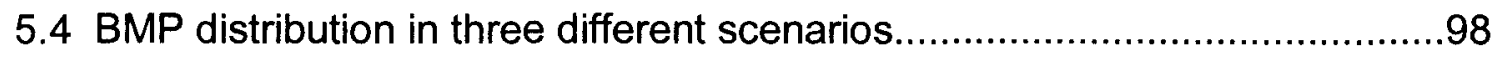




\section{LIST OF FIGURES}

$\begin{array}{lll}\text { Figure } & \text { Page }\end{array}$

1.1. Effects of Urbanization to Stormwater Runoff.........................................

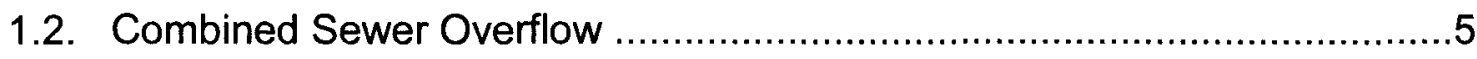

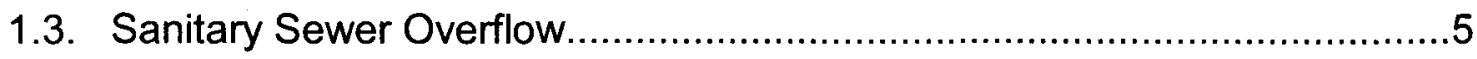

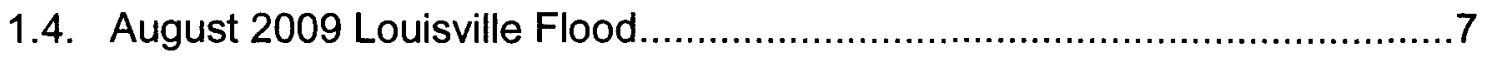

2.1. Permeable Interlocking Pavement.......................................................11

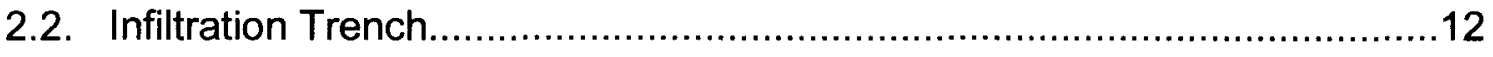

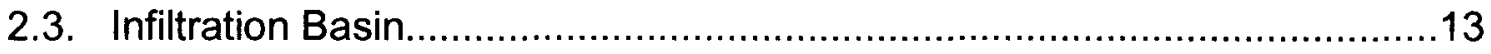

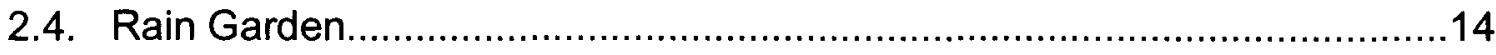

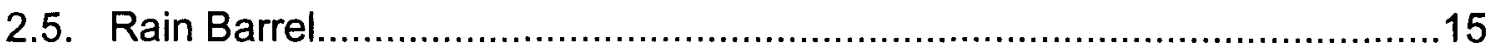

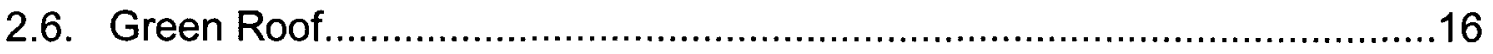

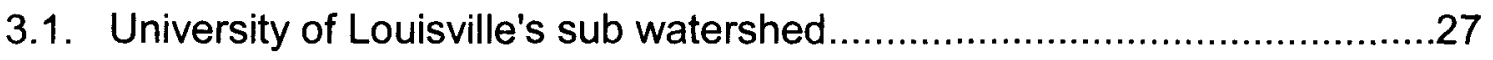

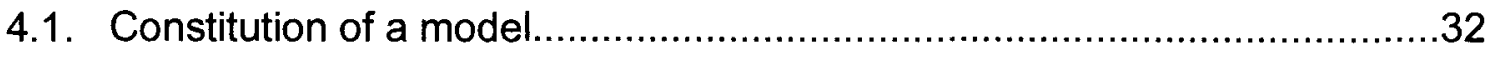

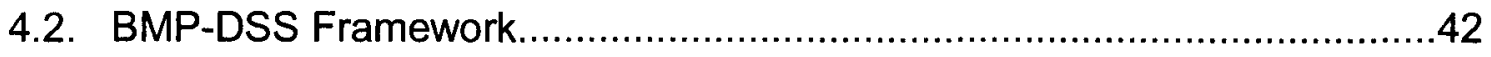


4.3. Water quality simulation processes.

4.4. Example of a basin model.

4.5. Cumulative plot for two month BMP simulation period .50

4.6. Key components and flow chart of SUSTAIN .58

4.7. Example of siting tool results. 62

4.8. The routing network showing the connections among the simulation components

4.9. Schematic showing the land simulation processes. 64

4.10. A schematic the BMP simulation processes modeled in SUSTAIN 68

4.11. Conceptual overview of the optimization module.

4.12. Example storm event viewer graph

4.13. Example outputs of cost-effectiveness report component .74

5.1. Recommended areas in campus for installing infiltration basins .80

5.2. Recommended areas in campus for installing infiltration trenches 81

5.3. Recommended areas in campus for installing permeable pavements.

5.4. Recommended areas in campus for installing rain gardens. .83

5.5. Sub watersheds of University of Louisville's campus .86

5.6. Annual rainfall in University of Louisville's campus .88 
5.7. Located BMPs for simulation.

5.8. Estimated flow rate in different conditions. 93

5.9. Estimated annual flow volume. 94

5.10. Optimization results: Cost $\sim$ control effectiveness. 95

5.11. Precipitation events sorted by total volume. .95

5.12. Cost-effectiveness curve. .96

5.13. BMP cost distribution .97 


\section{INTRODUCTION}

The technological boom in the late $20^{\text {th }}$ century has resulted in the rapid industrialization and urbanization of what once was a predominantly rural country. One of the many consequences of this rapid growth has been the alteration of the natural water-ways and soil profiles. Water which used to get detained in wetlands and estuaries, or slowly permeate into the ground water, has been redirected and channelized with hard surface construction. This disruption of the natural drainage system has increased stormwater runoff and deteriorated water quality (Livingston 2001).

In the last three decades the growth of urbanized areas of the United States has been dramatic and even exceeded the population growth. For example, from 1982 to 2007 the population has increased from 231 million to 301 million (30\%) while the urbanized areas has increased from 70.96 million acres to 111.25 million acres (56\%). This trend is expected to continue in the $21^{\text {st }}$ century and some studies indicate that the urbanized area will increase by an additional 65 million acres in the first quarter of the $21^{\text {st }}$ century in the United States(USDA 1997; D.Beach 2002; USDA 2009). 
As communities become more urbanized the pervious surfaces which provided temporary storage for stormwater flow or enabled groundwater recharge such as open spaces or forests are covered or altered as a result of roadways, parking lots and buildings. With the construction of the impervious surfaces the amount of stormwater runoff generated from a typical storm even increases significantly. In addition, pollutants from vehicles and other atmospheric sources are accumulated on impervious areas and are washed off by the stormwater and infiltrated into rivers, lakes, streams and coastal waters(F.Peluso and Marshall 2002).

To prevent stormwater runoff impacts in urban areas, it has become imperative to develop stormwater plans to manage water runoff discharges more effectively. The traditional stormwater management schemes focused on utilizing storm drains and other conveyance means to rapidly transport the water off-site. "Green" stormwater management strategies, however, concentrate on allowing the water to permeate into the ground before reaching the piped networks in order to reduce the risk of sewer overflowing and the amount of water entering the treatment plants.. Methods suggested by these strategies include strategic site and landscape planning, reducing impervious areas, and treatment of runoff water near the source of it. This approach differs from traditional stormwater systems that are designed to detain the flow, but still convey the stormwater through the water treatment plant(PEC 2006; EPA 2009).

An effective way to manage stormwater runoff with respect to both flow quantity and flow quantity has been to implement green infrastructure Best 
Management Practices (BMPs). BMPs consist of systems designed to prevent or reduce the volume of the runoff water from entering the stormwater collection system by diverting it to other features that will redirect the flow into the ground water system. The primary principles of BMPs are to permeate, evapotranspire and filter and the stormwater on site to reduce the volume and peak flow discharges of stormwater and control its quality. Figure 1.1 shows the impacts of urbanization on increasing stormwater runoff.
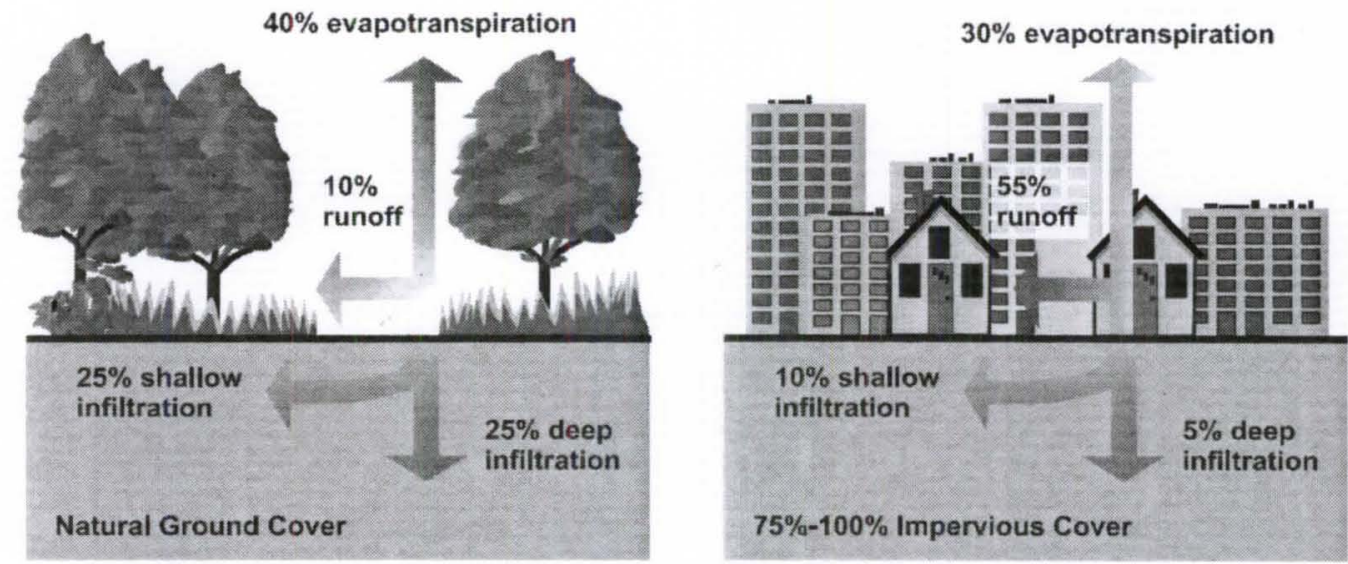

Sour

ce:

Figure 2.1 - Effects of Urbanization to Stormwater Runoff

In this project we are to create a stormwater management model for University of Louisville's Belknap campus using SUSTAIN modeling software for 
the purpose of guiding future BMP types and locations by predicting different scenarios efficiency based on runoff water permeation.

\subsection{Problem Statement}

The increase in stormwater runoff in urban areas has had several negative impacts on the communities. Many urbanized communities utilize combined sewer systems to convey both stormwater and sanitary sewer to water treatment plants before discharge into a surface water. For many rain events, this is an efficient system as all sanitary water and pollutants incorporated into the stormwater will be treated before discharge. In a big rain event, the stormwater runoff that enters the system may exceed the capacity of the sewer system or the treatment plant creating a combined sewer overflow (CSO) and in this case the extra wastewater is directed to natural water resources without treatment. The extra waste water is not pure rainwater, but is likely contaminated with human sewage, industrial waste and other hazardous materials. This has been an issue in more than 700 cities in the nation including the city of Louisville (EPA 2012). Another impact of excessive stormwater runoff on sewer systems is causing overflows in sanitary sewer collection systems. These systems are used in collecting sewage and other wastewater from different sources and direct it to wastewater treatment plants and are separate from the stormwater drainage system. Although these systems are not designed for collecting stormwater runoff, excessive hydrological event is considered as a main cause of sanitary sewer overflows (SSOs). During massive rain events, groundwater can infiltrate into sanitary sewers which has structural problems. Stormwater can also flow 
directly into the system through damaged access holes and roofs or drains connected to it. SSOs are hazardous to the environment as they release raw sewage into the streets, properties and natural surface waters before it reaches the sewage treatment plant(DEQ; EPA 2001). Figures 1.2 and 1.3 show the CSO and SSO.

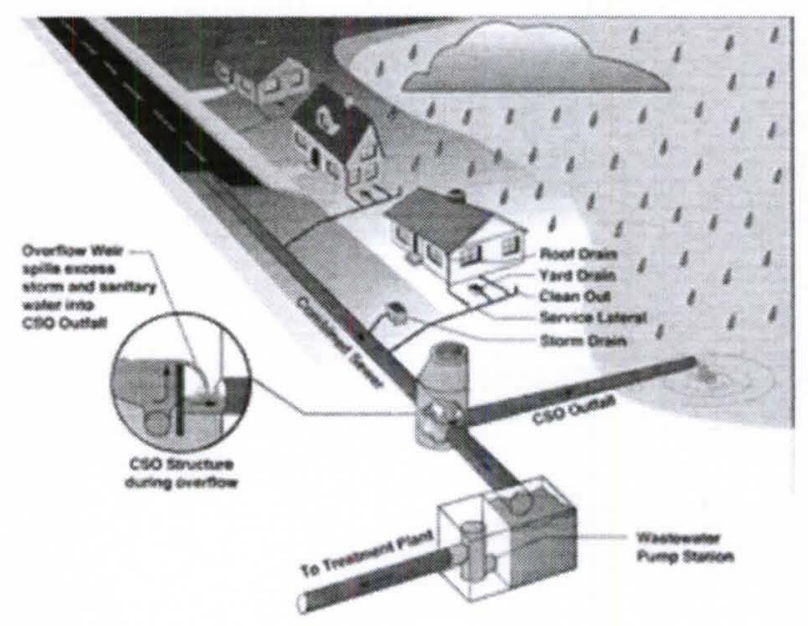

Figure 1.2 - Combined Sewer Overflow (Source:cityofbremerton.com)

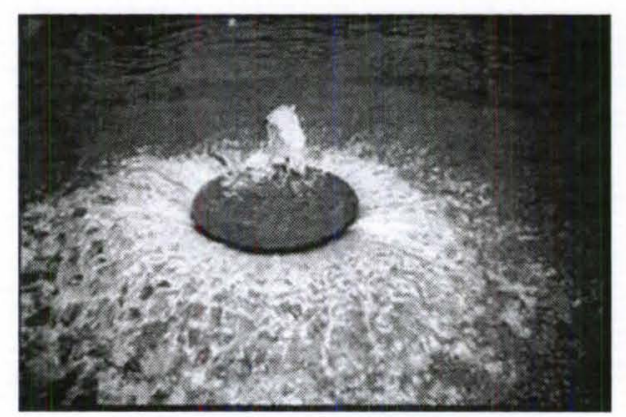

Figure 1.3 - Sanitary Sewer Overflow (Source: EPA)

Because of the combination of high precipitation and old existing sewer systems, stormwater runoff from the earliest data available for the region has been an issue in Louisville since the 19s. There are more than 700 miles of 
combined and sanitary sewer systems in Louisville and about half of them are in excess of 100 years old. SSOs and CSOs generally happen in massive rain events which occur about 30 days a year in Louisville. When a high volume of water enters the Louisville's combined sewer systems, the overflow including untreated wastewater and rainwater is directed into Ohio river and affects its quality (Schardein 2004).

Louisville has also had many flooding issues. Massive rain events have resulted in flash flooding for several years. In 1997, twelve inches of rain in two days caused another intensive flood in Louisville which affected about 40,000 people (IUPUI). The most recent flood happened in August 4, 2009, in which 6.5 inches of rain caused flash flooding that filled many parts of Louisville including the Louisville University and caused damages to many buildings in Belknap campus. The costs to repair the flooding damage on the University of Louisville's Belknap campus alone exceeded $\$ 20$ million dollars (Mog 2012). Figure 1.4 shows a bridge, located in the University of Louisville's campus during the massive flooding in year 2009. 


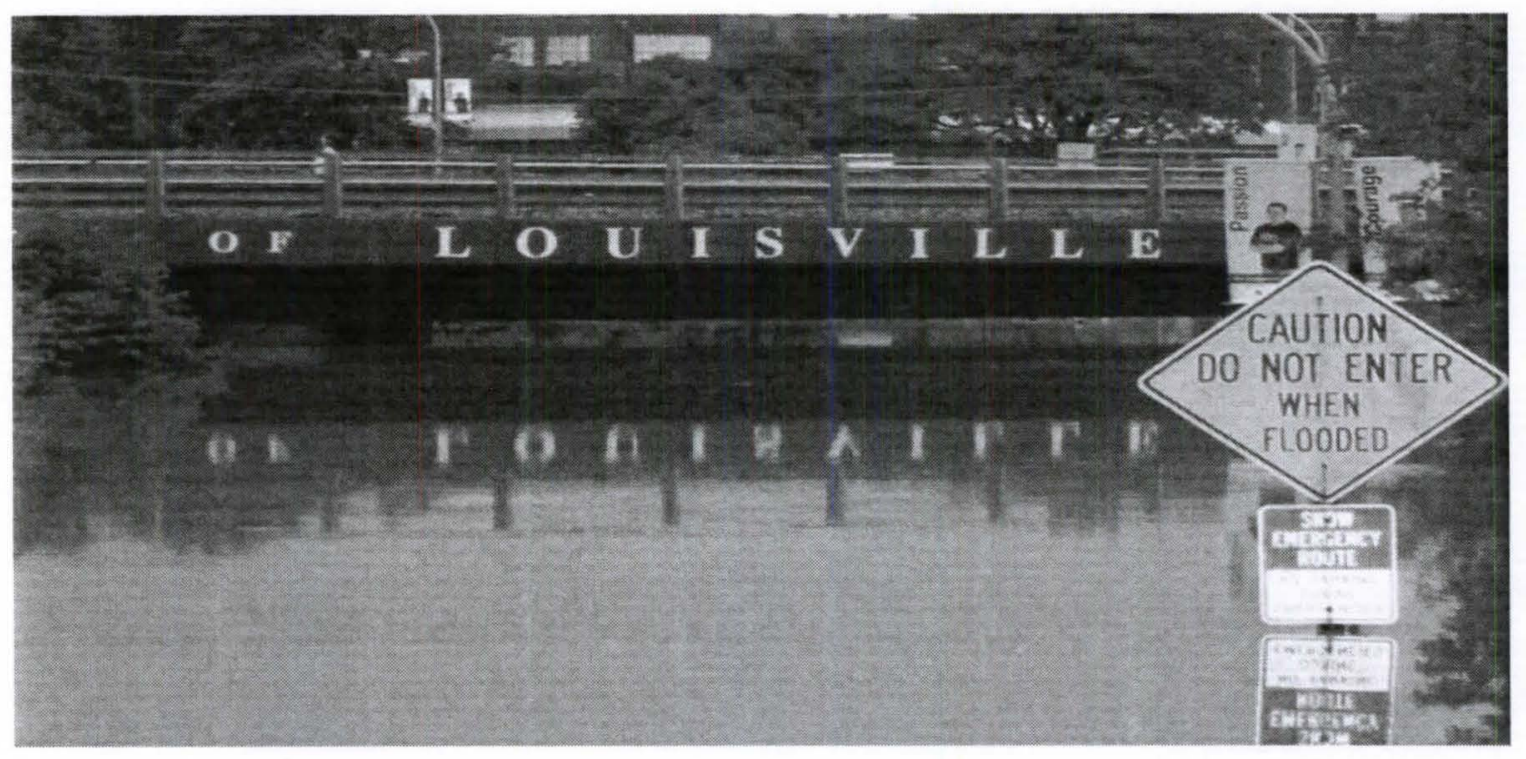

Figure 1.4 - August 2009 Louisville Flood

In order to alleviate the flooding issues in Louisville, Louisville and Jefferson county Metropolitan Sewer District began to develop a stormwater plan in 1988. The objectives of the plan were to help efficiently promote the stormwater drainage management practices and mitigate stormwater discharge rates in the region. This plan includes some stormwater alleviation techniques such as constructing detention basins, over sizing stormwater pipes and implementing BMPs to treat the stormwater runoff near its source(MSD 2010). As the University of Louisville is one of the larger stormwater generators in the city, the University is participating in this plan by developing a campus wide Green Stormwater Master Plan. This plan includes installing stormwater BMPs around campus to divert runoff into the groundwater before it enters the stormwater collection system. By diverting the stormwater, runoff from the campus will 
reduce the volume of water entering the system and thus not contribute to over flow or flooding events.

\subsection{Objectives}

The objectives of the Green Stormwater Plan for campus are first, to reduce overall stormwater flow and second, to reduce flooding during the 25 year storm event. The specific objective of this project is to utilize USEPA SUSTAIN, which is a ArcGIS based framework, to determine the type, quantities and locations of BMPs necessary to make a measureable difference on the campus' stormwater flow. This effort includes data collection, project setup, formulation of the optimization problem and analysis of results.

The following is the list of the four main goals of this project:

- Develop a stormwater management model

- Utilizing SUSTAIN to develop a detailed Green Master Plan of campus.

- Calculate the amount of reduced runoff water in campus to show the benefits of stormwater management.

- Evaluate the functionality of SUSTAIN 


\section{LITERATURE REVIEW}

This chapter includes the followings:

- A description of BMPs and their advantages

- Previous studies of implementation of BMPs in urban areas

- Previous studies of using geographic and municipal data in development of stormwater treatment plans

\subsection{Introduction}

Urbanization has several impacts in cities. It has affected the quality and quantity of stormwater runoff in several areas including the state of Kentucky. In Louisville, because of high precipitation and old existing sewer systems, stormwater runoff treatment has always been an issue. University of Louisville has been involved with these issues during the recent years. To mitigate the flooding and water quality issues in the university, a Green Stormwater Master Plan has been developed which prioritizes and identifies locations for BMPs in the campus.

The goal of Green Stormwater Master Plan for the University of Louisville's campus is to alleviate flooding and overflow issues. The stormwater 
reduction, however, must be performed in a cost effective manner. Developing this plan includes designing Best Management Practices (BMPs) and identifying the best scenario for locating them in the University. 
Implementing Best Management Practices (BMP) is typically considered an effective strategy to treat stormwater runoff. BMPs consist of systems designed to treat the stormwater runoff near the source of it in order to reduce its quantity and control its quality by infiltrating, filtering or withholding it (Day and Dickinson 2008).

A variety of BMPs are available to capture stormwater runoff or improve water quality, The BMPs are typically divided into different categories based on their design objective. Below is a brief description of most common types of BMPs.

- Permeable pavements: Permeable pavements are alternatives of the standard asphalt or concrete. They could be used in parking lots and roadways to treat the runoff water by infiltrating it into the lower soil layers. The most common types of permeable pavements are pervious concrete, pervious asphalt or permeable interlocking concrete. Figure 2.1 shows different layers of an example permeable pavement.

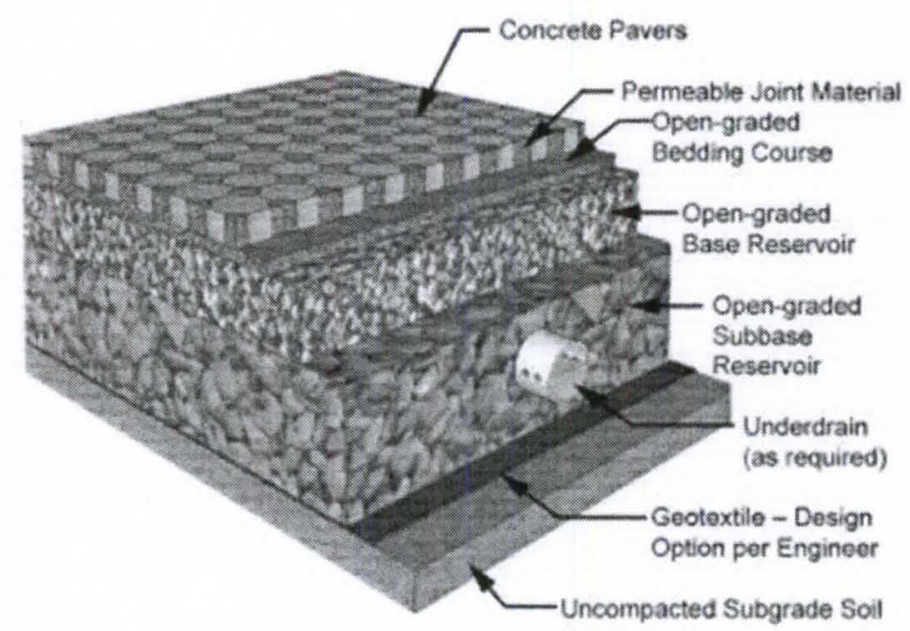

Figure 2.1 - Permeable Interlocking Pavement ( Source: ISPI) 
- Infiltration trenches: Infiltration trenches are long and narrow excavations filled with stone to allow water to infiltrate into the subsoil. The stormwater runoff is temporarily stored within the void space between the stones and over time is infiltrated gradually into the ground. Implementation of infiltration trenches result in both reducing the amount of runoff water by infiltrating and enhancing its quality by filtering the runoff water through different layers. Figure bellow represents the performance of an infiltration trench during a rain event. Figure 2.2 represents the performance of an infiltration trench during a rain event.

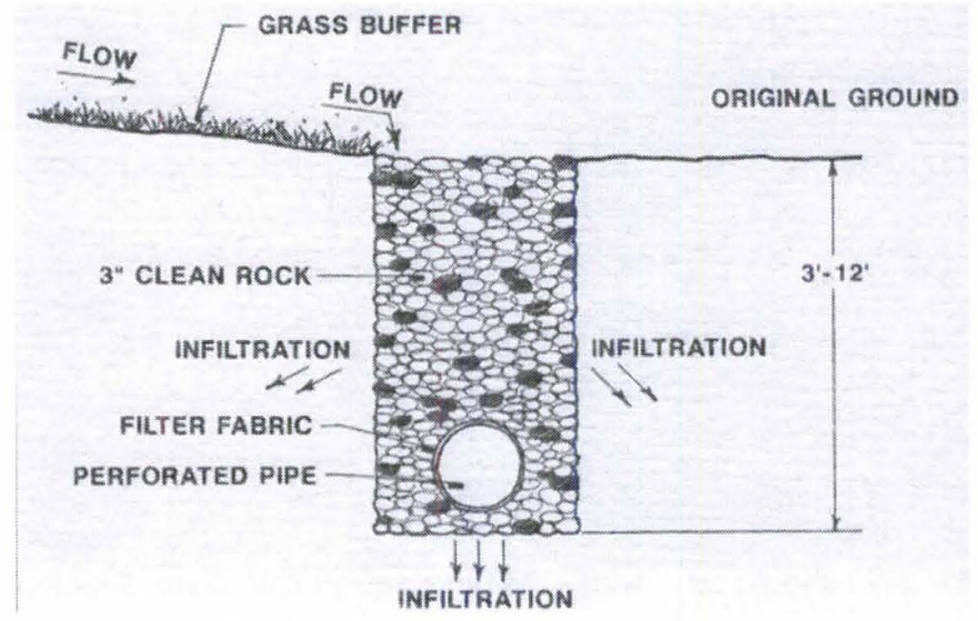

Figure 2.2 - Infiltration Trench (Source: Hallett Materials)

- Infiltration basins: Infiltration basins are water impoundments and are built on top of pervious soils. Similar to infiltration trenches, they can function in both reducing the amount of rainwater and controlling the quality of it. Figure 2.3 shows different views of an example of infiltration trench. 

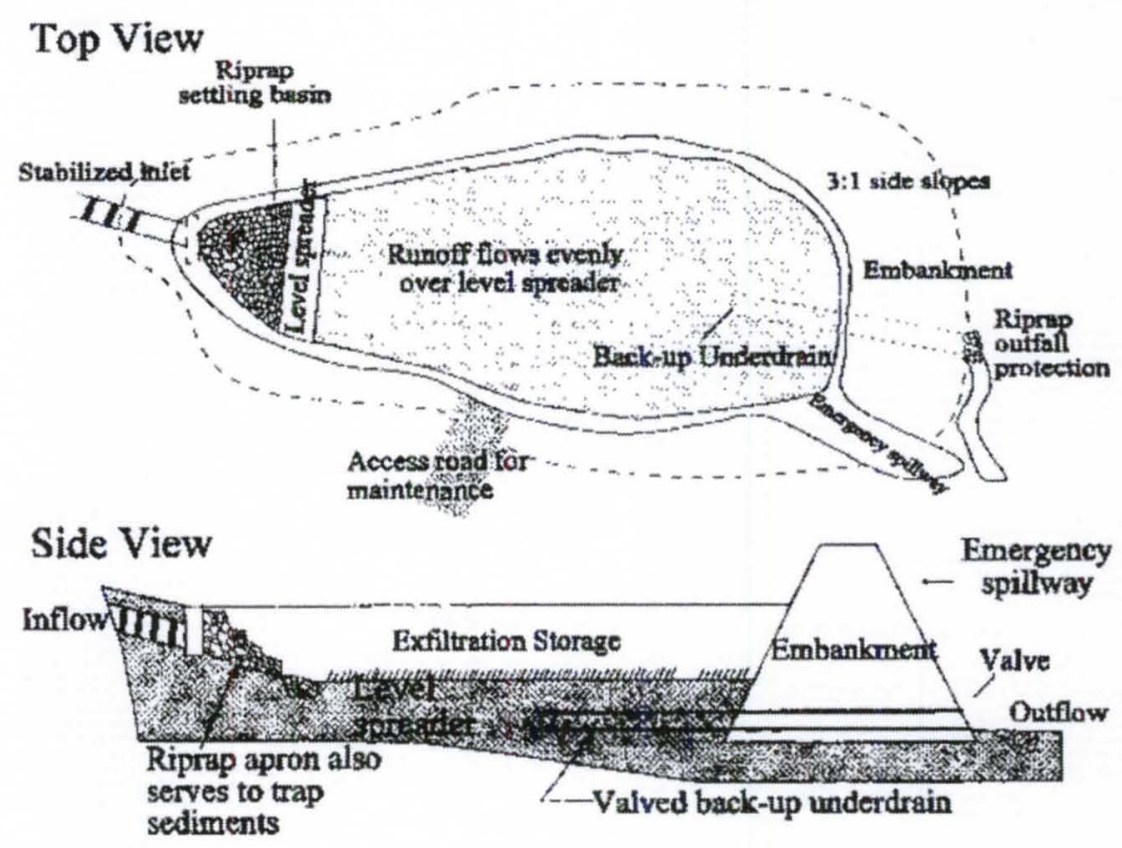

Figure 2.3 - Infiltration Basin (Source: FHWA)

- Rain Gardens: Rain gardens (also called Bioretention) are a garden that filter and infiltrate rainwater runoff from impervious areas. After the water is treated by layers of plants and soil, it is then permeated into the ground. One of specific advantages of rain gardens is they provide an aesthetic value as well as treating stormwater. Figure 2.4 shows an example of rain garden and its different layers. 


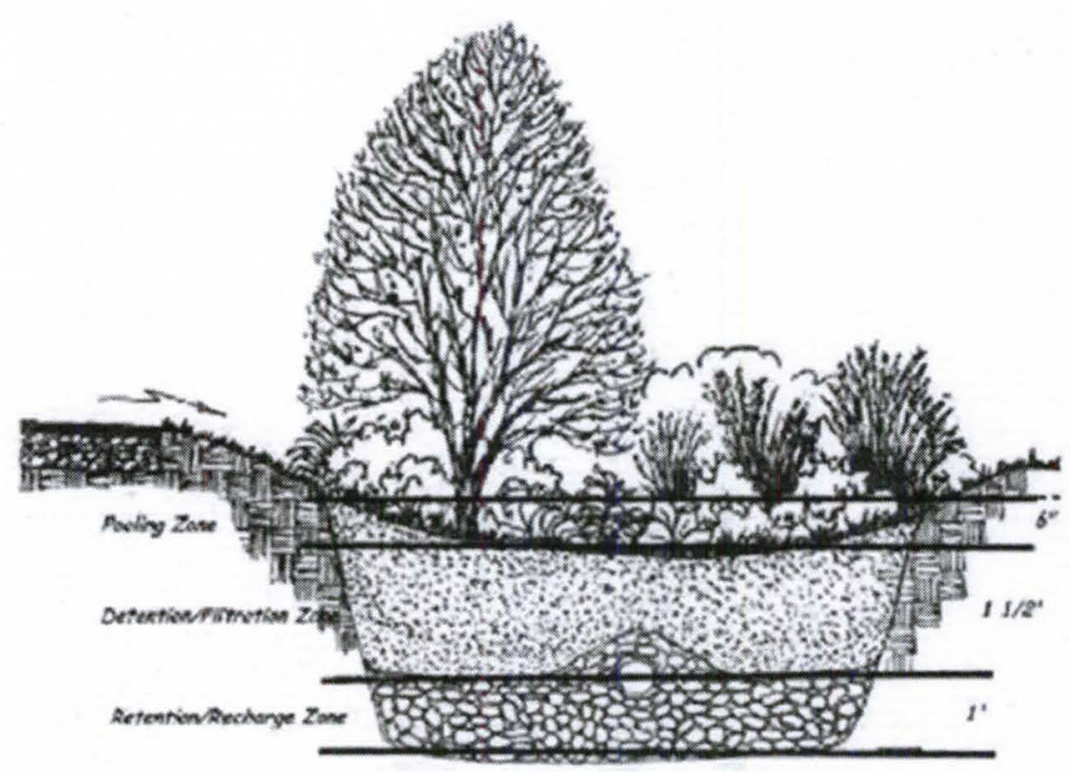

Figure 2.4 - Rain Garden (Source: www.DMGOV.org)

- Rain barrels: Rain barrels are containers that are used to collect and store rainwater typically from disconnected downspouts or rooftops. Water collected in rain barrels could be saved in storage area for future uses. They are considered as one of the least expensive practices among other BMPs. In figure 2.5, a common type of rain barrel is represented. 


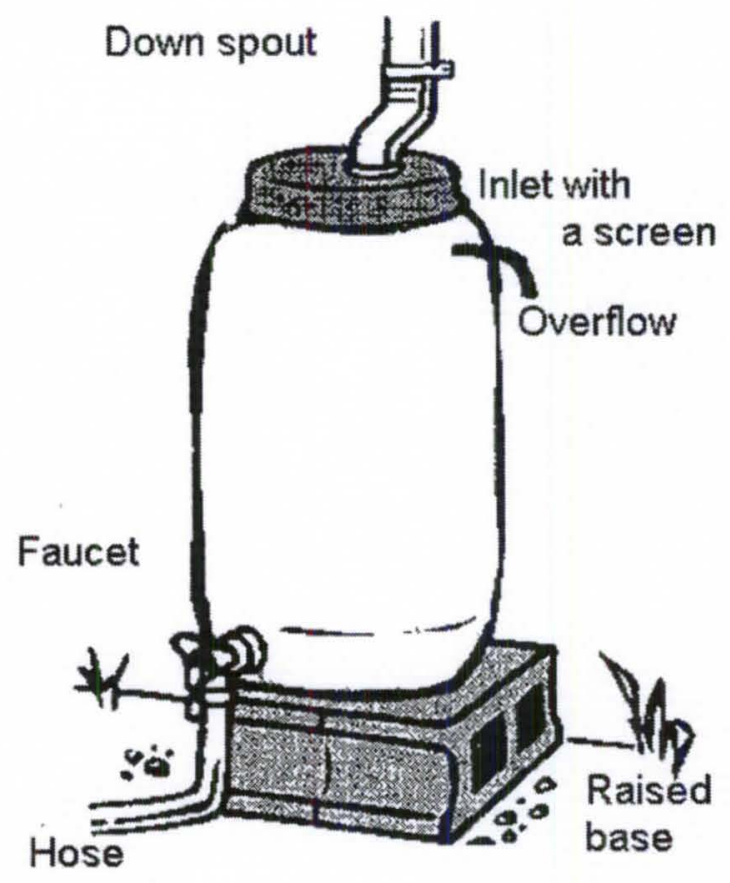

Figure 2.5 - Rain Barrel ( Source: ci.berkeley.ca.us)

- Green roofs: Green roofs are living plants implemented on top of a building roof. Other than the aesthetic benefits of installing green roofs, they are highly effective in reducing stormwater runoff volume and improving its quality by capturing the rainwater and permeating it in their root zone. Figure below shows the different basic layers of a green roof. Different layers of an example of green roof is represented in figure 2.6. 


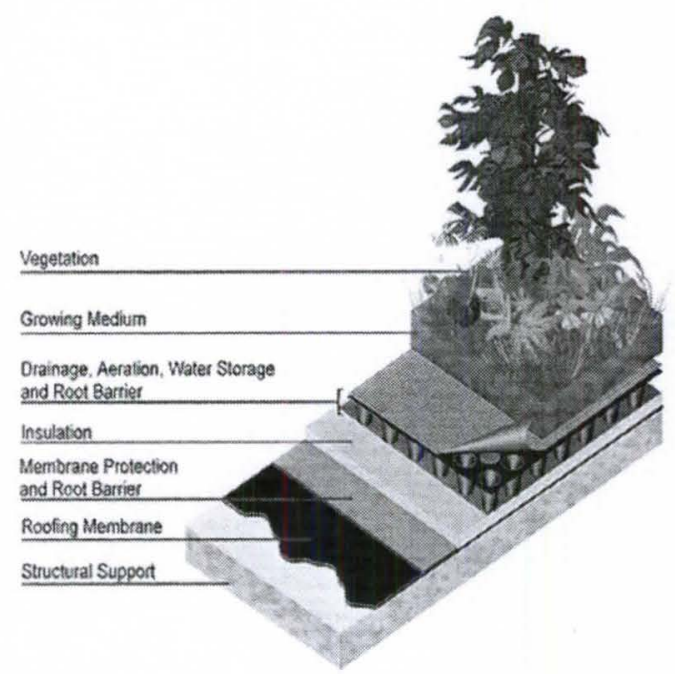

Figure 2.6 - Green Roof (Source: lid-stormwater.net)

Each of the above listed Best Management Practices has some distinct benefits and limitations with respect to outcomes typically desired by a community and are selected and applied based upon the objectives of stormwater management plans. Some of the environmental benefits include pollution reduction, protecting ground water storages, alleviating combined sewer overflow and etc. some other advantages are considered as land value benefits such as flooding prevention(EPA 2007). Below is the description of each of these benefits.

- Pollution reduction: BMPs help to improve water quality significantly. They reduce the pollutants in rainwater by filtering and adsorbing it through the sand layers before they reach waterbodies which also results in reducing water treatment costs. 
- Ground water protection: BMPs can assist in ground water protection by infiltrating the stormwater runoff through the lower layers and providing groundwater replenishment.

- Alleviating combined sewer system overflows: BMPs reduce the number and rate of CSO occurrence by diverting stormwater before it enters the collection system. The old approach of reducing the number of CSO is to increase a treatment plant's capacity in order to accommodate the total amount of water entering the system. The "green" alternative method utilizes BMPs to reduce the amount of water prior entering combined sewer systems eliminating the need for expensive plant size increases and also reduces the amount of stormwater that needs to be treated by the system. Thus, implementing BMPs can be a cost effective method to reduce treatment cost operations in the long term(Riverkeeper).

- Flooding prevention: One of the biggest negative effects of stormwater runoff in urban areas is flooding. BMPs store a large portion of the stormwater runoff temporarily and infiltrate it into the soil. They slow down the runoff, reduce total amount of rainwater and minimize the peak flow discharge and by these ways assist toward flooding control in urban areas.

Flooding and CSOs have been a daunting issue in Louisville in recent years. Implementing a stormwater BMP strategy within the city can work to both alleviate damages caused by floods and reduce the costs associated with 
upgrading the stormwater treatment plants in Louisville. To help achieve this goal, University of Louisville and the Metropolitan Sewer District are developing a green master plan for the campus. The purpose of this plan is to identify, locate and prioritize BMPs that will effectively reduce the stormwater runoff generated from the Belknap campus.

One of the most crucial steps in utilizing BMPs is selecting the optimal design, number and location for the BMPs. To select the type, number and location of BMPs, a feasibility study is required to identify the relation between cost and performance of different BMP implementation strategies (Damodaram and Zechman 2010). Different BMP implementation strategies should be assessed in order to select the most efficient strategy to achieve the desired goals of the stormwater management plan at the least cost. These efforts result in minimizing negative impacts of stormwater runoff in urban areas in the most cost effective approach.

Hydrological modeling is considered as an effective and practical method for optimizing best management practices' within a watershed. Hydrological models can be utilized to answer questions regarding hydrologic issues and conditions in an area. Although models could be very helpful in determining the future impacts of a hydrologic project, best results are achieved when the model is combined with validating data and measurements. For this reason it is very important to use the model with caution to get the best results and minimize the errors. A comprehensive effort in using hydrological models includes determining the followings(Bross 1953; Beven 2001): 
- Problems of concern

- Accessible data

- Available methods

- Project limitations

Hydrological models are generally used in two means(Bross 1953):

- Evaluating the current hydrology conditions.

- Forecasting the future hydrology conditions after development in the land use or any other changes made to the area.

This project deals with utilizing a modeling software, called SUSTAIN for simulating the current and future hydrological characteristics and optimizing Best Management Practices strategies in University of Louisville's Belknap campus.

\subsection{Previous studies}

The concept of using hydrologic models and methods for implementing best management practices started in early 80 s. the early studies were mostly focused on water quantity and did not deal with the water quality. In the 1980 s the sustainable development theory initiated and the it was stated that different components of stormwater and sewer systems are required to be integrated(W.Delleur 2003). In the 90 s water quality started to be taken into account in stormwater management plans and BMP implementation strategies(Sewell 1998). In the 90s and 2000s the invention of computer simulation models resulted in significant changes in the field of stormwater management. Application of hydraulic and hydrologic computer models facilitated 
the simulation of hydrologic impacts of stormwater runoff and performance of BMPs in urban and rural areas(W.Delleur 2003). This section includes the examples of evolution in stormwater management and BMP implementation since 1982.

In year 1982, a research was done in optimizing the size and location of BMPs in a stormwater catch basin. The methodology used in that project engaged combining dynamic programming algorithms and traditional methods to simulate the performance of BMPs in the area(Mays and Bedient 1982). In 1997 Kao utilized multi objective linear programming to define most cost effective BMPs regarding the reduction of phosphorus in the downstream of a watershed(Kao and Tsai 1997).

Newer methods have been utilized in recent BMP implementation projects. These methods, including the genetic algorithm(GA) have been used in computer modeling to mathematically identify the most effective BMP implementation strategies. GAs are search algorithms that mimic the process of natural genetics used for some types of optimization on mixed or combinational problems. The processes in these algorithms includes evaluating potential solutions taking into account the obtained information in order to define the solutions with higher effectiveness(Marczyk 2004). Utilizing GAs in BMP optimization results in different advantages. First, the output would include not only one solution, but many near optimal solutions for the problem. Also different assessment points could be taken into account using these algorithm. A research 
in 2002 indicates that genetic algorithm could be utilized together with pollution model in order to optimize BMPs implementation(Srivastava and Hamlett 2002).

There are multiple examples of utilizing GA and integrating it with other hydrologic techniques for optimizing BMP implementation., In year 2004, PerezPedini combined a rainfall-runoff model with a genetic algorithm to identify the best BMPs implementation strategy in order to reduce the peak flow discharge in an area in northeast United States(Perez-Pedini, James et al. 2005) . In 2010 Prakash Kaini and Kim Artita integrated a genetic algorithm with a semidistributed hydrological model, Soil and Water assessment Tool(SWAT) to identify the best strategy for implementing BMPs in order to achieve the treatment goals in an area. This project was based on reducing sediment and nutrient from the runoff water(Kaini, Artita et al.)

In some of the BMP implementation reports the performance of BMPs were assumed to be constant during the time. Since different environmental impacts such as clogging could affect the performance of BMPs, it is very important to estimate the long-term performance of them. In year 2008, a study developed the long-term effectiveness of 8 types of BMPs in different land uses based on a variety of water quality goals in New England by utilizing EPA's Stormwater Management Model(SWMM) and the BMP Decision Support System(BMPDSS). The results were used in order to evaluate the cumulative performance of BMPs in long period of time. (TetraTech 2008). 
As an example of developing stormwater management plans in communities, Louisville Metropolitan Sewer District has also started planning and installing several BMPs in Louisville. As a part of this plan, URS used a modeling software called InfoWorks to determine the effectiveness of implementing BMPs in a combined sewer overflow area. The results indicated that the "green" approach to treating CSOs is more cost effective than the traditional method(URS 2012). Also in order to estimate the effectiveness of existing BMPs, EPA plans to utilize software models(SUSTAIN,HSPF and SWMM-LID) to estimate the CSO in the area before installing BMPs, and integrate the results with the basin-wide monitoring data.

\subsection{Summary}

There are many studies on implementation of BMPs in urban and rural areas. In these studies, different methods and models have been selected base on the issues of concern, required and available data, cost of modeling, model's accuracy and characteristics of the watersheds. Earlier strategies in implementing BMPs were mainly focused on reducing the quantity of stormwater runoff to prevent flooding and CSO. The subsequence studies took into account controlling the water quality as well as reducing its quantity.

In the recent decades, computer simulation models have improved stormwater management. These models, by integrating different hydrologic and optimization techniques, assist in optimizing the size, location and type of BMPs and estimating the effectiveness of different management strategies. 
This study focuses in simulating the hydrologic behavior of different BMPs in University of Louisville by utilizing SUSTAIN. Different BMP strategies are simulated for varied flood events to estimate the best scenario to reduce overall stormwater flow and flooding during the 25 year storm event. 


\section{METHODOLOGY}

The goal of this study is to use a computer model to evaluate the current stormwater runoff condition of the campus, predict the flow and pollutant loading for input to BMPs and perform simulation in order to achieve the hydraulic performance of each selected BMP. Also an estimation is required for identifying the most cost effective BMP strategy in the area.

This chapter includes the steps required for utilizing the modeling tool, SUSTAIN, for campus. It discusses the problems and the methodology used for analyzing the current condition and developing a BMP plan for the University of Louisville's Belknap campus. The steps of hydrologic modeling of campus include the followings:

- Reviewing the study area and stating the problems

- Defining the goals and objectives

- Selecting the method to achieve the goals

- Choosing the software

- Collecting and appropriately modifying the required data

- Identifying potential locations for implementing BMPs 
- Configuring and placing BMPs in the land simulation

- Defining the evaluation factors and assessment points

- Simulating the defined BMPs

- Comparing the cost and performance of different BMP options and placement scenarios

\subsection{Introduction}

Stormwater management begins with analyzing the area and defining the issues. Next step is to define the goal and scope of the plan based on the problems in current or future conditions. Modeling is a significant part of stormwater management and BMP implementation in urban areas. Studies show that BMP effectiveness is based on different characteristics of the area such as land use, precipitation, geographic conditions and etc. Estimating BMPs effectiveness is more accurate by using dynamic models compared to using traditional techniques.(Acherman and Stein 2008). In a modeling approach to development of a stormwater plan, it is very important to choose the accurate modeling method which is helpful in solving the particular problem in the location(Tsihrintzis and Sidan 2008). Also through studies are required for selecting the relevant set of data in order to minimize the errors. Selected dataset is analyzed using the modeling method based on appropriate criteria.

For the final step, data mining, a complete understanding of the model and the utilized software is required to minimize the errors and eventually develop stormwater management. 


\subsection{Study Area}

The study area is entirely located on the property of University of Louisville, Kentucky. University of Louisville's 287 -acre Belknap campus is a dense development specifically in the north area. It includes institutional, residential, commercial land uses and is located in north-central Kentucky. University's sewer systems includes combined and sanitary sewer systems, and is directed to the city of Louisville's sewer network. The area is divided into 10 sub watersheds based on municipal and geological data. Figure 3.1 presents the study area and the blue lines indicate the sub watershed within the area. Almost $40 \%$ of surfaces in campus are parking lots, buildings and roadways which are all impervious. This number is greater in the north part of campus. Due to the high percentage of impervious areas, old existing combined sewer systems and massive rain events stormwater runoff is a great issue in campus. figure 3.1 represents the sub watersheds in University of Louisville. 


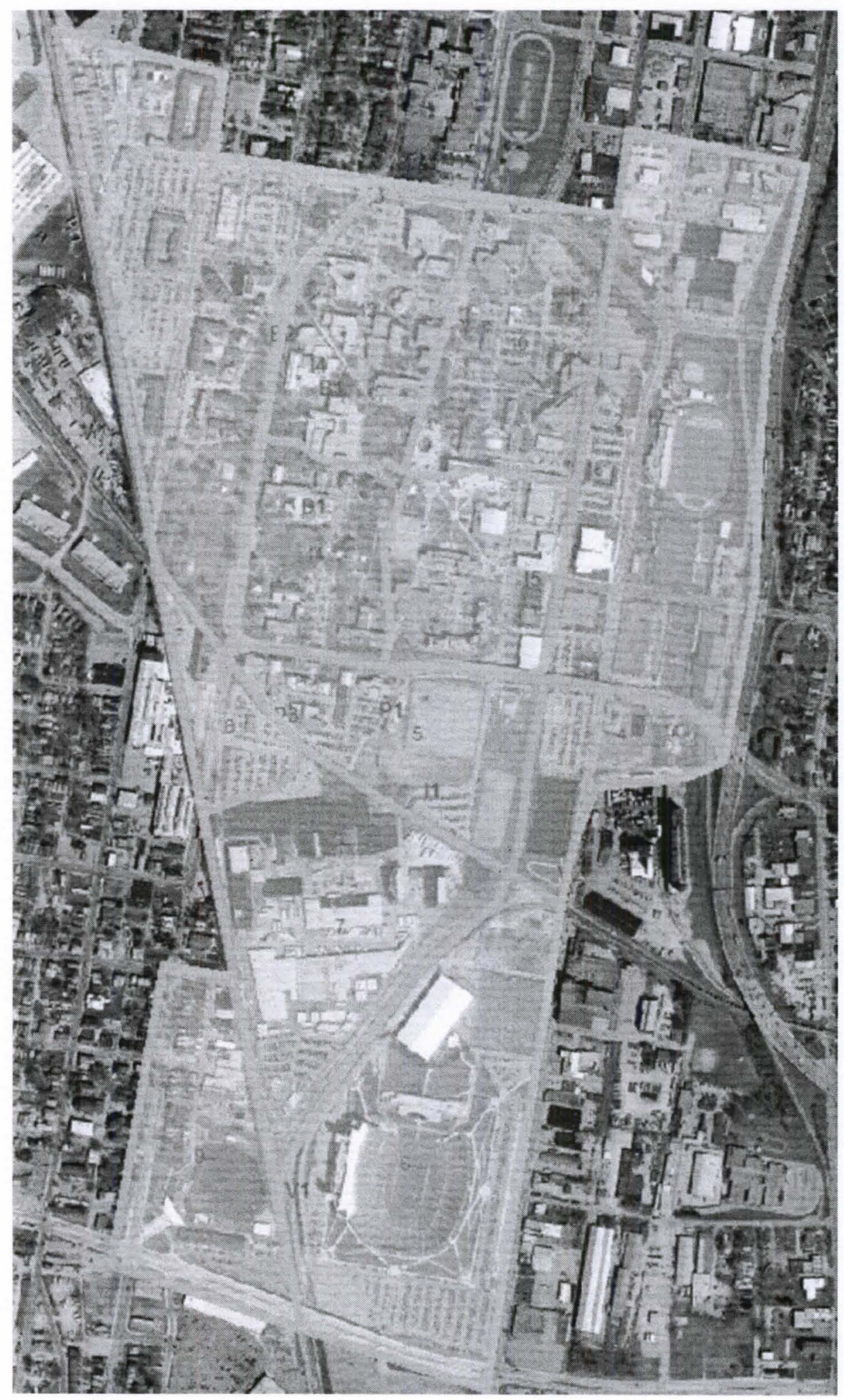

Figure 3.1 - University of Louisville's sub watershed 


\subsection{Software}

There are several software programs available for the purpose of BMP modeling. The choice for this study was based upon the practicability of the software for urban areas and the availability of the required data. In this study, in order to optimize and evaluate the implementation of BMPs, SUSTAIN was utilized to simulate the current situation and to create a BMP model based on proposed development in campus. The two goals of creating a BMP model using SUSTAIN are first to identify potential places in campus for installing different types of BMPs using SUSTAIN's sitingtool and second to simulate the performance of the BMPs based upon a given rain events in a year. The results of the SUSTAIN modeling include a comparison of performance and cost of various BMP options and their placement scenarios in which the best strategy is identified based on different amounts of total implementation costs.

\subsection{Data collection}

Data preparation is a primary component of any modeling project. The SUSTAIN model for University of Louisville's campus included a variety of information specific to the area. This information was obtained from a variety of public and private sources and then converted into a format usable by the software.

Information about the cost of design and installing different types of BMPs including permeable pavements, rain gardens, infiltration trenches and infiltration basins, and also municipal data such as sewer system network in campus were collected from Louisville MSD. University of Louisville's geological data includes 
urban land uses, soil types, roads and railroads, Digital Elevation Model (DEM), percent imperviousness and streams. They are all ArcGIS data and were collected from four different sources:

- Kentucky Transportation Cabinet (KYTC)

- Esri website

- The Louisville/Jefferson County Information Consortium (LOJIC)

- Center for Infrastructure Research, University of Louisville

Louisville's climate information, including evaporation, wind speed and temperature for the city was gathered from Agricultural Weather Center of University of Kentucky.

SUSTAIN land simulation model uses the hourly rainfall data. In this project, year 2001 was selected to use in the simulation for the reason that the rainfall in this year is approximately equal to the long-term annual average and it represents the rainfalls expected in a normal year in Louisville. A rain gage near Louisville International Airport was selected for the study and the data was gathered from website of National Climate Data Center (NDDC).

\subsection{Data analysis}

The first step in SUSTAIN modeling in University of Louisville was to utilize the BMP siting tool to create a suitability index map of campus based on site suitability criteria which includes drainage area and slope, infiltration rate, hydrological soil group, groundwater table depth, and impervious surfaces on Belknap Campus. All these information are obtained from the modified ArcGIS 
data set used as inputs. The result of this part served as guidance tool for the next SUSTAIN modeling step.

Next step was to simulate the stormwater flow and the performance of BMPs in campus. The area was divided into 10 sub watersheds based on geological data and sewer system network. Different types of BMPs were defined and located in the desired sub watersheds. SUSTAIN simulates the performance of located BMPs based upon the characteristics of the area, climate data and defined evaluation factors. Also by utilizing a cost module, it compares the cost and effectiveness of various BMP implementation strategies to create a cost effectiveness curve for the area.

\subsection{Summary}

This chapter provides an overview of the steps of this study. These steps includes:

After obtaining the desired results, they should be analyzed to find the ultimate solution for the stated problems. 


\section{SOFTWARE}

This chapter includes information about different methods and softwares used for modeling stormwater runoff and BMP strategies, and describes some studies in which these models have been utilized. It also explains the considerations that should be made for selecting an appropriate model.

\subsection{Introduction}

Computer modeling is known as the most effective way for predicting hydrological characteristics of an area and the performance of different BMP strategies (MPCA 2000). Figure 4.1 represents the different steps in modeling. 


\section{What constitutes a model?}

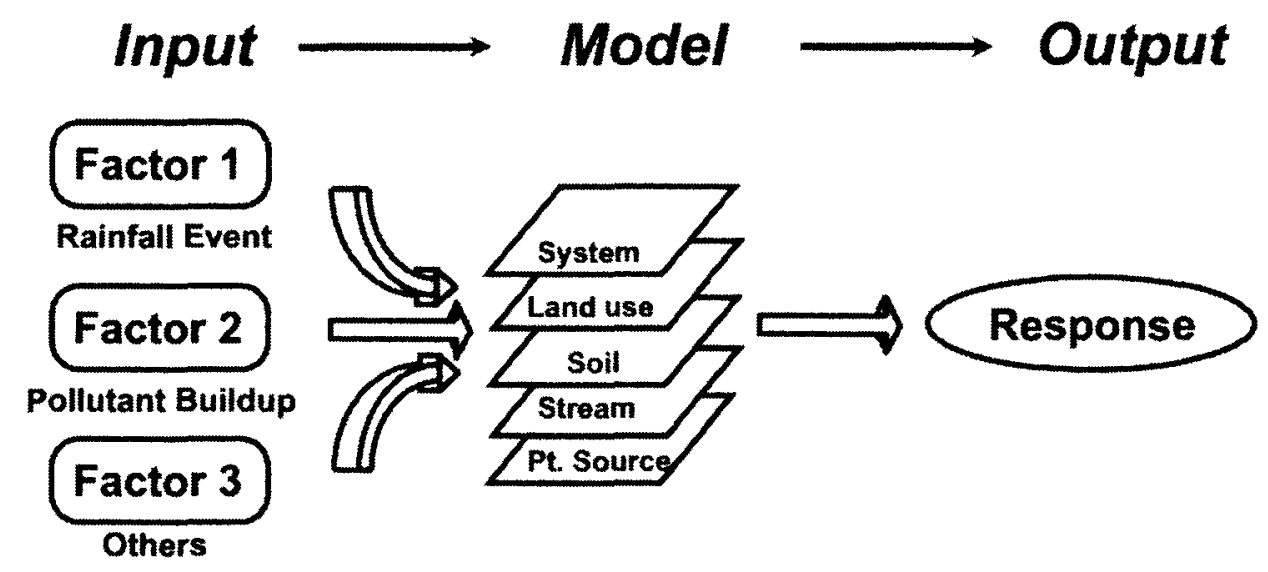

Figure 4.1 - Constitution of a model (Source: TetraTech)

Hydrologic models are described as mathematical methods which help in answering questions regarding the present and future hydrological characteristics of an area. They could be used in several ways including (Vijay 1995).:

- Predicting the impacts of land use development on stormwater runoff

- Estimating the affects of different scenarios on hydrological characteristic of an area

- Simulating the stormwater runoff flow based on rain events in watersheds

- Evaluating the performance of BMPs

- Evaluating the existing condition of stormwater quality and quantity

Utilizing models for stormwater management has several advantages. Followings are some of the advantages(Bross 1953): 
- It presents a frame for the issues

- Models could suggest farther researches if required

- Modeling is an inexpensive way for stormwater management

- Models increase the simplicity of understanding of the problems

Selecting the appropriate model is an important step in stormwater management. In selecting a model several points must be considered. These points include verifying:

- If the model is appropriate for a specific issue in a specific location

- The availability of data

- The accuracy of the model's output

- The easiness of running the model and deriving the results

Many models and methods are available for estimating stormwater runoff, peak discharge, BMPs' performance and other hydrological information in stormwater management strategies. In this chapter a description of models and methods used for estimating and predicting hydrological characteristic of an area.

There are several publicly available watershed models applicable for making simulations and predictions of hydrologic characteristics and performance of BMPs in watersheds:

- ANSWERS (the Areal Nonpoint Source Watershed Environment Response) 
- GLEAMS (Groundwater Loading Effects of Agricultural Management Systems)

- HSPF (The Hydrological Simulation Program-FORTRAN)

- SWAT (The U.S EPA Stormwater Management Model)

- WEPP (The Watershed Erosion Prediction Project)

- DWSM (The Dynamic Watershed Simulation Model)

- EPIC (The Erosion Productivity Impact Calculator)

- GISPLM (GIS-Based Phosphorus Loading Model)

- KINEROS2 (Kinematic Runoff and Erosion Model 2)

- LSPC (Loading Simulation Program in C++)

- P8-UCM (Program for Predicting Polluting Particle Passage through Pits, Puddles, and Ponds - Urban Catchment Model)

- REMM (Riparian Ecosystem Management Model)

- AGWA (Automated Geospatial Watershed Assessment)

- SPARROW (SPAtially Referenced Regression On Watershed Attributes)

- PRMS (The Precipitation-Runoff Modeling System)

- RZWQM (The root zone Water Quality Model)

- BMPDSS (The Best Management Practice Decision Support System)

- BASINS (Better Assessment Science Integrating point and Nonpoint Sources) 
This chapter, first describes Rational method, which is the most common and the simplest method for estimating stormwater pick flow discharge and its modified version has been used in some hydrological computer models. The subsequence sections includes more detailed explanation of most common hydrologic models used for performing hydrologic simulations and predictions in watersheds.

\subsection{Rational method}

One of the simplest and the most common method used for estimating peak flow discharges in small watersheds is the rational method. This method is most accurate for urban watersheds smaller than 300 acres(ODOT 2005). Rational method is also included in many modeling tools such as SWAT(Soil and Water Assessment Tool).

\subsubsection{Procedure}

The Rational method is based on this equation:

$$
Q_{T}=C i_{T} A(4.1)
$$

Where:

$Q_{T}=$ Calculation of the peak flow rate of runoff (cfs)

$C=$ Runoff coefficient correction factor, a dimensionless decimal factor to account for decrease in water absorption in massive rain events

$i=$ average rainfall intensity in time of concentration $(\mathrm{In} / \mathrm{Hr})$ 
$A=$ Drainage area in acres

Detailed explanation of these variables follow:

Runoff coefficient (C): This coefficient indicates the interaction of different factors such as infiltration, void spaces on surface, ground water characteristics, evaporation and all other factors that could affect the time distribution and peak flow discharge. This coefficient is the most difficult input of Rational method to estimate. A typical list of runoff coefficient for different surfaces and soil types have been provided in table 4.2.1.1. Different soil types in this table are classified into four hydrological soil groups (HSGs) to represent the minimum rate of infiltration (ISU 2008).

Group A: Soils have slow runoff potential and high infiltration rates even when wetted.(Water transmission rate of more than $0.30 \mathrm{in} / \mathrm{hr}$ )

Group B: Sandy loam soils with moderate runoff potential and infiltration rate. These soils have a moderate rate of water transmission( $0.15-0.30 \mathrm{in} / \mathrm{hr}$ )

Group C: Soils with slow infiltration rate, especially when wetted. They mainly include of soils with a layer near the surface that slow down the downward water movement or soils with moderately fine to fine texture. These type of soils have a low rate of water transmission $(0.05-0.15 \mathrm{in} / \mathrm{hr})$

Group D: Soils with high runoff potential and very low infiltration rate. These soils consist of clays with high water tables, soils with a claypan or clay layer at or 
close to the surface and shallow soils over nearly impermeable material. Different runoff coefficient for the Rational method is represented in the table 4.1.

\begin{tabular}{|c|c|c|c|c|c|c|c|c|c|c|c|c|}
\hline Hyatrologie Soll Group & \multicolumn{3}{|c|}{$A$} & \multicolumn{3}{|c|}{$B$} & \multicolumn{3}{|c|}{$\mathrm{C}$} & \multicolumn{3}{|c|}{$\mathrm{D}$} \\
\hline Recurrexee Interval & 5 & 10 & 100 & 5 & 10 & 100 & 5 & 10 & 100 & 5 & 10 & 100 \\
\hline $\begin{array}{l}\text { Land Use Or Surface } \\
\text { Characterivios } \\
\text { Basiness: } \\
\text { A. Commercial Area } \\
\text { B. Neighbonhood Area }\end{array}$ & $\begin{array}{l}.75 \\
.50 \\
\end{array}$ & $\begin{array}{l}80 \\
55 \\
\end{array}$ & $\begin{array}{l}.95 \\
.65 \\
\end{array}$ & $\begin{array}{r}80 \\
55 \\
\end{array}$ & $\begin{array}{l}.85 \\
.60 \\
\end{array}$ & $\begin{array}{r}95 \\
.70 \\
\end{array}$ & $\begin{array}{r}80 \\
.60 \\
\end{array}$ & $\begin{array}{l}85 \\
65 \\
\end{array}$ & $\begin{array}{l}.95 \\
.75 \\
\end{array}$ & $\begin{array}{r}.85 \\
.65 \\
\end{array}$ & $\begin{array}{r}.90 \\
.70 \\
\end{array}$ & $\begin{array}{r}95 \\
.80 \\
\end{array}$ \\
\hline $\begin{array}{l}\text { Residentivi: } \\
\text { A. Single Family } \\
\text { B. Mult-Lnit (Detachod) } \\
\text { C. Muln-Lnit (Atched) } \\
\text { D. I/2 Lot Or Larger } \\
\text { E. Aparments }\end{array}$ & $\begin{array}{l}25 \\
35 \\
45 \\
20 \\
50\end{array}$ & $\begin{array}{r}35 \\
40 \\
50 \\
20 \\
55\end{array}$ & $\begin{array}{l}30 \\
.15 \\
.55 \\
25 \\
60\end{array}$ & $\begin{array}{l}30 \\
10 \\
50 \\
25 \\
55\end{array}$ & $\begin{array}{l}35 \\
45 \\
55 \\
.25 \\
40\end{array}$ & $\begin{array}{l}50 \\
50 \\
65 \\
30 \\
70 \\
\end{array}$ & $\begin{array}{r}40 \\
45 \\
55 \\
35 \\
60\end{array}$ & $\begin{array}{l}45 \\
50 \\
60 \\
40 \\
65\end{array}$ & $\begin{array}{l}50 \\
.55 \\
.70 \\
.45 \\
.75 \\
\end{array}$ & $\begin{array}{l}45 \\
50 \\
60 \\
40 \\
65\end{array}$ & $\begin{array}{l}50 \\
.55 \\
.65 \\
45 \\
70 \\
\end{array}$ & $\begin{array}{l}.55 \\
.65 \\
.75 \\
50 \\
.80\end{array}$ \\
\hline $\begin{array}{l}\text { Industral } \\
\text { A. Light Areas } \\
\text { B. Heavy Areas } \\
\end{array}$ & $\begin{array}{l}.55 \\
.75 \\
\end{array}$ & $\begin{array}{l}60 \\
80 \\
\end{array}$ & $\begin{array}{r}70 \\
.95 \\
\end{array}$ & $\begin{array}{r}60 \\
.60 \\
\end{array}$ & $\begin{array}{r}65 \\
\times 5 \\
\end{array}$ & $\begin{array}{r}75 \\
95 \\
\end{array}$ & $\begin{array}{r}65 \\
80 \\
\end{array}$ & $\begin{array}{r}70 \\
85 \\
\end{array}$ & $\begin{array}{r}80 \\
95 \\
\end{array}$ & $\begin{array}{r}30 \\
.80 \\
\end{array}$ & $\begin{array}{r}75 \\
85 \\
\end{array}$ & $\begin{array}{r}90 \\
95 \\
\end{array}$ \\
\hline $\begin{array}{l}\text { Parks, Cameteries } \\
\text { Playgrounds }\end{array}$ & 10 & 10 & 15 & 20 & .20 & 25 & .30 & 35 & .40 & .35 & 40 & 45 \\
\hline Schools & 30 & 35 & 40 & 40 & 45 & 50 & 45 & 50 & 55 & .50 & 55 & 65 \\
\hline Railroad Yard Areas & 20 & 20 & .25 & 30 & 35 & 40 & 40 & 45 & 45 & 45 & $\$ 0$ & 55 \\
\hline $\begin{array}{l}\text { Sirtets } \\
\text { A. Paved } \\
\text { B. Gravel }\end{array}$ & $\begin{array}{l}85 \\
25\end{array}$ & $\begin{array}{l}90 \\
25\end{array}$ & $\begin{array}{l}95 \\
.30\end{array}$ & $\begin{array}{l}85 \\
35\end{array}$ & $\begin{array}{l}90 \\
40\end{array}$ & $\begin{array}{l}.95 \\
.45\end{array}$ & $\begin{array}{l}85 \\
.40\end{array}$ & $\begin{array}{l}.90 \\
.45\end{array}$ & $\begin{array}{l}95 \\
. \$ 0\end{array}$ & $\begin{array}{l}85 \\
.40\end{array}$ & $\begin{array}{r}90 \\
45\end{array}$ & $\begin{array}{l}.95 \\
.50\end{array}$ \\
\hline $\begin{array}{l}\text { Drives, Walks, \& } \\
\text { Roofs }\end{array}$ & 85 & .90 & 95 & 85 & .90 & .95 & 85 & $\infty$ & .95 & 85 & 90) & 95 \\
\hline $\begin{array}{l}\text { Lans } \\
\text { A. } 50 \%-75 \% \text { Ciras } \\
\text { (Fair Condition) } \\
\text { B. } 35 \% \text { On More Grass } \\
\text { (Good Condition) }\end{array}$ & 10 & 10 & .15 & $\begin{array}{r}30 \\
.15 \\
\end{array}$ & .20 & $\begin{array}{r}.25 \\
.20 \\
\end{array}$ & $\begin{array}{r}30 \\
25 \\
\end{array}$ & $\begin{array}{r}35 \\
.25 \\
\end{array}$ & .40 & .30 & 35 & .40 \\
\hline $\begin{array}{l}\text { Undevoloped Surface (By Slope) } \\
\text { A. Slat }(0-1 \%) \\
\text { B. Average }(2.6 \%) \\
\text { C. Stecp }\end{array}$ & & $\begin{array}{l}04.0 \\
09.0 \\
13.0\end{array}$ & & & $\begin{array}{l}07-0 \\
12.0 \\
18.0\end{array}$ & & & $\begin{array}{l}11.0 \\
16-0 \\
23-0\end{array}$ & & & $\begin{array}{l}15-0 \\
200 \\
28 \cdot 0\end{array}$ & \\
\hline
\end{tabular}

Undeveloped Surfice Delinition Fonest and agricuitural land, open space.

"Sotare: Stom Dranage Design Mambal, Ene and Niagara Coumes Regonal Planning Bowd.

Table 4.1 - Runoff coefficients for the Rational method (ISU 2008) 
Also when a watershed includes different types of soils and/or surfaces, a composite coefficient for the total watershed should be used. The composite is calculated by this formula(ODOT 2005):

Composite $C=\frac{\sum\left(C_{\text {Individual Areas }}\right)\left(A_{\text {Individual Areas })}\right.}{A_{\text {Total Area }}}$

It should be noted that this equation should not be used to estimate the average coefficient for large segments with multiple land uses of a wide variety(ISU 2008).

Rainfall Intensity: This variable represents the severity of rain events in inches per hour. It is estimated in a duration equal to the time of concentration (Tc) and is used for calculating the pick flow discharge.

Time of concentration: Time of concentration is estimated as the time for runoff to flow from the most hydraulically remote point of the watershed to the point under analysis. It is usually assumed to equal the summation of two travel times. first is the duration of overland flow and the second is the travel time in the conveyance elements (swales, sheet flow, shallow concentrated flow, etc). Time of concentration is a very important value in Rational method, and sometimes it is difficult to estimate (Marek 2011).

Area (A): This value represents the area of the watershed in acres. Different characteristics of the area such as permeability and the flow path should be considered while estimating the watershed. 
Adjustment of $\mathrm{C}$ values: Large rain events require adjusted runoff coefficient because in severs rain events infiltration and other losses of the surfaces have lower impact on stormwater runoff. Runoff coefficient adjustment factors are represented in table 4.2 .

\section{RECURRENCE INTERVAL}

10 years or less

25 years

50 years

100 years

\section{RUNOFF COEFFICIENT ADJUSTMENT FACTOR}

1.0

1.1

1.2

1.25

Table 4.2 - Runoff Coefficient Adjustment factors (ODOT 2005)

\subsubsection{Limitations}

Some limitations and assumptions should be considered in utilizing Rational method. These include:

- The watershed should be less than 300 acres

- It is assumed that the peak flow happens when the whole drainage area is contributing runoff

- The rainfall is considered to be consistent during the duration of the storm

- The method is valid only when if the time of concentration is less than the duration of peak rainfall intensity

- Stormwater is distributed equally in the watershed

- The only output of the model is the peak flow discharge 
- In order to enhance the accuracy of results a good engineering judgment is required when estimating the runoff coefficient

- This method assumes the storage in the area to be filled

\subsubsection{Summary}

Due all the limitations of Rational method and considerations required to be made, this method is the most common and the simplest method to estimating stormwater peak flow discharge. The steps in utilizing Rational method are estimating the time of concentration, Determining design rainfall intensity for duration for selected frequency, configure rational equation model and computing design peak flow. The two most important parts of using this method is to estimate the most appropriate runoff coefficient factor and time of concentration. 


\subsection{BMPDSS}

BMPDSS( Best Management Practice - Decision Support System), is an ArcGIS based decision making tool for placing BMPs at various locations in urban watersheds. This tool combines different data sets and hydrological, hydraulic and water quality models to analyze the over performance of different types of BMPs in different locations and figure out the most efficient strategy for implementing them. The ArcGIS interface of BMPDSS eases reading and editing spatial data sets and creates a platform for locating BMPs, delineating subwatersheds and setting up routing networks(TetraTech 2010). Figure 4.1 shows the frame work of BMP-DSS. 


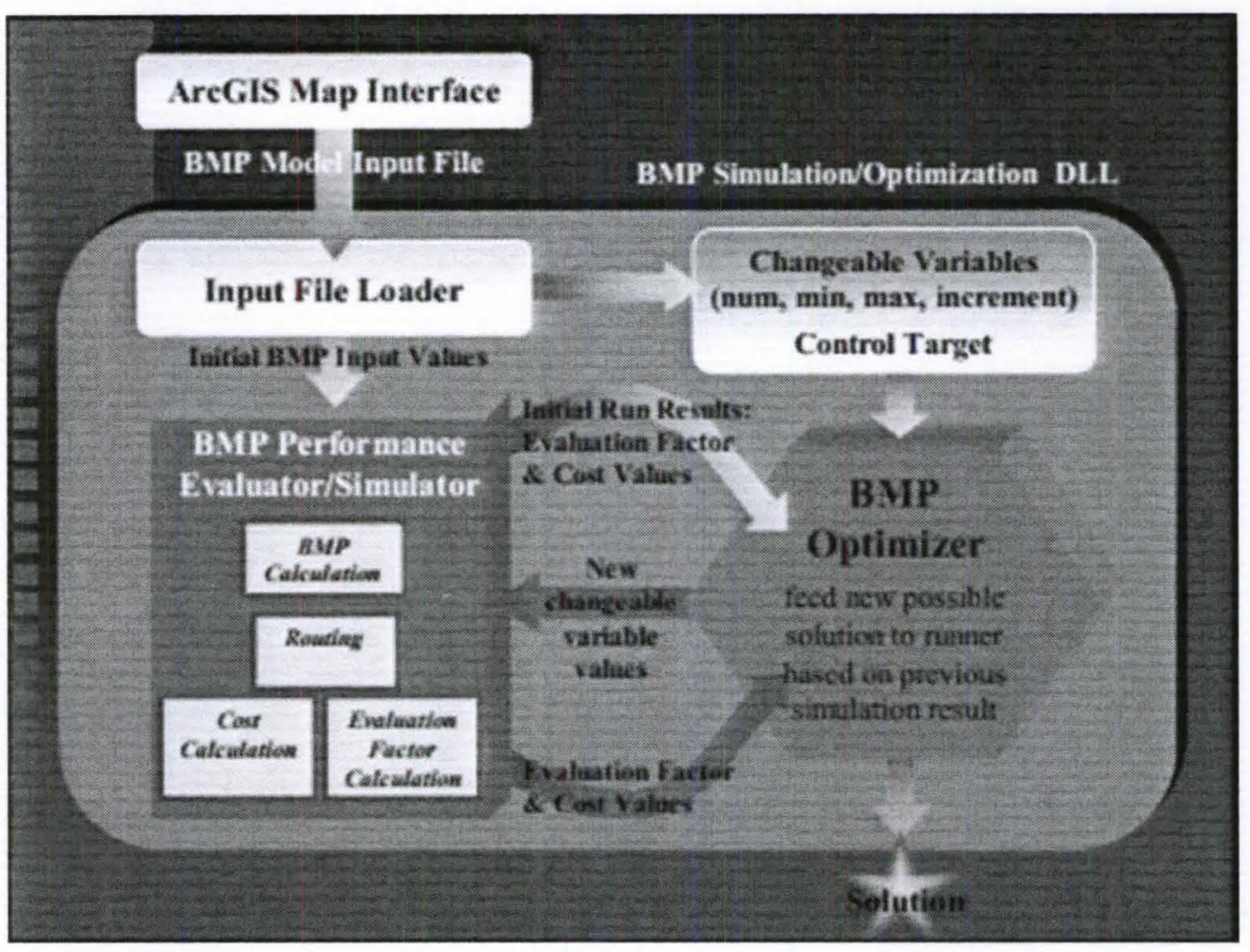

Figure 4.2 - BMP-DSS Framework (Source: NCSU)

\subsubsection{BMP performance simulation}

BMPDSS uses a BMP simulation module to simulate the performance of BMPs in different storm events, locating scenarios and flow routing configuration. Several mathematical procedures are included and considered in this module including infiltration, evaporation, under drain overflow, bottom orifice, overflow spillway and etc. Several types of BMPs can be used in this model, such as permeable pavements, rain barrels and infiltration trench. The performance of BMPs are categorized in two parts, runoff volume and pick flow reduction and pollutant removal. The BMP module uses Holtan-Lopez empirical method to indicate infiltration and evapotransporation during a rain event which 
assumes that infiltration is relative to the capacity of soil to pile up water(Maidment 1993):

$f=G I A S_{a}^{1.4}+f_{c}$

Where:

$f:$ Infiltration rate (inch/hour)

$G I$ : Growth index of vegetation in percent maturity (from 0.1 to 1.0 )

$A$ : Infiltration capacity based upon surface permeability and density of vegetation

$S_{a}$ : Existing capacity of surface for storing water (Inches)

$f_{c}$ : The final constant infiltration rate based un hydrologic soil groups (from 0.0 in group $D$ to 0.3 inch/hour in group A).

The water simulation method includes two methods, general loss of sediments and sediment filtration by the surface. The first one in indicated by utilizing a first order equation(Gross 2005):

$C_{t}=C_{0} e^{(-k t)}$

Where:

$C_{t}$ : Concentration of sediments at time

$C_{0}$ : Initial concentration of sediments 
$k:$ Reaction rate constant $\left(T^{-1}\right)$

$t$ : Time

Sediment filtration though the surface is estimated by using the following equation:

$C_{\text {ud_out }}=P_{\text {rem }} C_{\text {in }} e^{(-k t)} / 100$

Where:

$C_{u d_{\text {_out }}}:$ The underdrain outflow sediment concentration

$C_{i n}$ : Sediment concentration in inflow to the surface

$P_{r e m}:$ Percent removal rate

Figure 4.2 represents the water quality simulation processes.

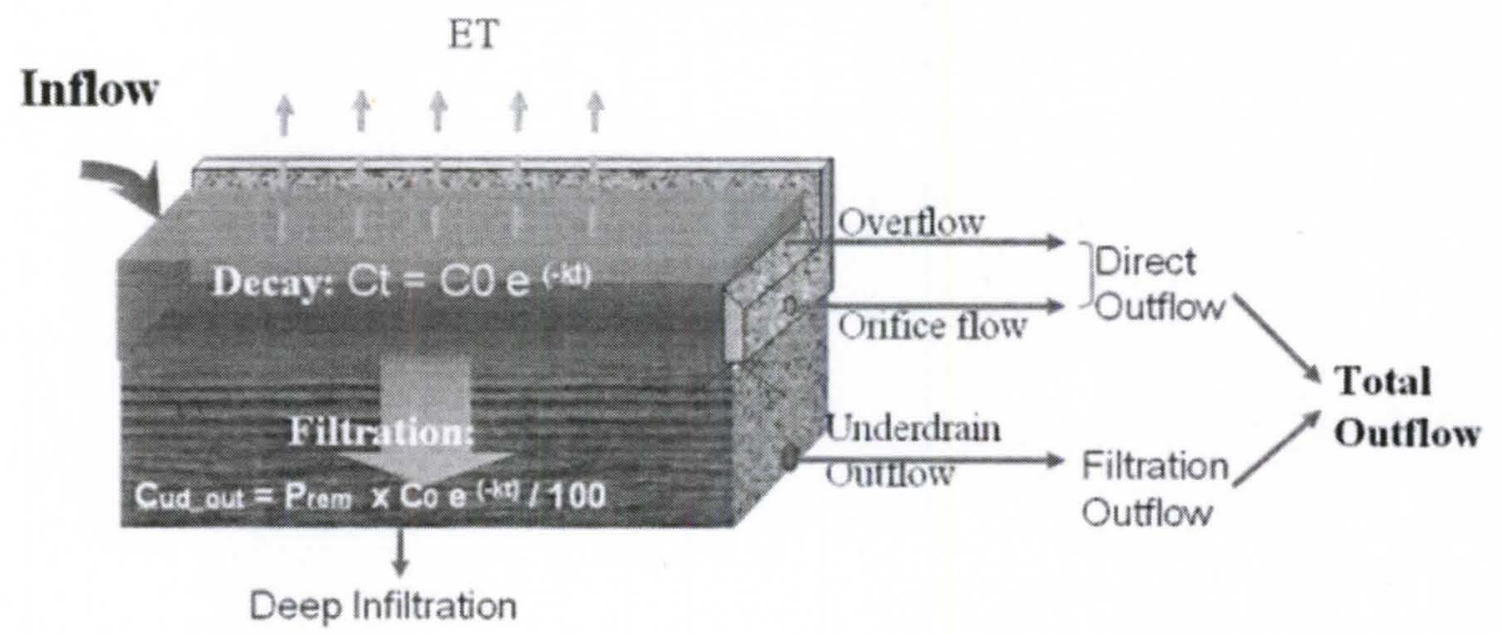

Table 4.3 - Water quality simulation processes (Source: EPA) 


\subsubsection{Optimization module}

The optimization module uses evolutionary methods to estimate the most efficient BMP strategies based on user-defined criteria (assessment points and evaluation factors) at the least cost for the area. This module identifies the placement scenarios, types and designs of the BMPs that best suit the userdefined water quality and runoff volume at the defined cost. BMPDSS gives the users several options to choose as the evaluation factors(TetraTech 2010):

- Stormwater runoff volume

- Annual average Flow Volume (AAFV)

- Peak Flow Discharge( PFD)

- Flow Exceeding Frequency( FEF)

- Stormwater quality factors

The optimization module uses the scatter search method, which is used for making compound decisions in complex systems. Scatter search differentiates from other evolutionary processes by utilizing systematic methods and designs instead of approaches based on randomization. It uses methods for search diversification and amplification that have proved efficient in different optimization problems(Marti and Laguna 2003).

\subsubsection{Post processor}

Post-processor has been included in BMPDSS in order to enhance the procedure, analysis and assessment of output data. The post-processor has two parts. One is in the ArcGIS platform which represents the evaluation factor 
values for each defined assessment point; the other is a Microsoft Excel table. This tool is used to assist the evaluation of BMPs efficiency and to determine the followings(TetraTech 2010):

- Hydrologic consequences of a projected or existing development plan

- Sensible pre-development circumstances of an area

- Differences between the pre-developed developed and developed-withBMPs strategy conditions

- Performance of each BMP in different rain events

- Affects of consecutive rain events in efficiency of BMPs

- The long-term performance of BMPs

\subsection{HEC-HMS}

HEC Hydrologic Modeling System (HEC-HMS) is one of major stream flow simulation tools and is designed to estimate the stormwater runoff in watersheds. This tool is applicable in both urban and rural areas. Hydrographs created by HEC-HMS are used directly or in combination with other tools for studies in runoff flow prediction, future impacts of development, flood damage alleviation and also in BMP performance assessment(Bracmort 2002).

This section includes the description of capabilities of HEC-HMS to assist in developing stormwater management plans.

\subsubsection{Watershed Physical Description}

HEC-HMS describes the physical characteristics of watersheds using several methods. The processes of this methods are proceeded from upstream 
components in a downstream route. Hydrologic elements such as sub watersheds and junctions are linked together in a system to simulate runoff procedures. Processes utilized by HEC_HMS in describing the characteristics of watersheds include(USACE 2010):

- Estimate infiltration losses in a sub watershed

- Estimating the stormwater runoff based on the excess rainfall

- Indicating baseflow contributions to watershed runoff

- Estimating the flow in open channels

All required information and data to indicate watershed characteristics for the mentioned processes are entered using a basin model. A basin model is one of the major parts in a project and describes the elements of the catch basins and represents the stream network in the area. It includes the modeling elements that define infiltration, stormwater runoff, natural water sources, baseflow, ect. These elements are used to divide the watershed into smaller easy to manage sub watersheds(H.Doan). Figure 4.3 shows an example of a basin model. 


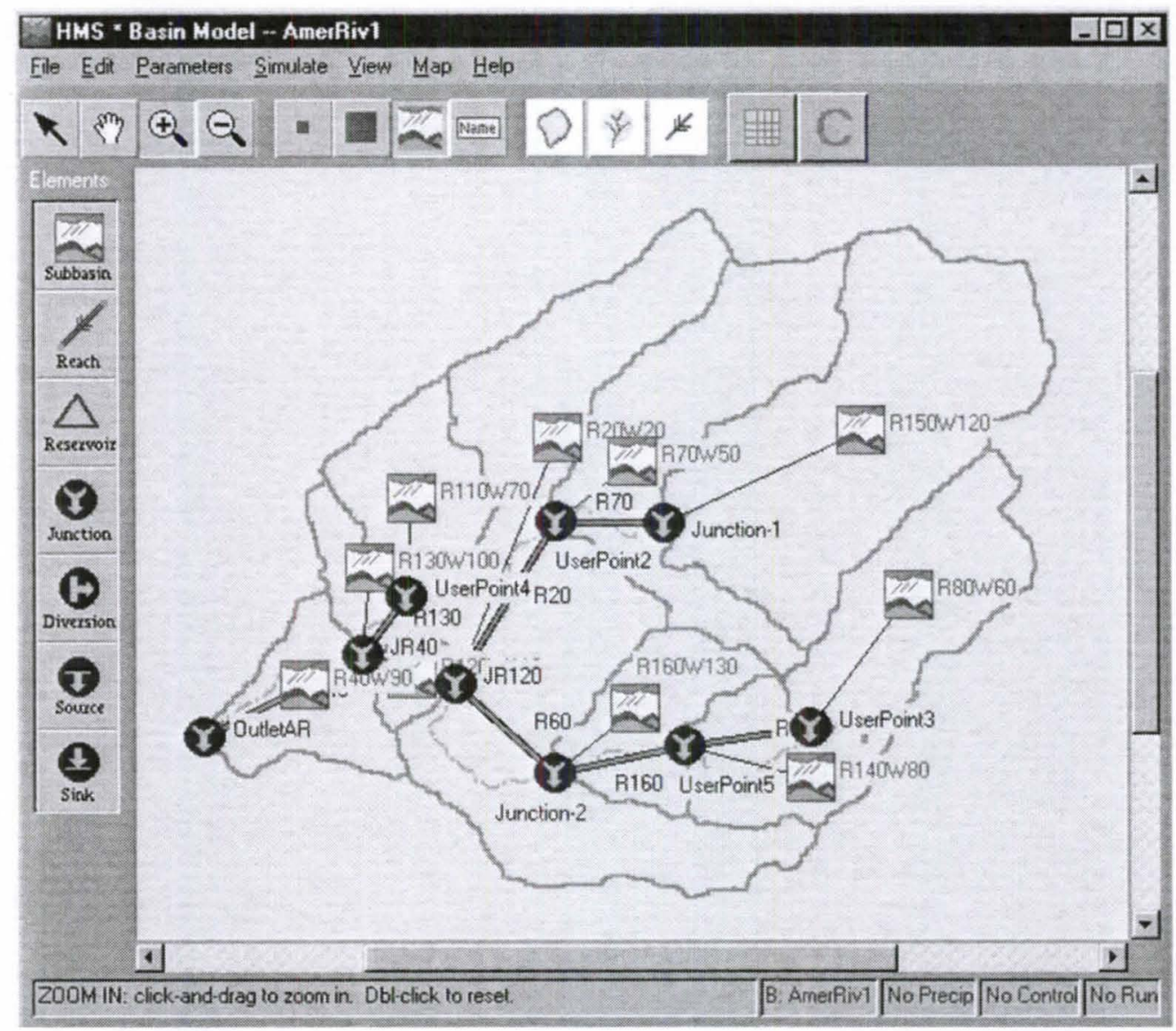

Figure 4.4 - Example of a basin model (Source: ESRI)

\subsubsection{Meteorology Description}

Three components of the meteorology model in HEC-HMS are snow and rain events, snowmelts and evapotransporation. Multiple processes are performed in the meteorology model including:

- Analyzing historical precipitation

- Creating unnatural precipitation (i.e. storms with a particular probability of occurrence)

- Estimating the probable evapotransporation

- Estimating the snow melt rate 


\subsubsection{BMP and Hydrologic Simulation}

HEC-HMS is commonly used for simulating infiltration BMPs, specially when interacts with streams or entering into river analysis is required. It also includes multiple elements for simulating the performance of other types of hydrologic structures such as dams and pumps.

The hydrologic simulation is performed by integrating a basin model, meteorological model and user-defined calculation intervals. The infiltration procedure within BMPs could be simulated by using a diversion element and storage overflow relationship(Emerson 2008). The simulation results could be viewed from the basin map. Multiple tables include information on peak flow discharges and total volume of stormwater runoff. Also time-series table are available for various elements. Figure 4.4 is an example of the output of HECHMS model. This figure indicates that the modeled BMP is expected to infiltrate a total of $16.000 \mathrm{ft}^{3}$ of runoff water in 7.78 inches of rainfall. 


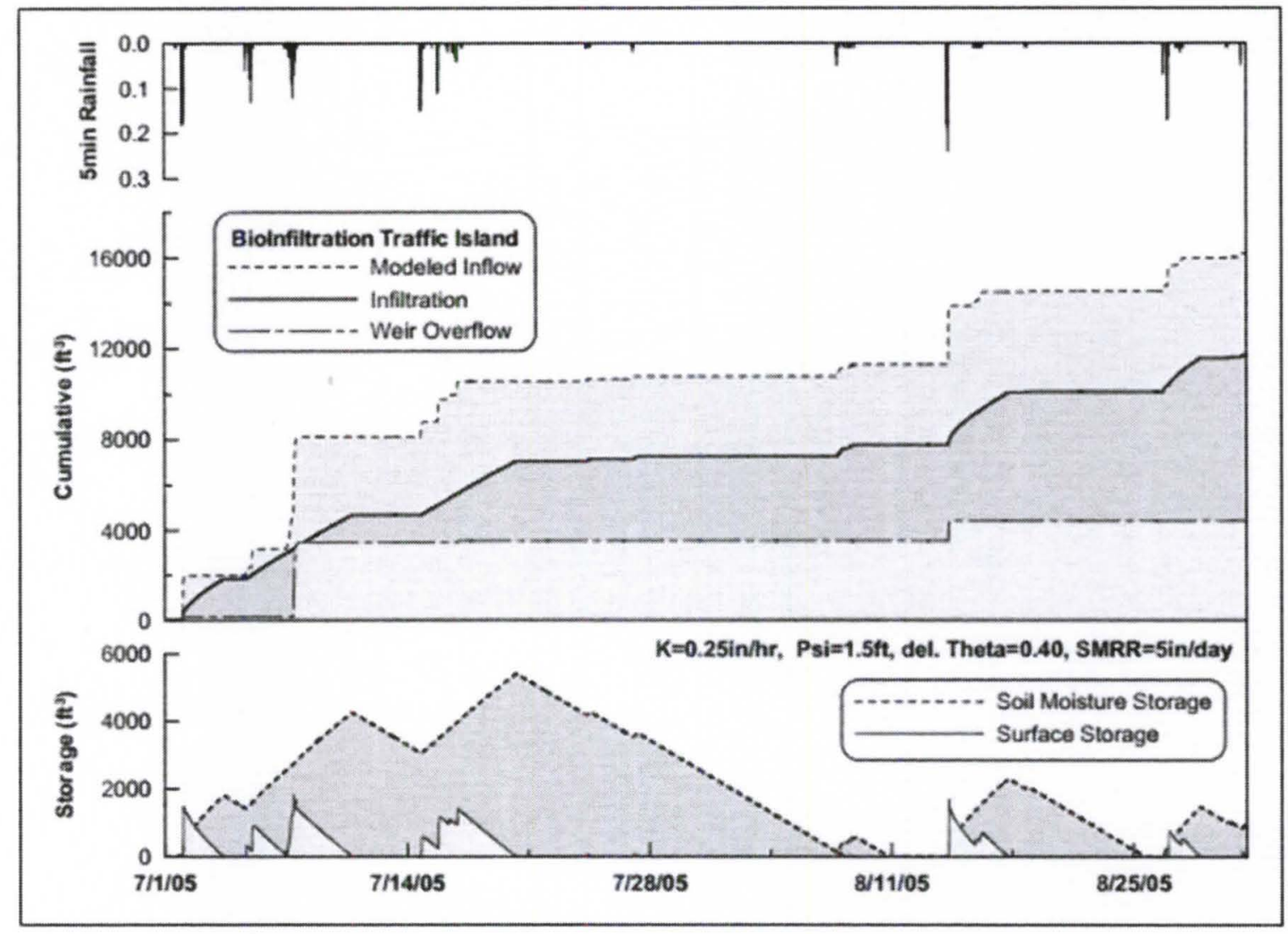

Figure 4.5 - Cumulative plot for two month BMP simulation period (Source:(Emerson 2008))

\subsubsection{HEC-GeoHMS}

There is a HEC-GeoHMS extension, which converts the drainage paths and catch basin boundaries into a data set that indicates the impacts of runoff water on watersheds in an ArcGIS platform and provides basin model files and meteorological model files. It allows users to visualize spatial information, estimate the characteristics of catch basins and delineate sub watersheds. The output of HEC-GeoHMS could be imported into HEC-HMS in which the simulation is executed to create the hydrologic model. HEC-Geo HMS provides several features to ease and improve the simulation including(USACE 2010): 
- Data management, by providing multiple tasks that assist the user to manage the derived data

- Terrain preprocessing, in either a step by step style or batch mode

- Basin preprocessing, which assist the user in sub watershed delineation, processing and manipulation

- Hydrologic parameter estimation, by providing a Curve Number and other loss rate parameters based on watershed characteristics

\subsubsection{Summary}

HEC-HMS provides single event and continues simulation of the stormwater runoff procedures in watershed systems. It includes multiple options of models for indicating precipitation distributions, estimating runoff flow and estimating peak flow discharges. Three major modules used in HEC-HMS are basin model, meteorological model and control specifications. This tool could also be used in assessment of BMPs' performance during different rain events by estimating their water intake and simulating their impacts on runoff water.

HEC-GeoHMS provides a geospatial hydrology toolkit for users that assists them in several steps of the simulation such as watershed delineation and performing spatial study.

Utilizing HEC-HMS for BMP simulation includes some limitations as well. First, it does not consider water quality in BMP assessment and the evaluating BMPs are based upon their impacts on reducing stormwater runoff volume and peak flow discharge. Also the watershed characteristics such as boundaries, 
initial condition and parameters of the model are assumed to be precisely identified. In addition Constant parameter values are assumed to be stable overtime. Despite all the limitations, HEC-HMS is widely used in developing stormwater management plans and designing other water management structures such as dams.

\subsection{SWMM}

The USEAP's Stormwater Management Model (SWMM) is a comprehensive dynamic watershed model which is widely used for analyzing quantity and quality issues associated with stormwater runoff, combined sewers, sanitary sewers and other drainage systems in mainly urban areas(USEPA 2009). It could be used for simulating a single event or continuous rain events.

SWMM is perhaps the most likely used modeling tool in developing stormwater management plans in urban areas during the recent 30 years. This section describes the capabilities and functionalities of this tool in different aspects of stormwater simulating.

\subsubsection{SWMM capabilities}

SWMM has the ability to perform several methods and models in order to describe hydrologic and hydraulic characteristics and estimate water quality in watersheds.

\subsubsection{Hydrological model description}

The inflow on the surface that causes runoff water is rainfall and the outflows would be evaporation, infiltration and runoff. Stormwater runoff occurs 
when the amount of precipitation exceeds the maximum depression storage of the surface. In order to estimate the hydrological impacts of rainfall, SWMM divides the area into smaller sub watersheds which contain its own percentage of pervious and impervious surfaces. Multiple hydrologic procedures are considered in SWMM to estimate the stormwater runoff(USEPA 2004):

- Rainfall intensity

- Evaporation of standing surface water

- Snow melting

- Rainfall blocked from depression storage

- Amount of infiltrated runoff water

- Percolation of infiltrated water into groundwater

- Interaction between groundwater and the drainage system

- nonlinear reservoir routing of overland flow

There three methods that could be defined in SWMM in order to estimate the infiltration rate in pervious surfaces. These three methods are Horton's, Green-Ampt and Curve Number techniques. These methods differ in complexity and the availability of input data. They consider preliminary soil moisture conditions, hydraulic performance, soil moisture, and its regeneration in their processes to estimate the rate of infiltration. 


\subsubsection{Hydraulic model description}

Flow routing in SWMM is managed by the conservation of mass and momentum equation for different flow in one dimension. SWMM is capable of utilizing this equation in three different levels of complexity(USEPA 2009):

- Steady flow routing, which is the simplest type of routing and is based on the assumption that flow is stable and consistent during the computational time. The Manning equation is used in this level.

- Kinematic wave routing, in which the slope of the surface runoff is assumed to be the same as the slope of the conduit. For this level, the continuity equation and a basic type of the momentum equation is utilized in each conduit.

- dynamic wave routing, which because of solving the complete onedimensional Saint Venant flow equations provides the most precise results.

\subsubsection{Water quality model description}

SWMM allows users to define several types of pollutants for inflow and transport estimation. Pollutants are defined for each type of land use in sub watersheds. Each land use category represents a type of development or surface characteristics. For each of them multiple procedures related to pollutant loads generated during a stormwater event could be identified (USEPA 2004; USEPA 2009):

- Dry weather pollutant buildup 
- Pollutant washoff

- Impacts of street cleaning on dry weather buildup

- Affects of BMPs on pollutant reduction

- Routing of water quality constituents

\subsubsection{Applications of SWMM}

Since year 1970 in which SWMM incepted, this tool has been utilized in several watershed studies and stormwater management plans. Almost all aspects of the urban watersheds hydrologic and quality cycles could be modeled and estimated using this tool. Following includes the usual applications of SWMM:

- Designing BMPs' and evaluating their performance in reducing stormwater runoff volume, reducing peak flow discharge and controlling runoff water quality

- Assessment the affects of inflow and infiltration on both sanitary sewer systems and combined sewer systems

- Modeling facilities for reducing CSOs

- Generating non-point source pollutant loadings

SWMM has also some limitations. The speed of simulating is slower than similar tools, its hydraulic models are more unstable compared to other hydraulic tools, it is not applicable to very large rural watersheds, cannot use very complicated precipitation data and is more of an analysis tool rather than an automated design tool(USEPA 2009). 


\subsubsection{Summary}

SWMM is a inclusive computer model for analyzing quantity and quality of stormwater runoff specially in urban watershed. It has been used in several studies related to stormwater management and BMP optimization for both planning and design. It simulates the stormwater runoff within each sub watershed and estimates its hydrological and hydrological characteristics. Since SWMM is an open source model, it has been reviewed by many modelers and many of its bugs has been identified and solved but it still has some limitations in some aspects.

\subsection{SUSTAIN}

SUSTAIN (System for Urban Stormwater Treatment and analysis Integration) is an ArcGIS based decision-making support framework to assist in selecting, designing and placement of BMPs in both urban and rural watersheds in order to alleviate stormwater quantity and control its quality. It is consist of hydraulic, hydraulic and water quality models in order to identify optimal stormwater management strategies to achieve multiple objectives at the least cost. SUSTAIN uses a graphical platform by which users have the ability to visualize the area, place BMPs and identify the linkages(USEPA 2009). It also has the ability to integrate with other stormwater management models such as SWMM and InfoWorks by accepting other watershed modeled information as input. 
SUSTAIN helps modelers to answer the following questions:

- How the BMPs affect the stormwater runoff total volume, peak flow discharge and quality?

- What are the efficient BMP strategies to achieve the objectives based on defined factors as the least cost?

- Which locations has the potential for installing different types of BMPs?

- What are and dimensions should be selected for BMPs ?

SUSTAIN includes multiple modules which are integrated in an ArcGIS platform. This section describes the methods and algorithms used in these modules. They include simulation modules and optimization modules and all of these perform under a framework manager. The results of the simulation modules are represented by a post-processor which alleviates the analysis and understanding the results. This components are shown in figure 4.5: 


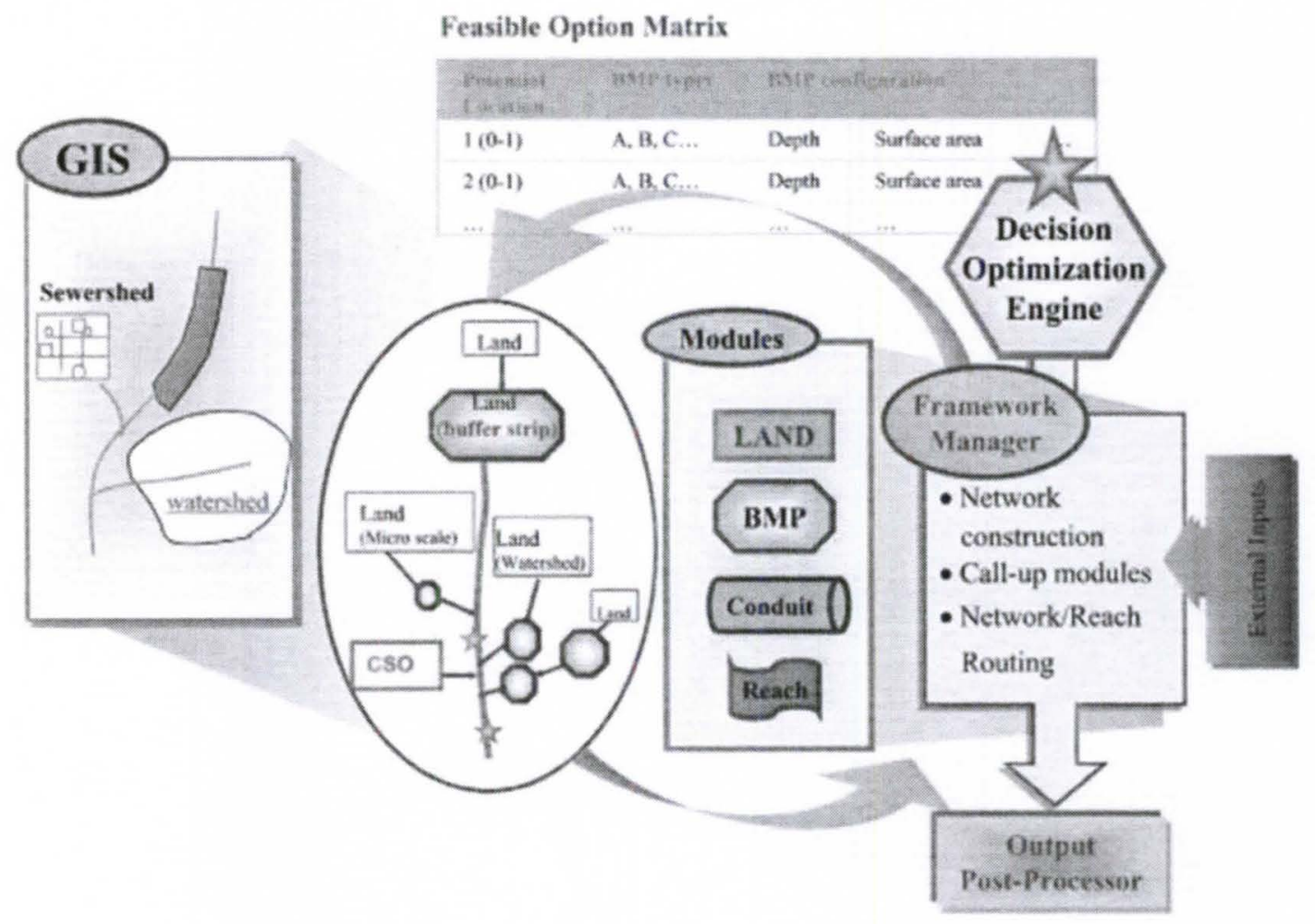

Figure 4.6 - Key components and flow chart of SUSTAIN (Source: USEPA)

Framework manager facilitates the linkage between different components and coordinates external outputs. It also checks the appropriateness of input data for different modules. Modules are usually applied in series. The modeling procedure typically starts with BMP siting tool which supports users in identifying potential locations for installing different types of BMPs in watersheds. This module consider several criteria such as soil type, slope, road and building buffer and land uses in its performance. Different types of BMPs that are supported by this tool includes point BMPs (i.e. rain gardens), linear BMPs( i.e. infiltration trenches) and area BMPs( i.e. permeable pavements)(USEPA). The land 
simulation module is utilized in order to compute the runoff volume and pollutants. It also allows the user to import time-series created by other modeling tools.

BMP module performs a simulation of runoff flow and pollutants for multiple types of BMPs by applying a combination of procedures such as flow routing and infiltration in order to estimate the performance of BMPs(USEPA). The cost database in SUSTAIN is classified based on different factors in constructing and installing BMPs and is indicated in unit cost for each type of BMP. The conveyance module is utilized in order to estimate and simulate the movement of water and sediments in the physical watershed components such as conduits, BMP and land.

The optimization module utilizes the output of other modules to evaluate and identify efficient BMP strategies that achieve the user-defined objectives of the study at the least cost. The results of this module could be presented in Microsoft Excel by utilizing post processor module. This component represents significant information that illustrates the cost effectiveness of the modeled BMPs. The output includes storm event classification, storm event viewer, storm performance summary and cost-effectiveness curve(USEPA 2009). Table 4.3 categorizes the modules used in SUSTAIN based upon their methodologies: 


\begin{tabular}{|c|c|c|}
\hline Module & Component & Methodology \\
\hline \multirow[t]{3}{*}{ Framework Manager } & Data management component & $\begin{array}{l}\text { Path identification } \\
\text { GIS Interfaces }\end{array}$ \\
\hline & BMP site selection component & $\begin{array}{l}\text { ArcGIS } \\
\text { Site suitability criteria } \\
\text { Highlighted suitability areas }\end{array}$ \\
\hline & Routing network component & ArcGIS interfaces \\
\hline \multirow[t]{3}{*}{ Land module } & Weather component & $\begin{array}{l}\text { Precipitation } \\
\text { Snowmelt } \\
\text { Evaporation }\end{array}$ \\
\hline & Hydrology component & $\begin{array}{l}\text { Internal simulation } \\
\text { Infiltration: Green-Ampt equation } \\
\text { Overland flow } \\
\text { Groundwater flow } \\
\text { External simulation } \\
\text { Unit area flows and loads } \\
\text { File linkages }\end{array}$ \\
\hline & Water quality component & $\begin{array}{l}\text { Erosion } \\
\text { Pollutant buildup } \\
\text { Pollutant washoff } \\
\text { Particle size distribution }\end{array}$ \\
\hline \multirow[t]{4}{*}{ BMP module } & Simulation component & $\begin{array}{l}\text { Storage routing method } \\
\text { Infiltration filtration methods } \\
\text { Evapotranspiration method } \\
\text { Underdrain method } \\
\text { Pollutant routiag and removal methods }\end{array}$ \\
\hline & Buffer strip component & $\begin{array}{l}\text { Overland flow routing } \\
\text { Pollutant interception }\end{array}$ \\
\hline & Aggregate BMP component & $\begin{array}{l}\text { Interception } \\
\text { Treatment } \\
\text { Storage }\end{array}$ \\
\hline & Cost database component & $\begin{array}{l}\text { Unit area cost estimates } \\
\text { Construction components }\end{array}$ \\
\hline Conveyance module & Routing component & $\begin{array}{l}\text { Flow routing } \\
\text { Sediment } \\
\text { Transport pollutant routing }\end{array}$ \\
\hline Optimization module & & $\begin{array}{l}\text { Problem formulation } \\
\text { NSGA-II } \\
\text { Scatter Search } \\
\text { Tiered analysis }\end{array}$ \\
\hline Post-processor & $\begin{array}{l}\text { Storm evaluation } \\
\text { Storm viewer } \\
\text { Performance summary report } \\
\text { Cost-efectiveness report }\end{array}$ & \\
\hline
\end{tabular}

Table 4.3 - Modules and Componenets in SUSTAIN (Source: USEPA) 


\subsubsection{Framework Manager}

Framework manage in SUSTAIN serves as the command module , manages the database and tasks, provides connection between different components and helps in modeling and optimization processes. This module includes three major components: data management, BMP site selection and routing network.

The data management component collects and manages the required data for SUSTAIN. The first step of this component is to define the path to the databases including cost database, file geodatabase and the temporary folder. The second part of this components is to collect the needed data for different options. Another component of SUSTAIN's framework is the BMP siting tool. It helps users to select potential locations for placement of the most common structural BMPs based on site suitability criteria. The output of siting tool represents the locations that meet the specified criteria for placement of different BMPs. This map could be served as a guidance for future BMP implementation plans in the area(USEPA 2009). Data required for siting tool are presented in the table 4.4: 


\begin{tabular}{|l|l|l|}
\hline GIS Layer & Format & Description \\
\hline DEM & Raster file & $\begin{array}{l}\text { The DEM is used to calculate the drainage slope and drainage area that are } \\
\text { used to identify the stutable locations for BMPs. }\end{array}$ \\
\hline NLCD Land Use & Raster file & $\begin{array}{l}\text { The USGS Multi-Resolution Land Characteristics Consortium NLCD land } \\
\text { use grid is used to eliminate the unsuitable areas for BMPs. }\end{array}$ \\
\hline $\begin{array}{l}\text { Percent } \\
\text { Imperviousness }\end{array}$ & Raster file & $\begin{array}{l}\text { The impervious grid is used to identify the suitable locations for BMPs for } \\
\text { the given suitability criteria. }\end{array}$ \\
\hline Soil & Shape file & $\begin{array}{l}\text { The soil data contain the soil properties such as hydrological soil group, } \\
\text { which are used to identify suitable locations for BMPs. }\end{array}$ \\
\hline Urban Land Use & Shape file & $\begin{array}{l}\text { The urban land use data contain the boundaries for the buildings and the } \\
\text { impervious areas needed to identify suitable locations for LIDs. }\end{array}$ \\
\hline Road & Shape file & $\begin{array}{l}\text { The road layer is used to identify suitable locations for some BMPs that } \\
\text { must be placed within a specific road buffer area. }\end{array}$ \\
\hline Stream & Shape file & $\begin{array}{l}\text { The stream layer is used to define a buffer so that certain BMP types can be } \\
\text { placed outside the buffer to minimize the impact on streams. }\end{array}$ \\
\hline $\begin{array}{l}\text { Groundwater Table } \\
\text { Depth }\end{array}$ & Shape file & $\begin{array}{l}\text { The groundwater table depth layer is used to identify suitable locations for } \\
\text { the infiltration BMPs; derived from monitoring data. }\end{array}$ \\
\hline
\end{tabular}

Table 4.4 - Required GIS data for siting tool (Source: USEPA)

Figure 4.6 shows an example of output of siting tool in which highlighted green

areas represent the suitable locations for placing rain gardens in a sample area:

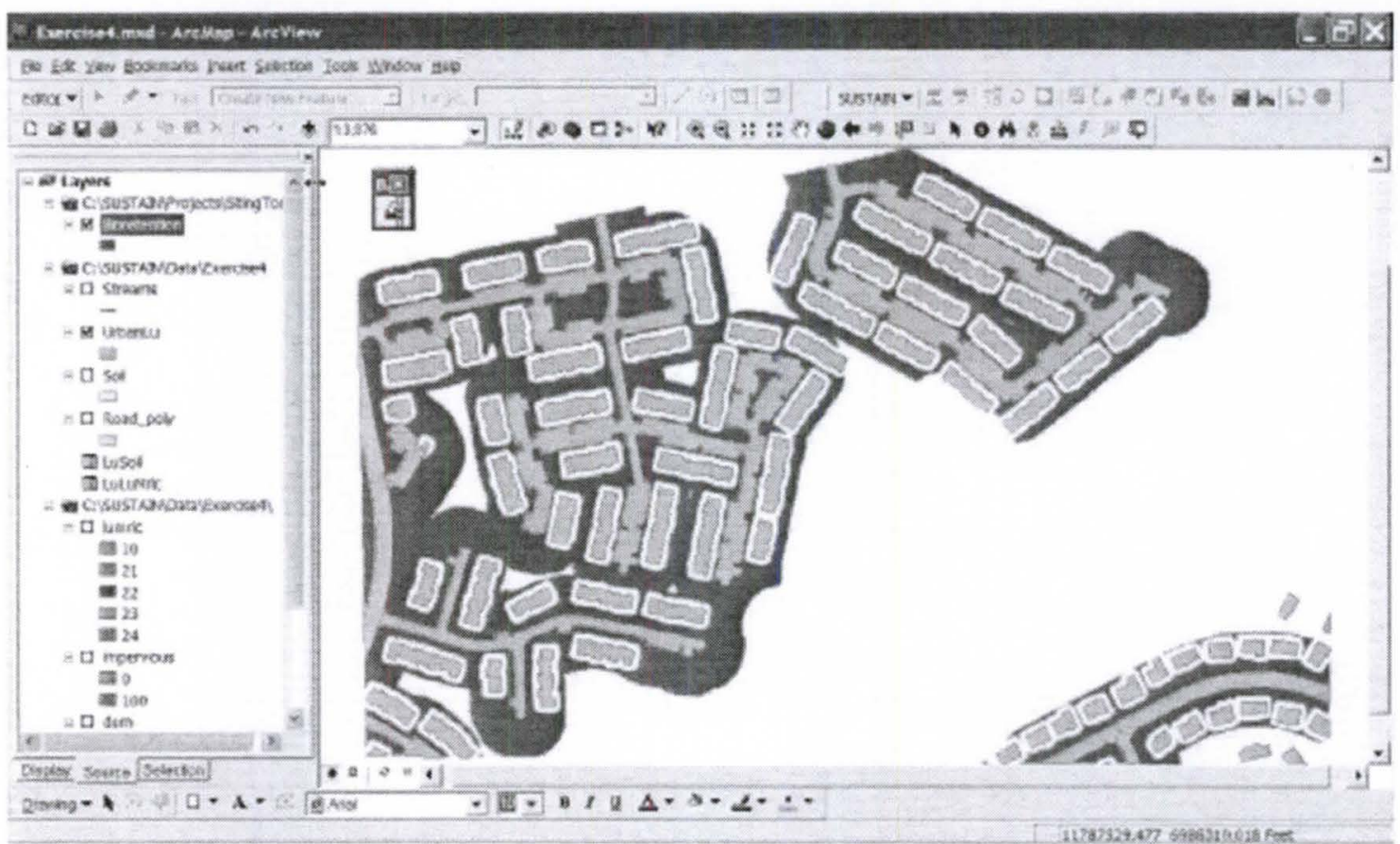

Figure 4.7 - Example of siting tool results (Source: USEPA)

The third component of framework is the routing network which provides

the linkages between different simulation components. After placing BMPs for 
simulation, routing network system connects the land segments that drain to each BMP and connects BMPs to the downstream one. Figure 4.7 represents the function of routing network system:

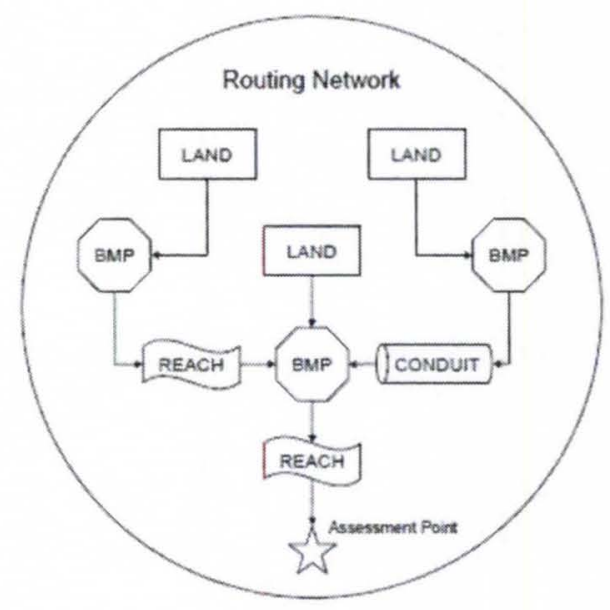

Figure 4.8 - The routing network showing the connections among the simulation components (Source: USEPA)

\subsubsection{Land Module}

Land simulation module is utilized in SUSTAIN in order to estimate runoff flow and pollutants from the watershed by two ways, internal and external simulations. In internal simulation, hydrographs and pollutographs are estimated using different algorithm by SUSTAIN. In external simulation method, SUSTAIN uses the externally imported time series(USEPA 2009). Figure 4.8 represents a schematic of the land simulation procedures: 


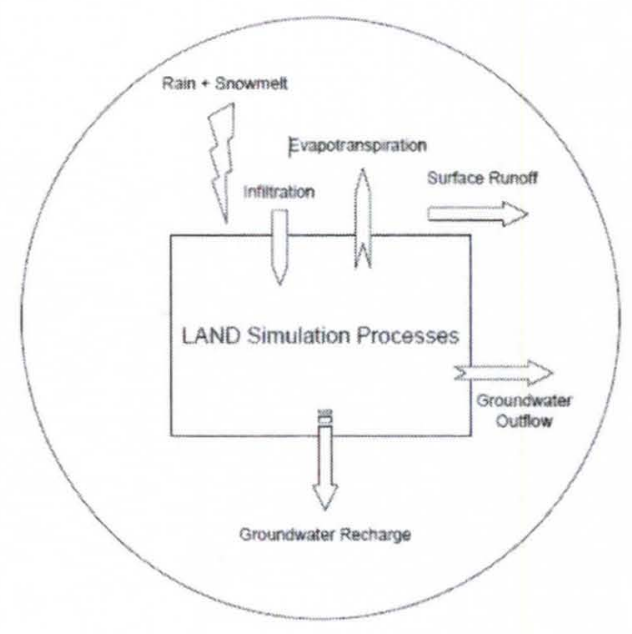

Figure 4.9 - Schematic showing the land simulation processes (Source: USEPA)

Outputs of land simulation module includes hourly outflow, hourly sediment concentration and hourly pollutant concentration time series. Three major parts of land module are weather, hydrology and water quality components. Each of these utilize different methods and algorithms for their processes as are summarized in table 4.5 : 


\begin{tabular}{|c|c|c|c|c|}
\hline Process & Option 1 & Option 2 & Option 3 & Reference \\
\hline Rainfall & Weather data file & $m$ & $-\ldots$ & Rossman 2005 \\
\hline Snowmeit & $\begin{array}{l}\text { Degree-Day equation: } \\
\text { NWS equation }\end{array}$ & $\cdots$ & $\cdots$ & Rossman 2005 \\
\hline Evaporation & Constant value & $\begin{array}{l}\text { Monthly average } \\
\text { value }\end{array}$ & $\begin{array}{l}\text { User-supplied } \\
\text { time series }\end{array}$ & Rossman 2005 \\
\hline Infiltration & Green-Ampt & $\cdots$ & 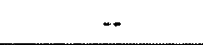 & Rossman 2005 \\
\hline Groundwater flow & $\begin{array}{l}\text { Modified two-zone } \\
\text { groundwater model }\end{array}$ & $\cdots$ & - & $\begin{array}{l}\text { Rossman } 2005 \\
\text { Bicknell et al } \\
2001\end{array}$ \\
\hline Overhand flow & Non-linear reservour & $\cdots$ & $+\infty$ & Rossman 2005 \\
\hline Pollutant buildup & Power function & $\begin{array}{l}\text { Exponential } \\
\text { function }\end{array}$ & $\begin{array}{l}\text { Saturation } \\
\text { function }\end{array}$ & Rossman 2005 \\
\hline Pollutant washoff & Exponential finction & Rating curve & $\begin{array}{l}\text { Event mean } \\
\text { concentration }\end{array}$ & Rossman 2005 \\
\hline Street cleaning & $\begin{array}{l}\text { User-specified pollutant } \\
\text { removal efficiency }\end{array}$ & - & - & Rossman 2005 \\
\hline $\begin{array}{l}\text { Sediment erosion } \\
\text { and transport }\end{array}$ & $\begin{array}{l}\text { Production and removal } \\
\text { from the pervious land } \\
\text { Buildup and washoff from } \\
\text { the impervious land }\end{array}$ & $\ldots$ & - & $\begin{array}{l}\text { Bicknell et al } \\
2001 \\
\text { Rossman } 2005\end{array}$ \\
\hline $\begin{array}{l}\text { Particle size } \\
\text { distribution }\end{array}$ & $\begin{array}{l}\text { User defined (sand, silt. } \\
\text { clay) }\end{array}$ & $-\infty$ & $-m$ & $\begin{array}{l}\text { Bicknell et al } \\
2001\end{array}$ \\
\hline
\end{tabular}

Table 4.5 - Land simulation methods used in SUSTAIN - (Source: USEPA)

Weather component utilizes different information about the climate, rainfall, snowmelt and evaporation in the study area. All the data used in weather component should be in U.S units. The climate data for utilizing in this component requires to include year, month, day, maximum and minimum temperature. The rainfall data includes the month, day, hour, minute and nonzero rainfall reading. The rainfall amounts are converted to snowfall in temperature bellow which precipitation fall as snow(Rossman 2005).

The hydrology component of land simulation module simulates the runoff processes and connects the climate data and movement of rainfall runoff in the watershed. The processes include estimating infiltration, surface runoff and 
groundwater flow. Infiltration of runoff into permeable areas are estimated by utilizing Green-Ampt algorithm. The surface runoff is estimates using Manning's method.

Green-Ampt estimates the infiltration based upon different characteristics of soil such as soil moisture and saturated hydraulic conductivity:

If $I<k_{s}$ then $f=I(4.4)$

If $I>K_{S}$ then $f=I$, until $F=F_{s}=\frac{\left(\theta_{s}-\theta_{i}\right) \times \psi_{f}}{1-I / K_{s}}$

Following surface saturation,

$f=\frac{d F}{d t}=K_{s}\left[1+\frac{\left(\theta_{s}-\theta_{i}\right) \times \psi_{f}}{F}\right]$

For $I>K_{s}$, and $f=I$ for $I \leq K_{s}$

where:

$I=\operatorname{Inflow}$ rate $(\mathrm{in} / \mathrm{hr})$

$f=$ amount of infiltration (in)

$F_{s}=$ amount of infiltration up to surface saturation

$F=$ infiltration rate $(\mathrm{in} / \mathrm{hr})$

$K_{s}=$ saturated hydraulic conductivity (in/hr)

$\theta_{s}=$ saturated moisture content

$\theta_{i}=$ initial moisture content 
$\psi_{f}=$ average wetting front suction head (in)

Rainfall surface runoff happens when the surface water depth gets higher than surface storage depth, $d_{p}$. In this case Manning equation is used to estimate the runoff flow:

$Q=W \frac{1.49}{n}\left(d-d_{p}\right)^{5 / 3} S^{1 / 2}$

where:

$Q=$ outflow rate (cfs)

$\mathrm{W}=$ sub watershed width $(\mathrm{ft})$

$\mathrm{n}=$ Manning's roughness coefficient

$\mathrm{d}=$ water depth $(\mathrm{ft})$

$d_{p}=$ depth of depression storage $(\mathrm{ft})$

$\mathrm{S}=$ sub watershed slope $(\mathrm{ft} / \mathrm{ft})$

The water quality component of land module estimates the movement of pollutants and sediments on the basis of total flow. By utilizing this component, SUSTAIN can compute the generation and movement of any number of userdefined pollutants and categorize them into two groups, sediments (sand, tilt and clay) and non-sediments. The total pollutant load is then summed in each drainage area for routing to a BMP or conduit component(USEPA 2009). 


\subsubsection{BMP Module}

The BMP module includes process based simulation of runoff flow and pollutant movement for different types of BMPs. Simulation in this module includes multiple processes such as evaporation, infiltration, percolation of runoff water into groundwater and outflow. Figure 4.9 represents the simulation procedures in this module:

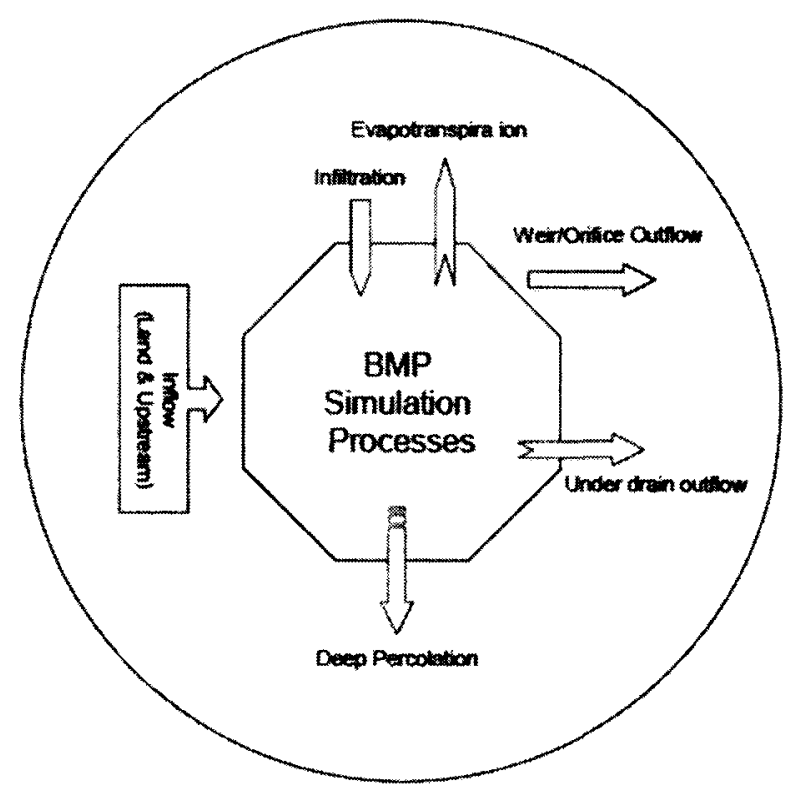

Figure 4.10 - A schematic the BMP simulation processes modeled in SUSTAIN (Source: USEPA)

The results of BMP module includes three time series, Sub-hourly outflow, Sub-hourly sediment concentration and sub-hourly pollutant concentration(USEPA 2009). Different supported types of BMPs and methods used for performing simulations on them are shown in table 4.6: 


\begin{tabular}{|c|c|}
\hline BMP & Recommended Simulation Methods \\
\hline Detention pond & $\begin{array}{l}\text { Constant ET rate or monthly average value, or daily values } \\
\text { Calculate potential ET using Hamon's method } \\
\text { Stage-outflow storage routing using weir or orifice equations } \\
\text { Completely mixed pollutant routing } \\
\text { CSTR in series pollutant routing } \\
\text { First order decay (k'-C* method) } \\
\text { Sediment settling and transport }\end{array}$ \\
\hline Constructed wetland & $\begin{array}{l}\text { Green-Ampt method } \\
\text { Holtan-Lopez equation } \\
\text { Constant ET rate or monthly average value, or daily values } \\
\text { Calculate potential ET using Hamon's method } \\
\text { Stage-outllow storage routing using weir or orifice equations } \\
\text { Completely mixed pollutant routing } \\
\text { CSTR in series pollutant routing } \\
\text { First order decay ( } k^{\prime}-C^{*} \text { method) } \\
\text { Sediment settling and transport }\end{array}$ \\
\hline Bioretention & 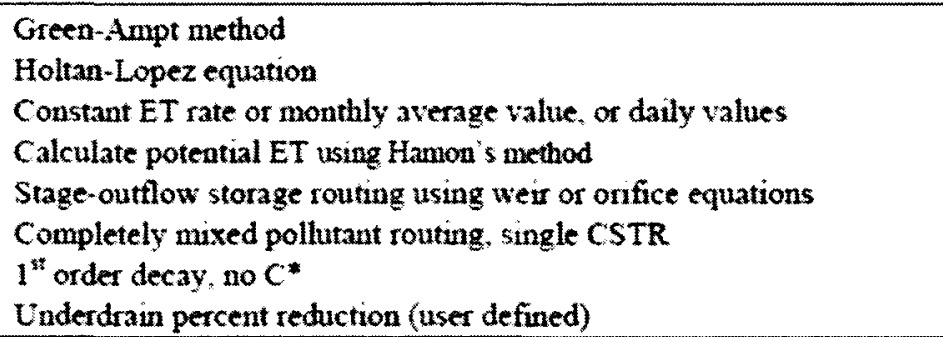 \\
\hline Infiltration trench & $\begin{array}{l}\text { Green-Ampt method } \\
\text { Holtan-Lopez equation } \\
\text { Constant ET rate or monthly average value, or daily values } \\
\text { Calculate potential ET using Hamon's method } \\
\text { Stage-outflow storage routing using weir or orifice equations } \\
\text { Completely mixed pollutant routing, single CSTR } \\
1^{\text {st }} \text { order decay, no } C^{*}\end{array}$ \\
\hline $\begin{array}{l}\text { Hydrodynamic storage } \\
\text { device }\end{array}$ & $\begin{array}{l}\text { Stage-outflow storage routing using weir or onfice equations } \\
\text { Completely mixed pollutant routing } \\
1^{\text {s* }} \text { order decay, no } C^{*} \\
\text { Sedimentation }\end{array}$ \\
\hline Grassed swale & $\begin{array}{l}\text { Kinematic flow routing by solving the coupled continuity equation and } \\
\text { Manning s equation } \\
\text { Completely mixed pollutant routing. single CSTR } \\
1 \text { order decay, no } C^{*} \\
\text { Sediment setting and transport using user defined setting velociny and } \\
\text { critical shear stress }\end{array}$ \\
\hline Vegetated filterstrip & $\begin{array}{l}\text { Kinematic wave oterland flow routing } \\
\text { Process-based sediment interception simulation method (VFSMOD) } \\
1^{\text {s* }} \text { order decay pollutant removal, no } C^{*}\end{array}$ \\
\hline
\end{tabular}

Table 4.6 - Representative BMPS and recommended simulation methods in SUSTAIN (Source: USEPA) 
BMP module includes four components: BMP simulation, overland flow routing and pollutant interception, aggregate BMP and BMP cost database. BMP module estimates the storage, routing, evapotranspiration and underdrain infiltration and pollutant routing in BMPs through its BMP simulation component. Its aggregate BMP component allows the user to simulate the combined performance of multiple BMPs in runoff water reduction and removing pollutants in watersheds(USEPA 2009).

\subsubsection{Conveyance module}

The conveyance module routs the flow and water quality in a conduit in watersheds. Conduits in SUSTAIN are considered as pipes or one dimensional open channels which direct from one point to another. Different types of conduits could be defined by user in SUSTAIN. The output of this module includes sub hourly outflow, sediment concentration and pollutant concentration times series in conduits. This module includes estimating flow routing, sediment transport and pollutant movement.

\subsubsection{Optimization module}

SUSTAIN's optimization module is utilized in order to identify the most cost effective BMP strategies based upon user-defined assessment factors such as runoff volume and peak flow discharge reduction, and water quality factors. This module interacts with simulation modules during the search procedure. Simulation module estimates the hydrologic performance and evaluates the cost for BMPs. The results are then passed to optimization module to synthesize the information, compare the performance and cost of BMPs and adjust the search 
path in generating new solutions which are repeatedly assessed by simulation modules(USEPA 2009).

Required inputs for optimization module includes decision variables (dimension range of BMPs), assessment point and assessment factors, management goals (Runoff volume, peak flow discharge and pollutant reduction), and BMP cost functions. There are two options in this module and each of them uses a specific algorithm in its procedure. Minimize cost option uses Scatter Search technique, which is a metaheuristic search method that is generally used in optimizing compound systems. The generate cost-effectiveness curve option, uses NSGAll option which is an advanced version of Genetic Algorithm. A schematic of processes in optimization module is shown in figure 4.10: 


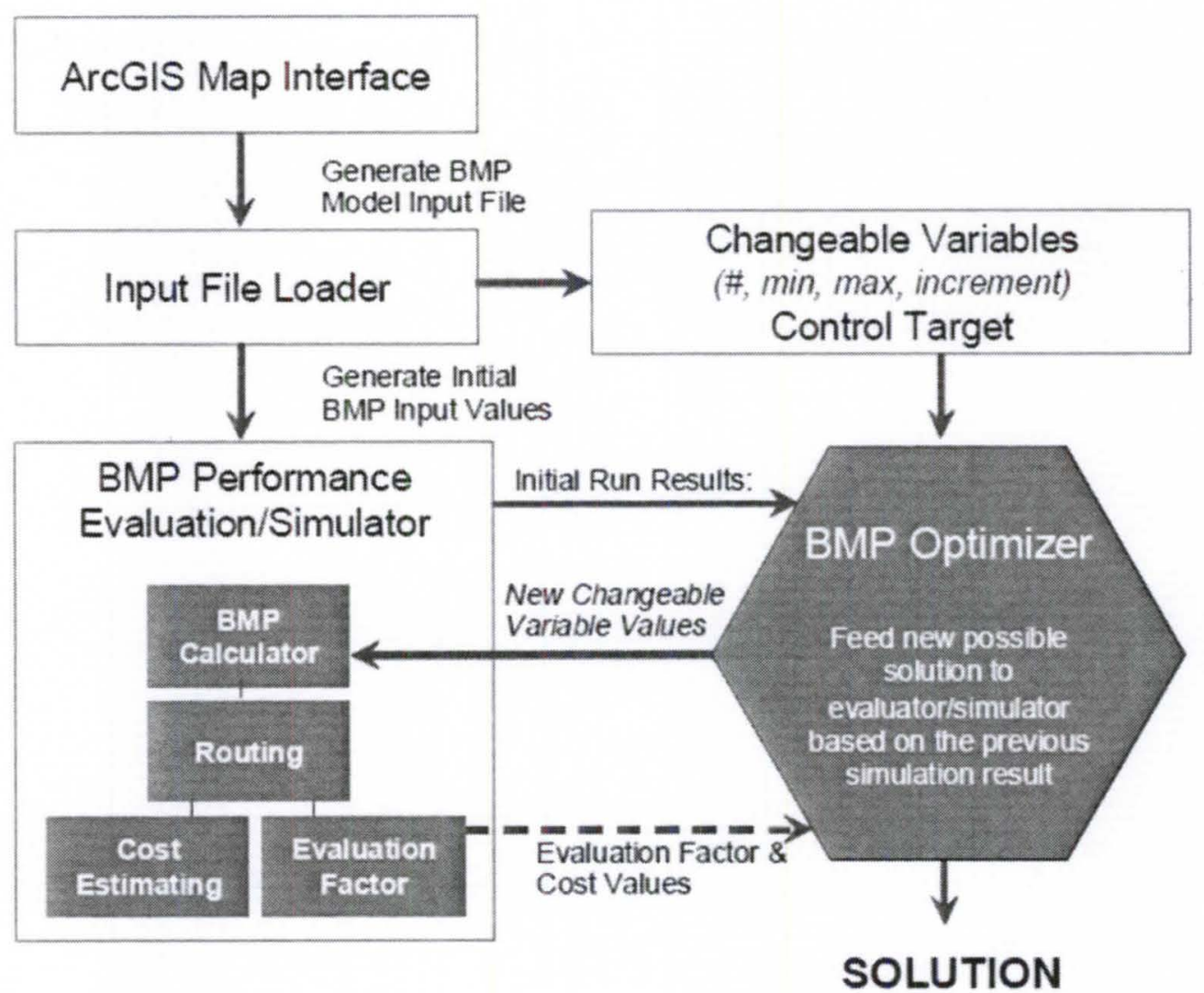

Figure 4.11 - Conceptual overview of the optimization module (Source: USEPA)

\subsubsection{Post-Processor}

Understanding outputs of different modules could be a daunting task, because of various outputs and factors of concern. Post processor module of SUSTAIN facilitates analyzing and evaluating the results by providing detailed graphical and tabular reports of the outputs and. The results of this module's processes include four types of outputs by utilizing Microsoft Excel which help the user to understand the effectiveness of different simulated management strategies. 
Storm event classification: This component assesses the rainfall data used in the simulation and classifies them into different storm events based on different identified criteria. It creates a set of rain events which have been used in simulating and assessing BMPs' performance(USEPA 2009).

Storm event viewer: This part visualizes the BMP impacts on runoff water quality and quantity in a specific rain event by representing postdeveloped, BMP scenario and pre-developed conditions. Figure 4.11 shows an example of this viewer:

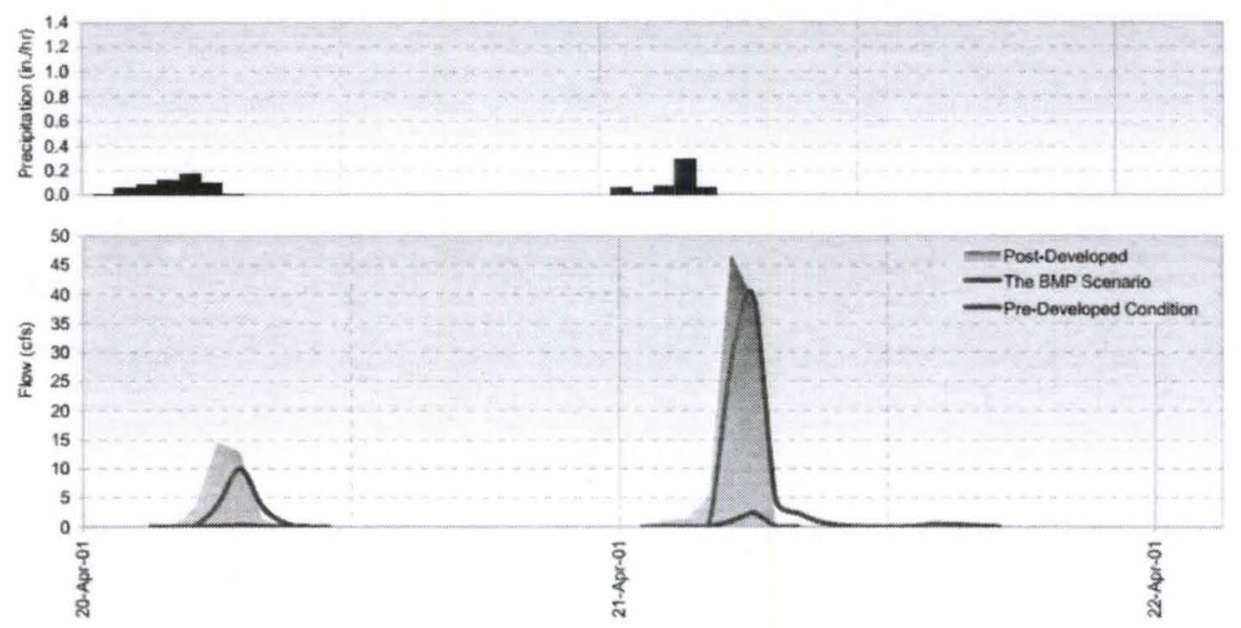

Figure 4.12 - Example storm event viewer graph (Source: USEPA)

Performance summary report: This component represents the impacts of BMP in all simulated rain events and could be used in defining storm events for modeling assessment.

Cost-effectiveness report: This report creates a cons effectiveness curve for a defined assessment point and represents all solutions which have been simulated and evaluated in simulation module. It also describes multiple 
key indicators related with cost effectiveness curve. This report is the final analysis component of post processor. An example of this report is represented in figure 4.12 .
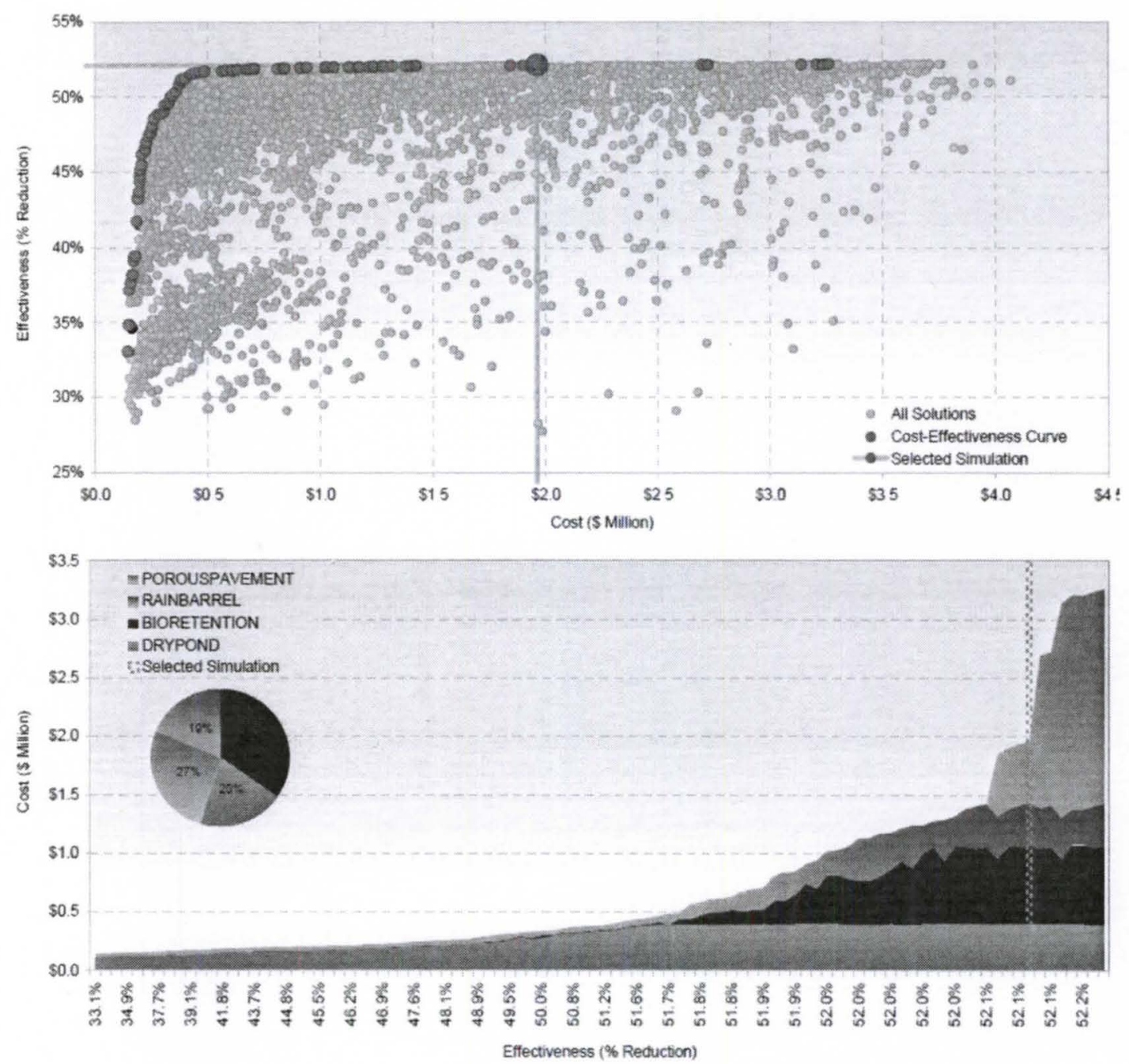

Figure 4.13 - Example outputs of cost-effectiveness report component (Source: USEPA)

\subsection{Summary}

This chapter provided information and description of several common hydrologic computer models for urban watersheds. Each of these models have limitations and advantages in their performance and are applicable for specific 
objectives. There are several factors that should be considered in selecting a model for evaluating hydromodification projects such as availability of data, ease of application, applicability of model's performance to meet goals and concerns and models capabilities(USEPA 2007).

The goal of this project is to perform hydrologic modeling in a 270 acre urban area in order to identify suitable locations for installing different types of BMPs and evaluate and develop efficient BMP strategies to meet the stormwater quality and quantity goals. For achieving these objectives, SUSTAIN was selected as the modeling tool because it has the capacity to perform the required simulation techniques which are necessary for the study. 


\section{SUSTAIN MODELING APPROACH}

This chapter provides a description of each step in modeling effort to identify cost effective BMP strategies for stormwater runoff control in Belknap campus. The initial step of stormwater management in University of Louisville's campus was to select BMP strategy in order to alleviate the negative impacts of stormwater runoff. In order to estimate the cost effective approaches, SUSTAIN is selected as the simulation model to assist in selecting the size, location and types of BMPs for implementation. Following are the required steps toward utilizing SUSTAIN for identifying best BMP scenarios:

- Collecting required data and information

- Identifying suitable locations for installing different types of BMPs using SUSTAIN's siting tool

- Simulate the performance of BMPs in a defined year event in order to estimate the cost effectiveness of different scenarios

- Analyzing the results to make recommendations for selecting the best BMP scenario

\subsection{Data collection}

Two different applications of SUSTAIN are used in order to estimate the most cost effective BMP scenarios, siting tool and BMP simulation. Each of these 
two applications require different data sets. These data sets include ArcGIS based geological, municipal and cost data and were collected from different sources. Typical data set used in SUSTAIN simulation are listed below:

Digital Elevation Model(DEM): DEM files are raster based data that include the elevation of the terrain over an area. DEM files are used in SUSTAIN in order to estimate the drainage slope and watershed delineation. This file was collected from Kentucky Transportation Cabinet.

NLCD land use: National Land Cover Dataset (NLCD) land use is required for identifying the suitability of different areas for installing BMPs. The land uses in this file are assigned by a land use look up table in which the categories and groupings of land uses are defined for each area. These two data were derived from LOJIC website

Urban land use: This data layer represents the different land uses in the area such as buildings, parking or roads. Urban land use data was obtained from LOJIC website.

Rain fall data: Rain fall data used in SUSTAIN contains the hourly precipitation data for the simulation year. The amount of rain in each rain event is represented in decimal inches per hour. This data was derived from National Climate Data Center (NCDC) website.

Percent Imperviousness: Percent imperviousness represents the permeability of different areas and is utilized in siting tool and BMP performance simulations. 
Road: The road file includes the maps and location of the roads in the area. Some types of BMPs should be implemented in a specific buffer from roads and siting tool using this file identifies the appropriate locations for those types of BMPs.

Soil: The soil data represents different soil types in the area. One important characteristic of soils regarding infiltrating water is their hydrological group. soils are categorized in four hydrological groups, $A, B, C$ and $D$ with a sorting of high permeability in group $A$ and very low permeability in group $D$. It is recommended not to install BMPs in locations with low permeable soils. Soil data was collected from LOJIC website.

\subsection{BMP siting tool}

SUSTAIN's BMP siting tool is utilized in order to identify suitable locations for different types of BMPs using GIS analysis and different types of data sets based on the suitability criteria. The suitability criteria defines the appropriate soil type, road, building and parking buffer, drainage slope, imperviousness, water table depth and drainage area for each type of BMP. This criteria was derived from two EPA reports(USEPA 2004a; USEPA 2004b) and in shown in table 5.1. 


\begin{tabular}{|c|c|c|c|c|c|c|c|c|}
\hline \multirow[b]{2}{*}{ BMP } & \multicolumn{8}{|c|}{ Site Suitability Criteria } \\
\hline & $\begin{array}{c}\text { Drainage } \\
\text { Area } \\
\text { (acre) }\end{array}$ & $\begin{array}{c}\text { Drainage } \\
\text { Slope } \\
(\%)\end{array}$ & $\begin{array}{c}\text { Imperviousness } \\
(10)\end{array}$ & $\begin{array}{c}\text { Hydrological } \\
\text { Soil Group }\end{array}$ & $\begin{array}{l}\text { Water } \\
\text { Table } \\
\text { Depth } \\
\text { (ft) }\end{array}$ & $\begin{array}{c}\text { Road } \\
\text { Buffer } \\
\text { (ft) }\end{array}$ & $\begin{array}{c}\text { Stream } \\
\text { Buffer } \\
\text { (fi) }\end{array}$ & $\begin{array}{c}\text { Building } \\
\text { Butfer } \\
\text { (ft) }\end{array}$ \\
\hline Bioretention & 2 & 5 & 0 & $A-D$ & 2 & 100 & $\therefore 100$ & - \\
\hline Cistern & $\ldots$ & $\ldots$ & $\cdots$ & $\ldots$ & $\ldots$ & 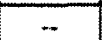 & $\ldots$ & 30 \\
\hline $\begin{array}{l}\text { Constructed } \\
\text { Wethand }\end{array}$ & 25 & 15 & 0 & $A-D$ & 4 & - & 100 & $\ldots$ \\
\hline Dry Pond & 10 & 15 & 0 & $A-D$ & 4 & - & 100 & - \\
\hline Grassed Swale & 5 & 4 & 0 & $A-D$ & 2 & 100 & - & - \\
\hline Green Roof & - & $\ldots$ & $\cdots$ & - & - & 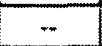 & $\ldots$ & - \\
\hline $\begin{array}{l}\text { Infiltration } \\
\text { Basin }\end{array}$ & 10 & 15 & 0 & $\mathrm{~A}-\mathrm{B}$ & 4 & $-\cdots$ & 100 & - \\
\hline $\begin{array}{l}\text { Infiltration } \\
\text { Trench }\end{array}$ & 95 & 15 & 0 & $A-B$ & 4 & - & 100 & - \\
\hline $\begin{array}{l}\text { Porouss } \\
\text { Pavement } \\
\end{array}$ & 3 & $\therefore 1$ & 0 & $A-B$ & 2 & $m$ & $\cdots$ & $\cdots$ \\
\hline Rain Bamel & $-m$ & - & - & $\cdots$ & - & - & - & 30 \\
\hline $\begin{array}{l}\text { Sand Filter } \\
\text { (non-surface) }\end{array}$ & 2 & 10 & 0 & $A-D$ & 2 & - & 100 & $\cdots$ \\
\hline $\begin{array}{l}\begin{array}{l}\text { Sand Filter } \\
\text { (surface) }\end{array} \\
\end{array}$ & 10 & 10 & 0 & $A-D$ & 2 & $m$ & 100 & $m$ \\
\hline $\begin{array}{l}\text { Vegetated } \\
\text { Filterstrip }\end{array}$ & - & 10 & 0 & $A-D$ & 2 & 100 & $\cdots$ & $\cdots$ \\
\hline Wet Pond & 25 & 15 & 0 & $A-D$ & 4 & - & 100 & .. \\
\hline
\end{tabular}

Table 5.2 - BMP suitability criteria ( Source: USEPA)

The seven ArcGIS data sets used in SUSTAIN's siting tool include DEM, NLCD land use, percent imperviousness, soil, urban land use, road.

\subsubsection{Siting tool results}

Proposed stormwater management plan for University of Louisville's campus includes implementing four types of BMPs: Pervious pavement, rain garden, infiltration trench and infiltration basin. These four types of BMPs were taken into account in siting tool. The output of this tool is a suitability index map of campus which illustrates the areas that meet the defined criteria for installing each type of BMPs and will serve as a guidance tool for simulating the performance of BMPs.(USEPA 2009) 
The output for four different types of BMPs are illustrated in figures $5.1,5.2,5.3$ and 5.4 .

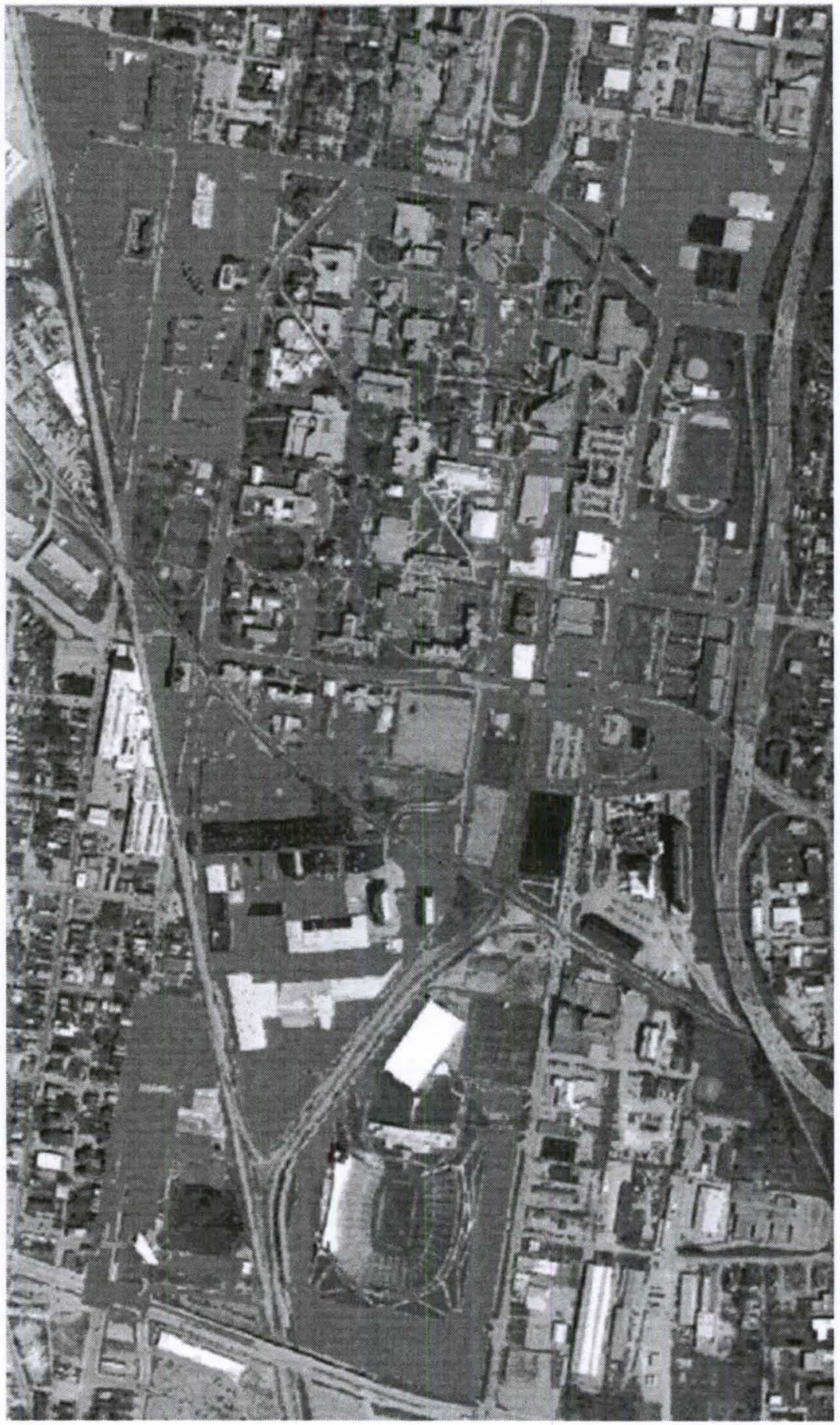

Figure 5.1 - Recommended areas in campus for installing infiltration basins 


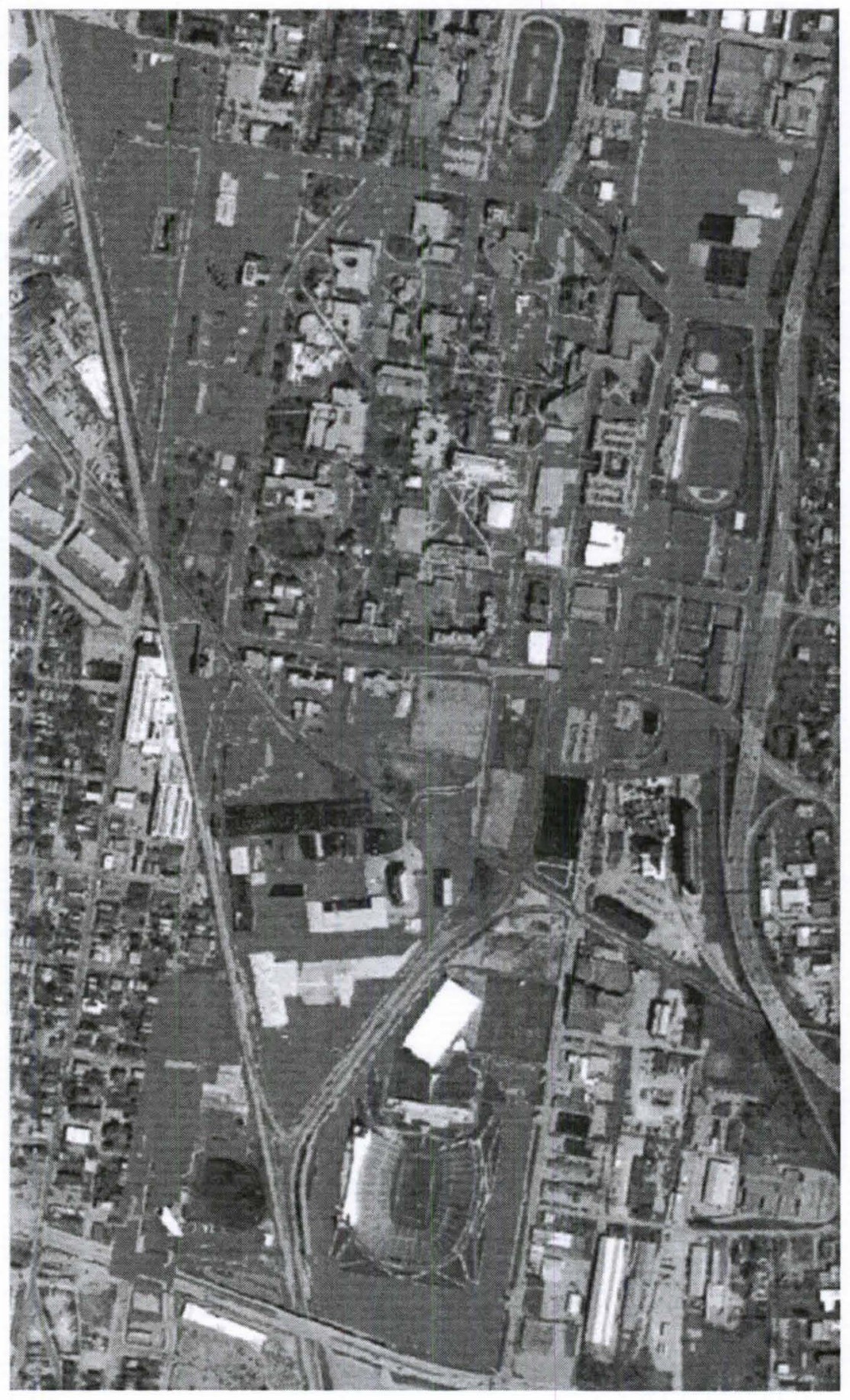

Figure 5.2 - Recommended areas in campus for installing infiltration trenches 


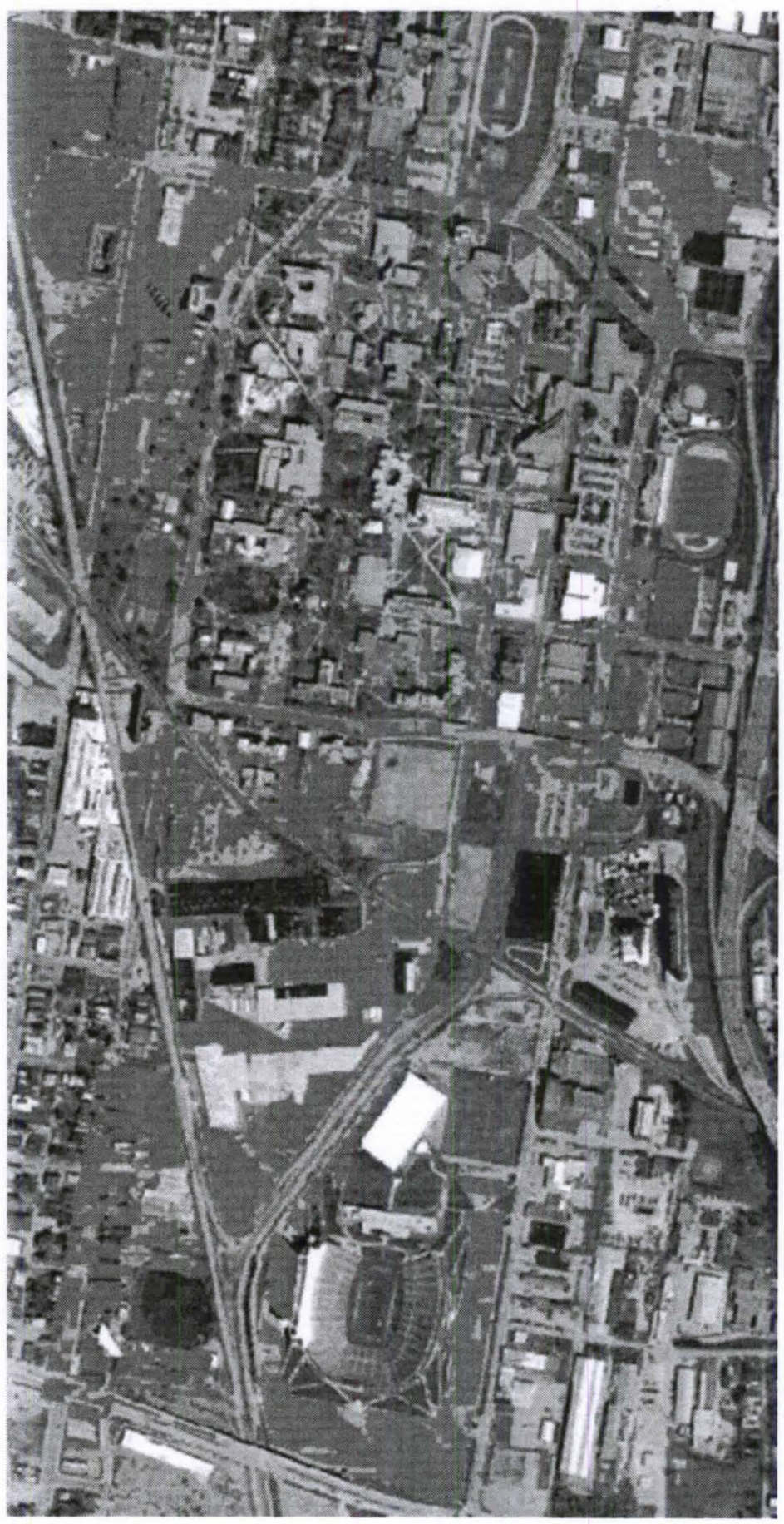

Figure 5.3 - Recommended areas in campus for installing permeable pavements 


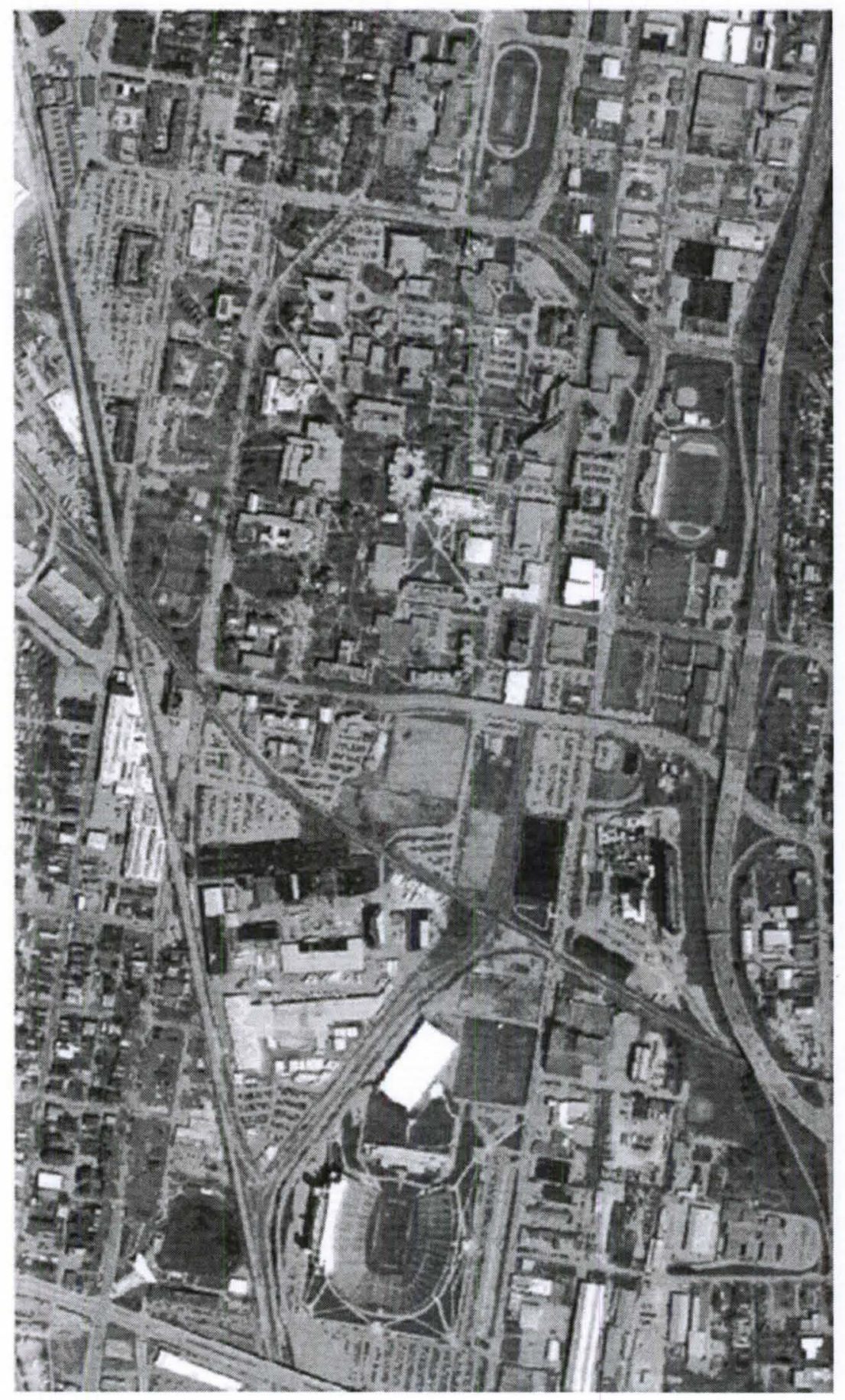

Figure 5.4 - Recommended areas in campus for installing rain gardens 


\subsection{BMP simulation model setup}

An important part of modeling solution approach to stormwater management is to simulate the performance of BMPs in the area in order to identify the most cost effective scenarios. The performance of BMPs changes based on the geological characteristics and the rain events in the area so a simulation should be performed in order to estimate the tradeoff between the effectiveness of BMPs during different rain event with the cost of implementing them. This approach will assist in selecting the number and the location of BMPs to achieve the best results at the defined budget(Damodaram and Zechman 2010).

The two available ways for simulating the performance of BMPs by SUSTAIN are called internal and external simulations. External simulations are based on different time series which includes the information about the run off during rain events in on different land uses and is derived from external softwares such as Infoworks(USEPA 2009). In internal simulation, the performance is based on rain and climate data instead of external time series data. Based on the availability of data, internal simulation was selected for this part of the study.

Performing SUSTAIN internal land simulation includes multiple steps. The required data for this part are land use data, land use look up table, stream network, DEM (in order to delineate the sub watersheds), cost, rainfall and meteorological data. After collecting the required data, sub-watersheds should be delineated. The BMP performance simulation is performed during a period of a 
defined rain year. The rain year is selected based on rain events in different years and represents the average rain events in a year.

\subsubsection{Sub watershed delineation}

In SUSTAIN BMPs are located in different sub watersheds for simulations. Sub watersheds were delineated based on different geological information of the area, such as surface flow direction, sewer network and the land uses. The surface flow direction was estimated using an ArcGIS frame work called ArcHydro. Archydro, by utilizing the DEM file, estimated the flow accumulation on the surface of the area based on the elevation of points. The sewer network, including sanitary and combined systems were obtained from Louisville MSD. By utilizing all these information and taking into account the land uses such as roads, railroads and buildings, the sub watershed boundaries were traced for University of Louisville's campus. Figure 5.5 represents the twelve delineated sub watersheds in the area. The characteristics of these sub watersheds are represented in table 5.2 . 


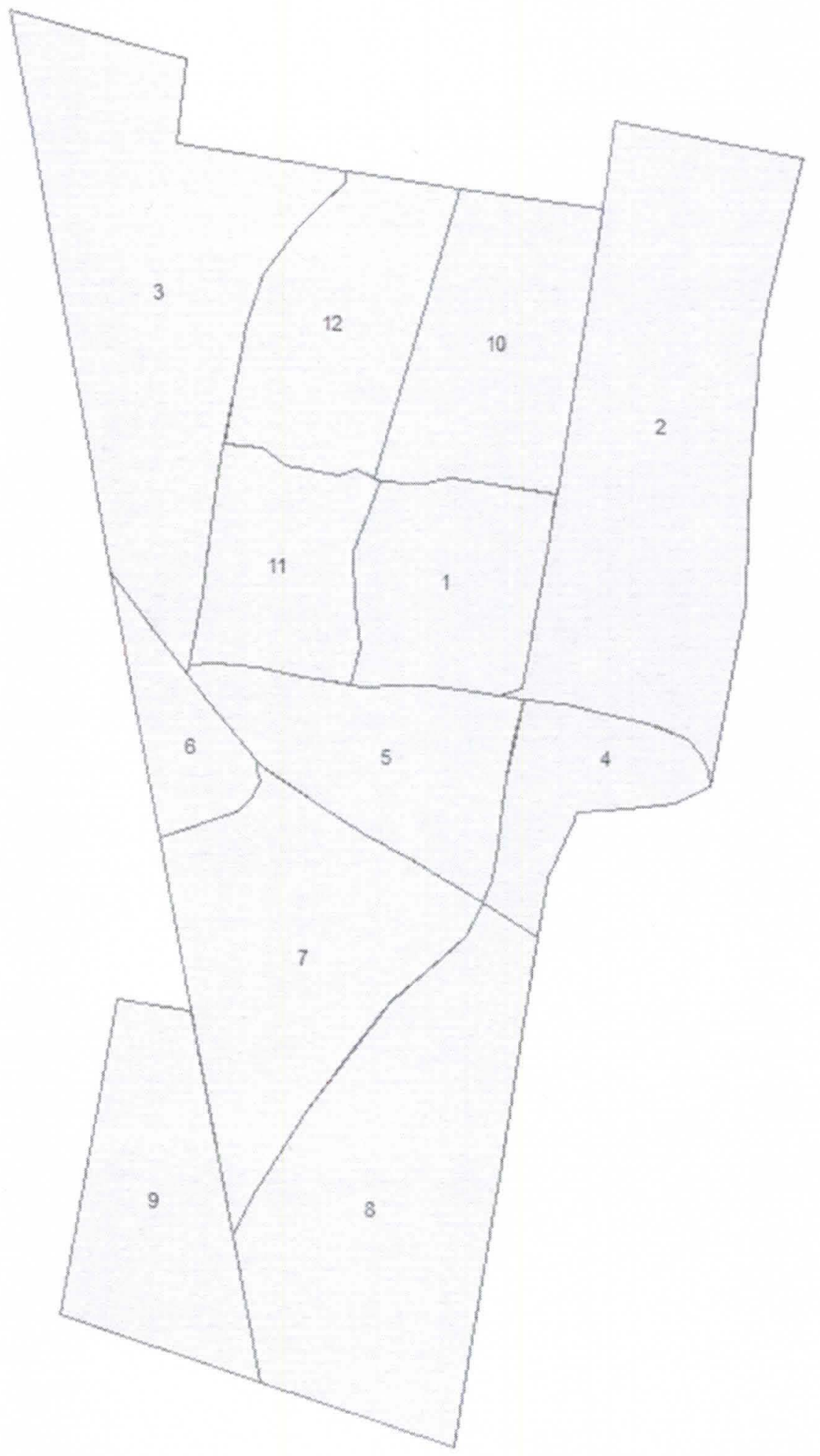

Figure 5.5 - Sub watersheds of University of Louisville's campus 


\begin{tabular}{|c|c|c|c|c|}
\hline Sub watershed ID & Area (Acre) & $\%$ Permeable & \%Impermeable & Width (ft) \\
\hline 1 & 21.76 & 44.79 & 55.21 & 973.51 \\
\hline 2 & 65.60 & 40.47 & 59.53 & 1690.41 \\
\hline 3 & 57.61 & 22.84 & 77.16 & 1584.16 \\
\hline 4 & 14.38 & 43.85 & 56.15 & 791.47 \\
\hline 5 & 25.01 & 52.28 & 47.72 & 1043.81 \\
\hline 6 & 9.74 & 14.91 & 85.09 & 651.30 \\
\hline 7 & 41.92 & $\uparrow 3.49$ & 86.51 & 1351.31 \\
\hline 8 & 56.31 & 42.55 & 57.45 & 1566.12 \\
\hline 9 & 27.57 & 34.57 & 65.43 & 1095.97 \\
\hline 10 & 27.66 & 45.09 & 54.91 & 1097.60 \\
\hline 11 & 19.24 & 67.41 & 32.59 & 915.50 \\
\hline 12 & 26.46 & 47.93 & 52.07 & 1073.55 \\
\hline
\end{tabular}

Table 5.2 - Characteristics of twelve delineated sub watersheds in University of Louisville's campus

\subsubsection{Simulation period}

The simulation component of SUSTAIN estimates the performance of BMPs in a user defined period. A rain year which represents the average rain events in Louisville was selected as the simulation period. Selecting the rain year requires taking into account several factors. The annual rain fall as well as the number of dry days in the defined year should be close to the average for recent 
years. Also big rain events shouldn't have occurred in the selected year. After analyzing rain events in the recent 15 years, year 2001 was selected as the simulation period. Figure 5.6 represents the annual rainfalls in the University of Louisville's campus since year 1996. This information were derived based on hourly readings of precipitation in station COOP:154954 near Louisville International Airport, obtained from NCDC website.

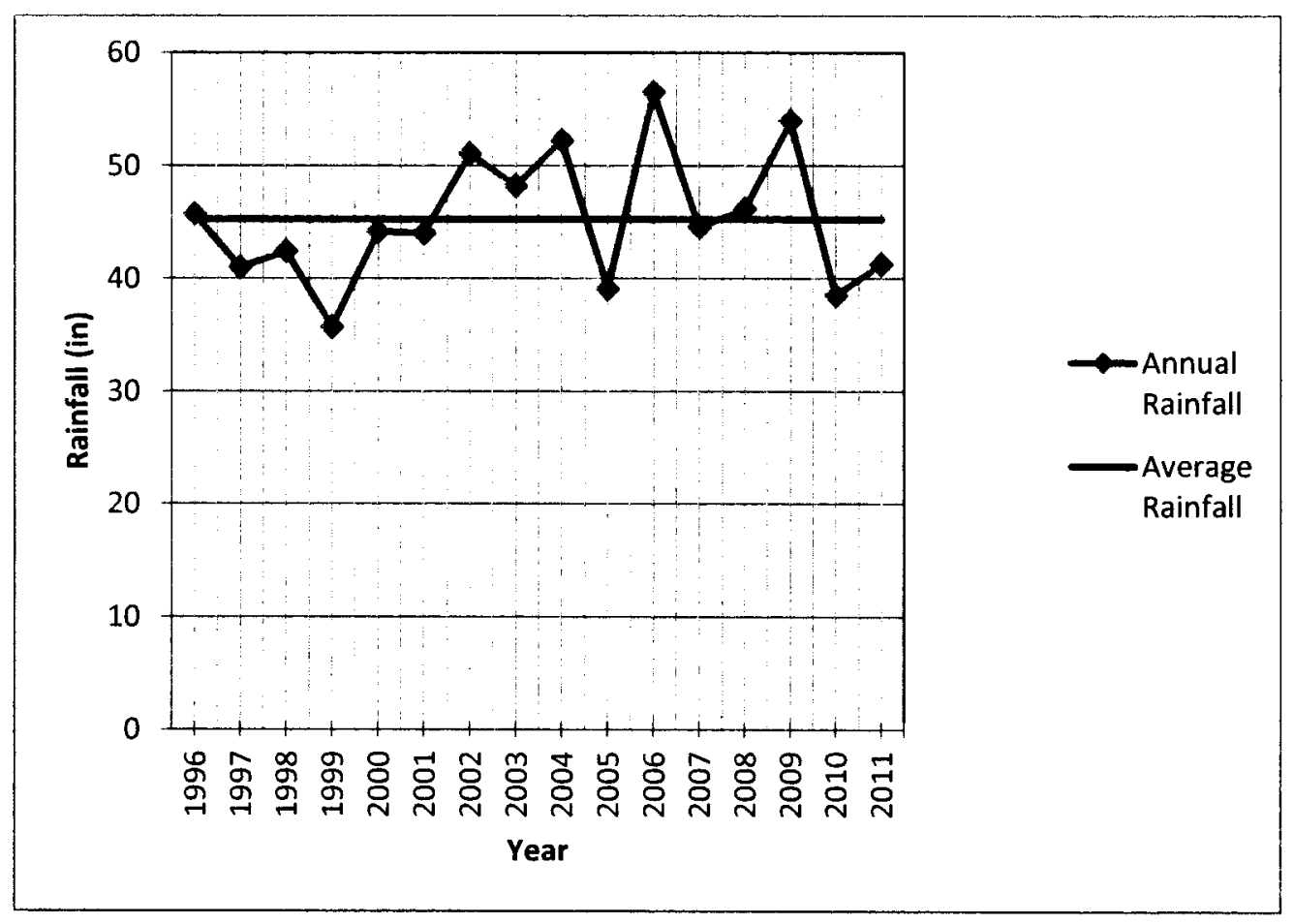

Figure 5.6 - Annual rainfall in University of Louisville's campus 


\subsubsection{Simulation setup}

The evaluation of BMPs performance and identifying cost effective scenarios involves analyzing an assortment of combinations of practices. This subsection provides the steps in setting up the BMP simulation.

After collecting the required information and inputting the needed data in SUSTAIN, BMPS should be represented for simulation. BMP representation includes defining their placement scenarios, configuration and cost. Four types of BMPs are selected for simulation, dry pond, infiltration trench, rain garden and permeable pavement. The cost information for each of these BMP were derived from Louisville MSD. Each dimension of BMPs could be set as decision parameters, by which SUSTAIN will create new scenarios based upon different dimensions but the size of existing BMPs are constant during the simulation.

The selection of BMPs for campus involves utilizing the BMP suitability map created by siting tool, and defining critical areas for flood related issues, taking into account the applicability of BMPs. In order to define the critical areas, information about previous floods on campus were reviewed. In addition, different sites of campus were visited during rain events to figure out which areas have a high potential of flooding. Different BMP scenarios were reviewed and simulated in order to achieve an efficient strategy.

In addition to defining BMP types and locations, SUSTAIN requires specifying virtual outlets in sub watersheds without any defined BMP. The location of virtual outlets were estimated by information about the sewer system 
and surface runoff direction in each sub watershed. Table 5.2 represents different types of BMPs selected for simulation and figure 5.7 shows illustrates the placement scenarios of selected BMPs, virtual outlets and the assessment point, which is discussed later in this section.

\begin{tabular}{|c|c|c|c|c|c|}
\hline BMP ID & Type & Length(ft) ${ }^{*}$ & Width(ft) & Capacity(ft^3) & Cost \\
\hline B1 & Rain garden ${ }^{*}$ & & & 4700 & $50000 \$$ \\
\hline B2 & Rain garden & 70 & 20 & & $6 \$ / \mathrm{ft}^{\wedge} 3$ \\
\hline D1 & Dry pond ${ }^{*}$ & & & 80000 & $600000 \$$ \\
\hline $\mathrm{P} 1$ & Permeable Pavement & 120 & 15 & & $12 \$ / \mathrm{ft}^{\wedge} 3$ \\
\hline $\mathrm{P} 2$ & Permeable Pavement & 40 & 20 & & $12 \$ / f^{\wedge} 3$ \\
\hline P3 & Permeable Pavement & 90 & 15 & & $12 \$ / \mathrm{ft}^{\wedge} 3$ \\
\hline 11 & Infiltration Trench & 40 & 6 & & $9 \$ / \mathrm{ft}^{\wedge} 3$ \\
\hline 12 & Infiltration Trench & 80 & 5 & & $9 \$ / \mathrm{ft}^{\wedge} 3$ \\
\hline 13 & Infiltration Trench* & & & 16000 & $200000 \$$ \\
\hline 14 & Infiltration Trench* & & & 7000 & $100000 \$$ \\
\hline 15 & Infiltration Trench & 100 & 5 & & $9 \$ / \mathrm{ft}^{\wedge} 3$ \\
\hline & ${ }^{\star}$ Existing BMPs & as del & & rameter for BMPs & \\
\hline
\end{tabular}

Table 5.3 - Defined BMPs for simulation 


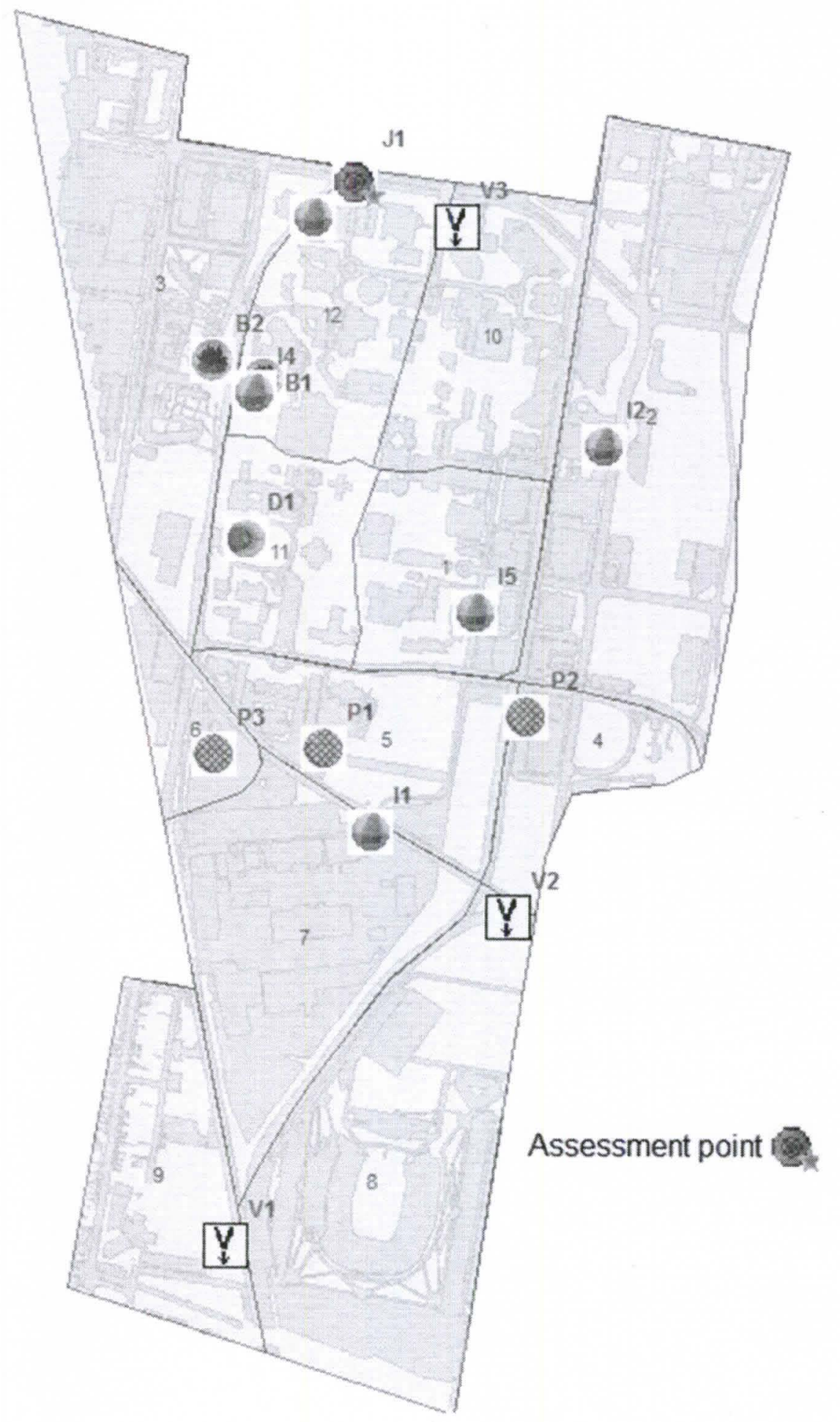

Figure 5.7 - Located BMPs for simulation 
Next step after representing BMPs includes defining the connection from drainage area to BMPs. SUSTAIN indicates this connection automatically and also allows the user to changed the estimated connections. The routing network should also be defined between each two points( BMPs, junctions or virtual outlets) in the order from upstream to downstream.

SUSTAIN requires runoff time series in order to drive the simulation. These time series represent the runoff on different range of land cover conditions and soil types and are created based on characteristics of sub watersheds and climate, pollutants, sediments and rainfall data. External simulation of SUSTAIN requires importing the runoff time series created by external models. In internal simulation the time series are created by Land module of SUSTAIN. Computing the hydrograph and pollutograph by utilizing land module includes a land simulation based on defined required climate information and sub watersheds' characteristics. The simulation estimates the runoff and pollutant in rain events based upon the precipitation, evapotranspiration, infiltration, groundwater outflow and groundwater recharge (USEPA 2009).

Next step in simulation model setup is to specify the assessment point and evaluation factors. An assessment point is the location that the runoff water parameters are evaluated and is located at the watershed outlet. The assessment point for the campus is located in the north section of it, sub watershed number 12 , as shown in figure 5.8 . Also water quantity has been 
selected as the evaluation factor at the assessment point. After defining the evaluation point and factors, the simulation can be done by creating an input file, based on the period of simulation, and running it.

\subsection{BMP simulation results}

The BMP simulation module of SUSTAIN evaluates the performance of different BMP scenarios based on the assessment factor in a specified period of time. Peak flow discharge was selected as the assessment factor and the simulation was applied in year 2001 as it represents the average rain year in Louisville. One of the results of simulation processes includes estimating the impact of stormwater runoff in different development conditions. Figures 5.9 and 5.10 represent the post developed and existing affect of stormwater runoff on flow rate and total annual runoff volume. The difference between existing and post developed conditions indicates the influence of defined BMP strategy on stormwater runoff in the area.

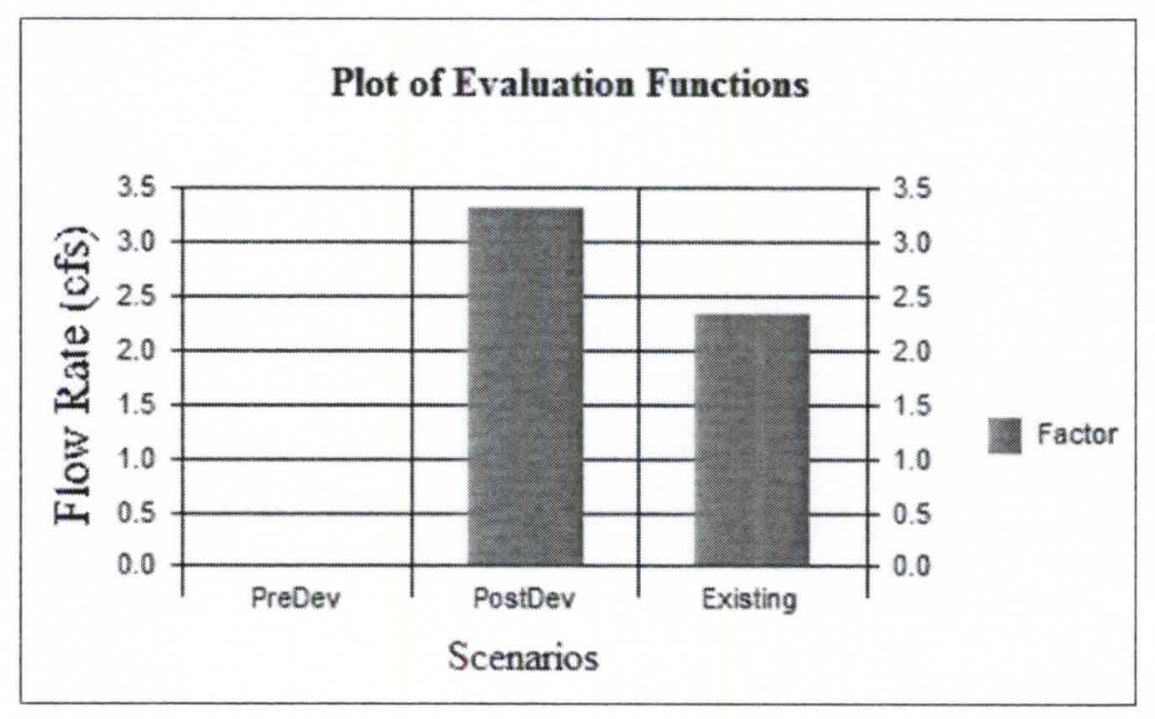

Figure 5.8 - Estimated flow rate in different conditions 
Figure above indicates that implementing the defined BMP scenario reduces the flow rate for approximately one cfs. It is notable that the post development condition is the existing condition without considering the defined BMPs in the area.

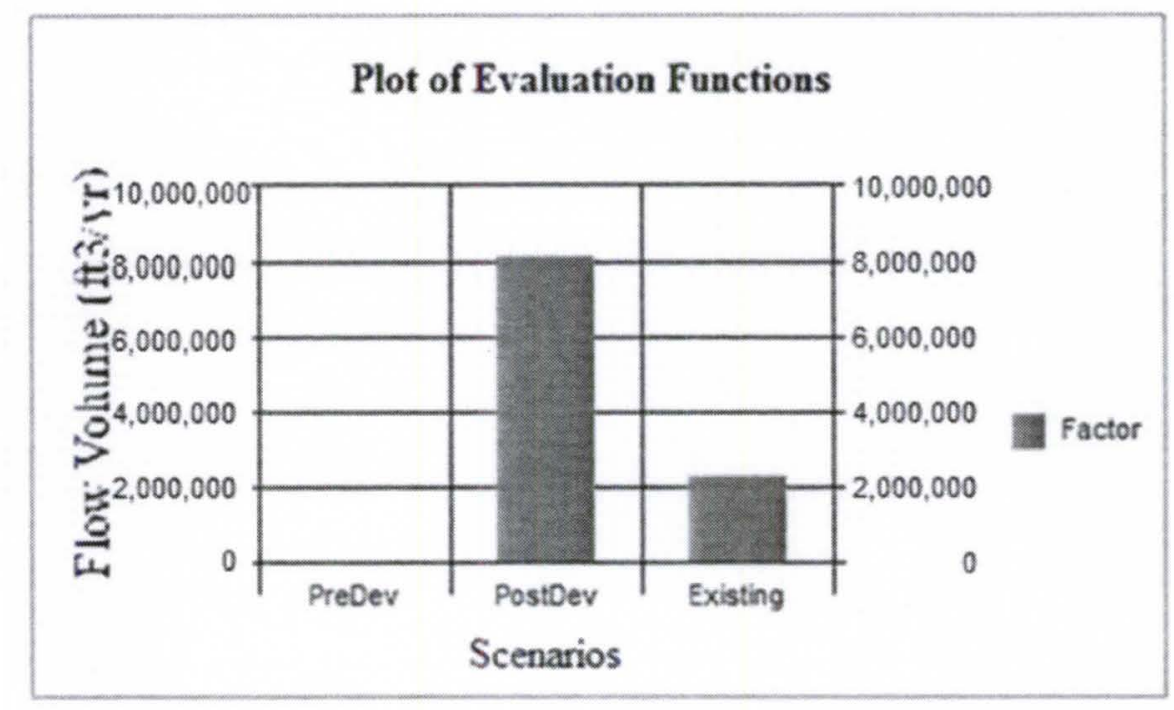

Figure 5.9 - Estimated annual flow volume

Figure above shows a reduction of $6 \mathrm{e}+6 \mathrm{ft}^{\wedge} 3$ in total amount of annual stormwater runoff by defined BMP strategy.

Another output of SUSTAIN BMP simulation is the cost effectiveness, which represents the most cost efficient scenarios based on the defined placement and types of BMPs. SUSTAIN creates this cost effectiveness curve by optimizing the specified decision parameters for each BMP. This curve shows the percentage of reduced stormwater peak flow discharge by different scenarios at the least cost. Figure 5.11 illustrates these optimization results. 


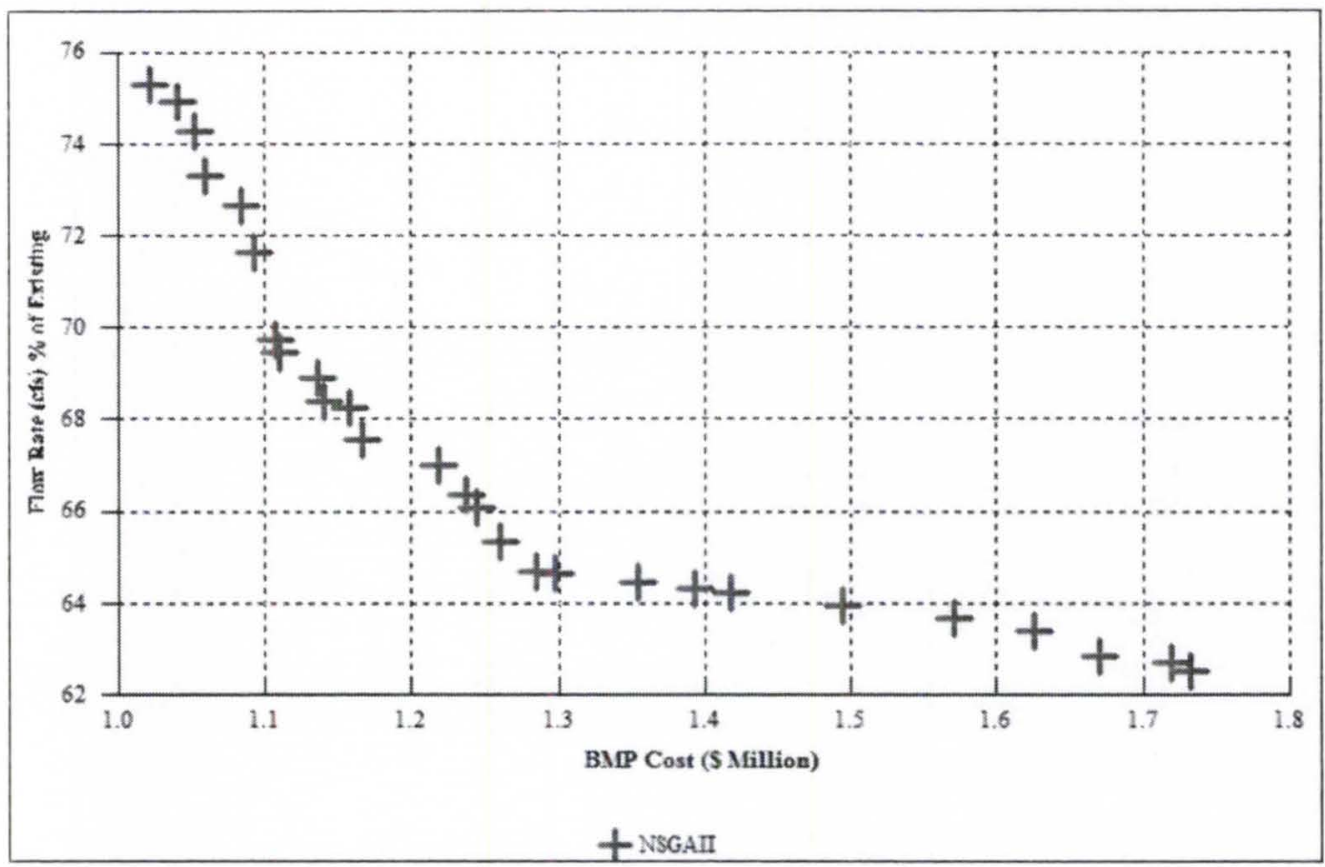

Figure 5.10 - Optimization results: Cost $\sim$ control effectiveness

The next results of SUSTAIN model simulation is derived by the postprocessor module which unifies the analyzes the simulation outputs. The storm event classification component of post-processor, assesses the rainfall data used in the simulation and classifies the storm events based on the user-defined criteria. figure 5.12 illustrates the storm events based on the total volume.

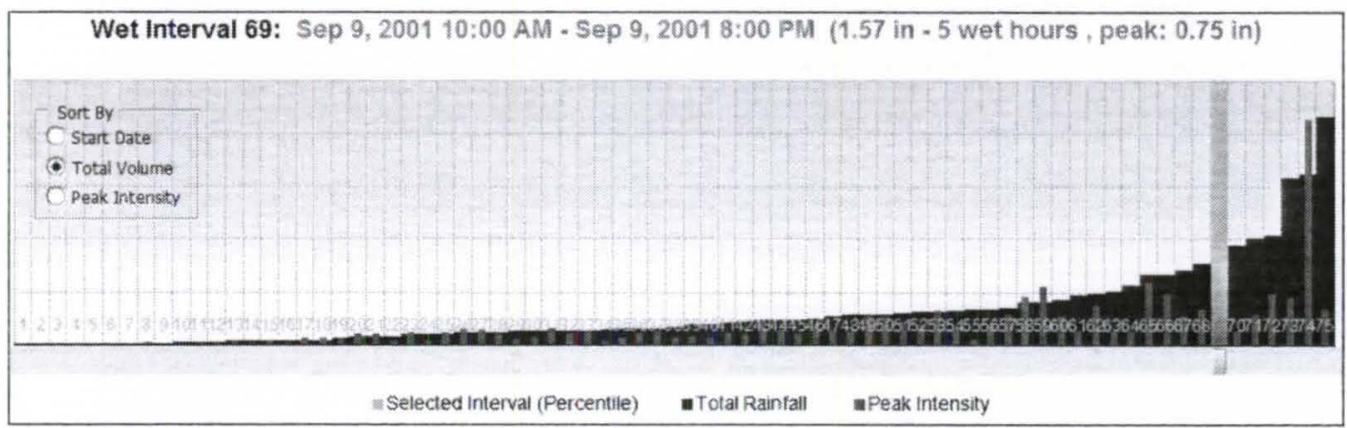

Figure 5.11 - Precipitation events sorted by total volume 
The other decision making support output of post-processor is a costeffectiveness curve. This curve shows the cost effectiveness of different BMP scenarios based on their impact on the defined evaluation factor (i.e. total runoff volume reduction). Figure 5.13 illustrates the average decrease in stormwater peak flow discharged by different scenarios based on their costs. In this figure, each point represents a BMP scenario which have been assessed during the optimization; the orange points represent the most cost effective selection at each percentage of runoff peak flow decrease.

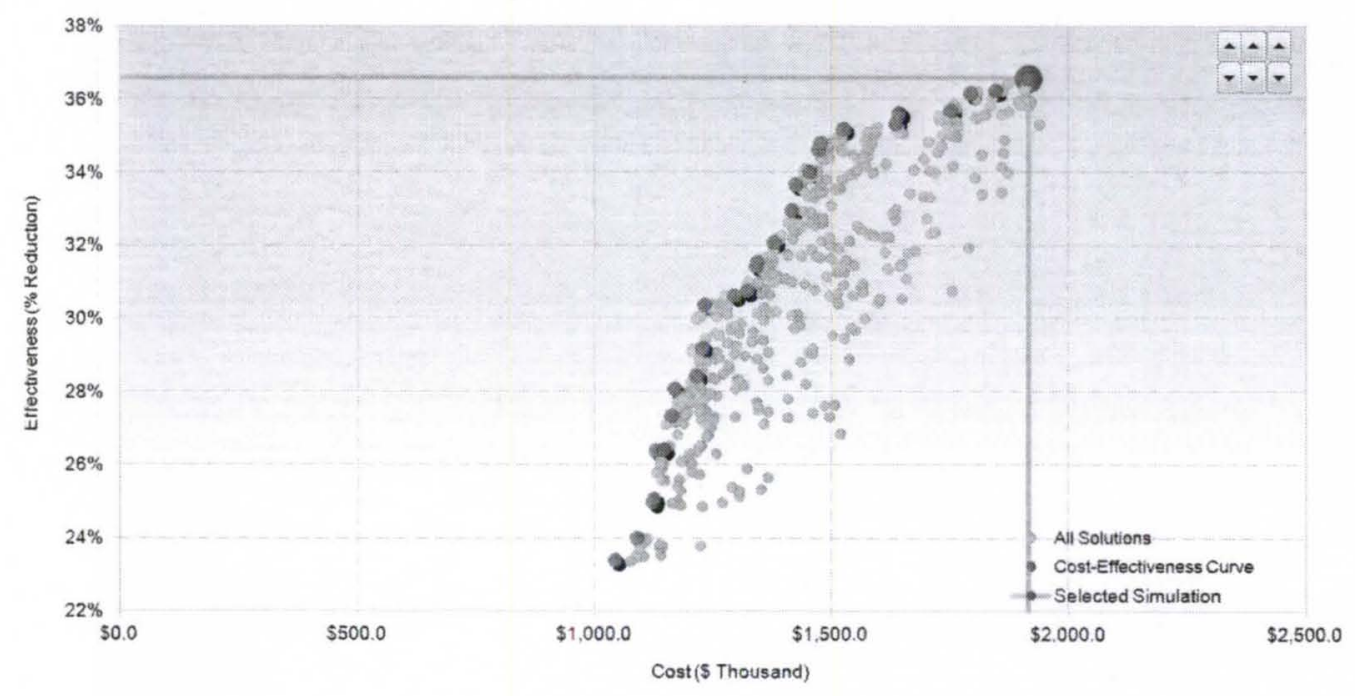

Figure 5.12 - Cost-effectiveness curve

The cost effectiveness curve pairs with a cost distribution graph. The user can select a BMP scenario from the cost effectiveness curve(figure 5.13) and see the detailed information of the selected scenario. These information include types and the distribution of BMPs in the scenario. As an example, information about the selected cost effective BMP scenario based on a $36.8 \%$ peak flow discharge in figure 5.13 are represented in figure 5.14 .In the selected scenario, $37 \%$ of the 
total cost is related to implementing permeable pavements. For dry pond this number is $31 \%$. The BMP distribution for three cost effective scenarios are represented in table 5.3.

Although this map doesn't provide specific information about the locations or the exact dimension of BMPs, knowing the related distribution of practices with the points in cost effectiveness curve helps the user into the order of selecting BMP types.

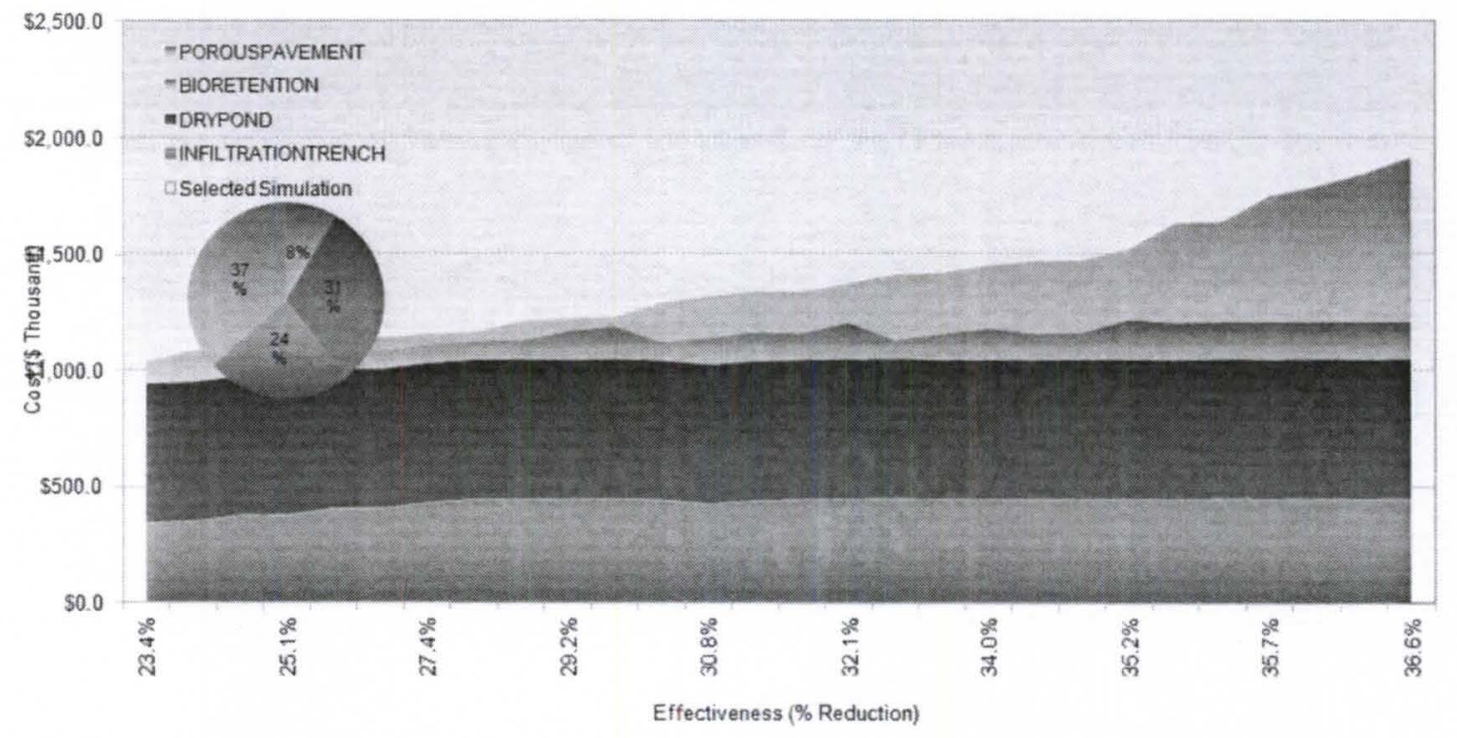

Figure 5.13 - BMP cost distribution 


\begin{tabular}{|c|c|c|c|c|c|}
\hline $\begin{array}{c}\text { Reduction } \\
\text { target }\end{array}$ & Cost & $\begin{array}{c}\text { Porous } \\
\text { Pavement }\end{array}$ & Bioretention & Dry pond & $\begin{array}{c}\text { Infiltration } \\
\text { trench }\end{array}$ \\
\hline $\mathbf{3 6 \%}$ & $1,845,000 \$$ & $34 \%$ & $9 \%$ & $33 \%$ & $24 \%$ \\
\hline $\mathbf{3 4 \%}$ & $1,453,000 \$$ & $19 \%$ & $9 \%$ & $41 \%$ & $31 \%$ \\
\hline $\mathbf{3 0 \%}$ & $1,231,000 \$$ & $3 \%$ & $12 \%$ & $49 \%$ & $36 \%$ \\
\hline
\end{tabular}

Table 5.4 - BMP distribution in three different scenarios

\subsection{Summary}

This chapter provided multiple steps in SUSTAIN model simulation approach for evaluating BMP scenarios and to estimate the most cost effective strategies to alleviate the negative impacts of stormwater runoff in University of Louisville. These steps include collecting the required data, representing BMPs for simulation, delineating sub watersheds, selecting the period for the simulation and defining the assessment point and factors. The assessment factor was selected as runoff peak flow discharge, because most of the negative impacts of stormwater runoff in Louisville are because of high flow rates. The initial results of simulation approach indicates the performance of defined BMP scenario on stormwater runoff peak flow discharge. A total reduction of one cfs was estimated by SUSTAIN. Also a cost effectiveness graph represents the most efficient scenarios for reducing runoff peak flow discharge at the least costs based on the defined BMP types and placement. This graph is created by optimizing the decision parameter for each BMP, which was specified during the BMP 
representation. Except for the existing BMPs, for all other BMPs the length factor was defined as the decision parameter.

The next step in SUSTAIN modeling is to post-processor module to work. This module simplifies the results of simulation. The post-processor outputs includes different graphs such as storm event classification and costeffectiveness curve. the storm event classification illustrates the rain events during the simulation period and gives the user the option to sort them by total volume or intensity. The cost effectiveness curve, which pairs with a cost distribution graph, helps the user to identify the cost effective BMP scenarios for achieving the desired effect on different stormwater negative impacts. Both the cost-effectiveness curve and the BMP cost distribution graphs are created based on the defined assessment point and factor. 


\section{DISCUSSION}

\subsection{Conclusion}

The research was aimed at utilizing SUSTAIN as a decision making tool to help the stormwater management plan of University of Louisville in different ways. By utilizing SUSTAIN's siting tool the potential locations for installing different types of BMPs were identified. The output of this part, a BMP suitability map, can be used in future stormwater management plans in the university by providing information about potentiality of different locations of campus for implementing BMPs. In addition, different BMP scenarios were identified based of different budgets by utilizing BMP simulation module of SUSTAIN. The results of simulation can be used for estimating the current hydrological condition of campus and the most cost effective scenarios for future plans.

The simulation model was created based on University of Louisville's geological, municipal and precipitation information. This model can be utilized for future plans in campus. Any proposed BMP scenario could be simulated by this model and the efficiency and performance of the scenario can be estimated by utilizing the created model.

The impacts of implementing BMP scenarios were estimated in this study. The results, as discussed in chapter 5 , indicates that BMP scenarios can help in 
stormwater management by reducing the stormwater runoff volume and peak flow discharge in University of Louisville. It was indicated that an average amount of $8,000,000 \mathrm{ft}^{\wedge} 3$ runoff water is caused by precipitation annually. This high volume is caused by the developed impervious surfaces and the intensive rain events in the city. Due to the high runoff volume and peak flow discharge, efforts to resolve these problems should be taken into account for future plans in University of Louisville. The results of simulation model indicates a significant reduction in stormwater runoff volume and peak flow discharge by implementing BMP scenarios. Also some recommendations were introduced for future BMP strategy plans.

There are several advantages associated with modeling stormwater flow with SUSTAIN. Its AcrGIS platform gives the users an easy-to-use interface. By utilizing the siting tool, the suitable locations for BMPs can be identified and the output could serve as a guidance tool for future planning efforts of campus. SUSTAIN also takes into account the water quality as well as water quantity into the simulation. Both flow and pollutant factors can be specified to simulate the performance of BMPs.

Even though SUSTAIN modeling effort has several advantages, it also has some limitations. One of the issues that may change the precision of the results is the accuracy of the precipitation data used in the simulation. The precipitation measured at the rain gage located near Louisville International Airport was assumed to be consistent on all campus' areas. Another limitation of SUSTAIN is that the long term performance of BMPs cannot be estimated by the 
simulation. The efficiency of BMPs decreases during time, mainly because of clogging. For this reason frequent maintenance is required for BMPS. SUSTAIN, as well as many other BMP simulation models, does not estimate the rate of clogging so the user cannot estimate and take into account the long term performance of BMPS and the cost of required maintenances. SUSTAIN does not consider the sewer system network in the simulations. The sewer system network can affect the stormwater runoff direction and is an important part of BMP performance simulation. This issue was resolved by taking into account the sewer system network in delineating sub watersheds as discussed in chapter 5 .

Based on the findings of the created simulation model and its outputs, the followings can be concluded:

- The maximum achievable stormwater runoff reduction through the use of cost effective BMP scenarios is $36.5 \%$

- The total annual surface runoff in campus without considering the BMPs is around $8,000,000 \mathrm{ft}^{\wedge} 3$. Implementing the suggested BMP scenario will reduce this number to $2,000,000 \mathrm{ft}^{\wedge} 3$.

- The flow rate in post development condition in campus is $3.25 \mathrm{cfs}$, and this number reduces to 2.25 with utilizing the defined BMP scenario.

- Based on the cost effectiveness curve, dry ponds and infiltration trenches have the most distribution in cost effective scenarios. By increasing the treatment levels the utilization of permeable pavements increases as well and in the flow reduction target of 
$36 \%$, it is higher than other BMPs. The utilization of rain gardens is almost consistent in different scenarios.

\subsection{Future works}

In order to be a practical and precise BMP simulation, the required data need to be more accurate. For example, obtaining more accurate rain fall data for campus would lead to a better simulation. In planning a stormwater management plan, in addition to installation cost of BMPs their maintenance costs should be taken into account. A research on the rate of clogging during long periods of time is required in order to enhance the preciseness of cost estimations.

For evaluating the simulation results, monitoring data is required. Before implementing future BMPs in campus, the performance of BMPs should be estimated by SUSTAIN using the current model, and based on the monitoring data an assessment could be made to estimate the accuracy of the model. 


\section{REFERENCES}

Acherman, D. and E. D. Stein (2008). "Evaluating the Effectiveness of Best Management Practices Using Dynamic Modeling." Environmental Engineering. $134(8), 628-639$.

Beven, J. K. (2001). Rainfall-Runoff Modeling, The Primer, John Wiley \& Sons Ltd., Chichester, 319, 2001.

Bracmort, S. (2002). The Black Creek Watershed Project: The Modeling of Terraces Using HEC-HMS, Purdue University.

Bross, I. D. J. (1953). Definition for design, The Macmillian Company, New York. N.Y.

D.Beach (2002). "Coastal Sprawl: The Effects of Urban Design on Aquatic Ecosystems in the United States (Arlington, VA: Pew Ocean Commission, 2002).".

Damodaram, C. and E. Zechman (2010). "Optimizing the Placement of Low Impact Development in an Urban Watershed."

Day, S. D. and S. B. Dickinson (2008). "Managing Stormwater for Urban Sustainability using Trees and Structural Soils. Virginia Polytechnic Institute and State University, Blacksburg, VA.".

DEQ Combined/Sanitary Sewer Overflow Information, Department of Environmental Quality.

Emerson, C. H. (2008). Evaluation of Infiltration Practices as a Means to Control Stormwater Runoff. Villanova University.

EPA (2001). Managing sanitary sewer overflows and combined sewer overflows to prevent contamination of drinking water. U. S. E. P. A.-O. o. Water.

EPA (2007). Reducing Stormwater Costs through Low Impact Development (LID) Strategies and Practices,EPA 841-F-07-006.

EPA (2009). Technical Guidance on Implementing the Stormwater Runoff Requirements for Federal Projects under Section 438 of the Energy 
Independence and Security Act. E.-B.-.-. United States Environmental Protection Agency - Office of Water. Washington.

EPA. (2012). "National Pollutant Discharge Elimination System - Combined Sewer Overflows." from http://cfpub.epa.gov/npdes/home.cfm.

F.Peluso, V. and A. Marshall (2002). BEST MANAGEMENT PRACTICES FOR SOUTH FLORIDA URBAN STORMWATER MANAGEMENT SYSTEMS, South Florida Water Management District.

Gross, M. A. (2005). Wastewater Characterization Text. in (M.A. Gross and N.E. Deal, eds.) University Curriculum Development for Decentralized wastewater Management. National Decentralized Water Resources Capacity Development Project. University of Arkansas, Fayetteville, AR.

H.Doan, J. Development and Application of Geospatial Hydrologic Model Extension HEC-GeoHMS. U. A. C. o. E.-D. Hydrologic Engineering Center, California.

ISU (2008) "lowa Stormwater Management."

IUPUI Stormwater Management Financing Case Study Louisville- Jefferson County Kentucky, Center for Urban Policy and the Environment - Indiana University.

Kaini, P., K. Artita, et al. "Optimizing Structural Best Management Practices Using SWAT and Genetic Algorithm to Improve Water Quality Goals." Water Resources Management: 1-19.

Kao, J. J. and C. H. Tsai (1997). "Multiobjective Zone TP Reduction Analyses for an Off-stream Reservoir." Journal of Water Resources Planning and Management, ASCE, Vol. 123, №. 4, 1997.

Livingston, E. (2001). Stormwater Management in Florida: The Past, The Present, and the Future, Bureau of Watershed Management, Florida Dept. of Environmental Protection.

Maidment, D. R. (1993). Handbook of Hydrology. McGraw-Hill, New York, NY. Marczyk, A. (2004). Genetic Algorithms and Evolutionary Computation, http://www.talkorigins.org.

Marek, M. A. (2011). Hydraulic Design manual. T. D. o. T. (TxDOT). Texas, Design Division (DES).

Marti, R. and M. Laguna (2003). Principles of Scatter Search, Universidad de Valencia. 
Mays, L. W. and P. B. Bedient (1982). "Model for Optimal Size and Location of Detention." Journal of Water Resources Planning and Management, ASCE, Vol. 108 , No. WR3, 1982 .

Mog, J. M. (2012). "Stormwater." from http://louisville.edu/sustainability/operations/stormwater.html. MPCA (2000). Storm Water Runoff Best Management Practices, Minnesota Pollution Control Agency.

MSD (2010). Stormwater Management Master Plan. L. a. J. C. M. S. District. ODOT (2005). Hydraulics Manual. O. D. o. Transportation. Oregon.

PEC (2006). Improving Stormwater Detention Basins for Better Stormwater Management, Pennsylvania Environmental Council.

Perez-Pedini, F. L. James, et al. (2005). "'"Optimal location of infiltration based best management practices for storm water management." Journal of water resources planning and management.

Riverkeeper "Sustainable Raindrops: Cleaning New York Harbor by Greening The Urban Landscape."

Rossman, L. A. (2005). "Stormwater Management M odel User's Manual, Version 5.0. EPA/600/R-05/040.

U.S. Environmental Protection Agency, Water Supply and Water Resources Division, National Risk Management Research Laboratory, Cincinnati, $\mathrm{OH}$.". Schardein, B. (2004). COMBINED AND SANITARY SEWER OVERFLOW ISSUES MSD, A NEW FOCUS Louisville \& Jefferson County Metropolitan Sewer District.

Sewell, J. (1998). EVOLUTION OF HYDROLOGICMATERSHED MODELING PROJECTS. T. A. E. Station.

Srivastava, P. and J. M. Hamlett (2002). "Watershed Optimization of Best Management Practices Using AnnAGNPS and a Genetic Algorithm." Water Resources Research, American Geophysical Union, Vol. 38, No. 3 .

TetraTech, I. (2008). Stormwater Best Management Practices (BMP) Performance Analysis United States Environmental Protection Agency - Region 1.

TetraTech, I. (2010). Stormwater Best Management Practices (BMP) Performance Analysis. U. S. E. P. A. R. 1. Boston. 
Tsihrintzis, V. A. and C. B. Sidan (2008). "ILLUDAS and PSRM-QUAL predictive ability in small urban areas and comparison with other models." Hydrological Processes, 22(17), 3321-3336.

URS (2012). Green infrastructure performance assessment: CSO 130 business case., URS Corporation, Louisville, KY, 1-12.

USACE (2010). HEC-GeoHMS Geospatial Hydrologic Modeling Extention. H. E. C. US Army Corps of Engineers.

USACE (2010). Hydrologic Modeling System HEX-HMS User's Manual. H. E. C. US Army Corps of Engineers.

USDA (1997). Summary Report: 1997 National Resources Inventory (Washington, DC: U.S. Department of Agriculture, Natural Resources Conservation Service, 1999 [revised 2000].

USDA (2009). "Summary Report: 2007 National Resources Inventory, Natural Resources Conservation Service, Washington, DC, and Center for Survey Statistics and Methodology, lowa State University, Ames, lowa. 123 pages.

http://www.nrcs.usda.gov/technical/NRI/2007/2007_NRI_Summary.pdf." USEPA SUSTAIN - System for Urban Stormwater Treatment and Analysis INtegration Model, U.S. Environmental Protection agency - Risk Management Water Research.

USEPA (2004). Storm Water Management Model User's Manual. U. S. E. P. Agency. Cincinnati.

USEPA (2004a). "Stormwater Best Management Practice Design Guide." EPA/600/R-04/121. U.S. Enviro nmental Protection Agency, Office of Research and Development, Washington, DC.

USEPA (2004b). "The Use of Best Management Practices (BMPs) in Urban Watersheds." EPA/600/R-04/184. U.S. Environmental Protection Agency, Office of Research and Development, Washington, DC.

USEPA (2007). National Management Measures to Control Nonpoint Source Pollution from Hydromodiication. U. S. E. P. A.-O. o. Water.

USEPA (2009). Storm Water Management Model Applications Manual. U. S. E. P. Agency.

USEPA (2009). SUSTAIN - A Framework for Placement of Best Management Practices in Urban Watersheds to Protect Water Quality. U. S. E. P. A.-O. o. R. a. Development. 
Vijay, P. S. (1995). Computer Models of Watershed Hydrology, Water Resource Publications.

W.Delleur, J. (2003). "The Evolution of Urban Hydrology:Past, Present, and Future." JOURNAL OF HYDRAULIC ENGINEERING. 


\section{CURRICULUM VITAE}

\section{EDUCATION}

University of Louisville - Kentucky - USA

Jan. 2011- August 2012

- Master of Science in Civil and Environmental Engineering (Specialized in Environmental and Transportation Engineering)

GPA: $3.55 / 4$

Saga University - Japan - Saga

Sep.2008 - Jan. 2009

- Department of Continuing Education

Ferdowsi University of Mashhad, Iran

Sep. 2004- June 2010

- Bachelor of Science, Civil Engineering (Specialized in Environmental, Transportation and Construction Engineering)

GPA: $2.62 / 4$

\section{HONOURS/AWARDS}

- Ranked $1^{\text {st }}$ in Water Professional Conference Student Poster Competition July 2011

- Honored to become a research assistant at University of Louisville, Civil Engineering Department - May 2011 
- Ranked 3rd in the Iranian Azad University of Tehran entrance exam in Civil Engineering, Summer 2004 among 40000 candidates

- Ranked in the top $15 \%$ of the Civil Engineering department of Ferdowsi University of Mashhad

- Ranked in the top $\mathbf{0 . 5 \%}$ of universities entrance exam in Iran among 500,000 participants

- Amongst 40 admitted students in Mashhad NODET high school \& preuniversity (Shahid Hashemi Nejad),competing 10,000 other participants

\section{RESEARCH INTERESTS}

Environmental Engineering: Green engineering, Wastewater treatment methods, Hurricane management and modeling, Renewable energies, Sediment transportation, Stormwater management and modeling

Transportation Engineering: Intelligent Transportation Systems, Transportation economics, Highway traffic and noise modeling

\section{RESEARCH EXPERIENCE}

\section{University of Louisville - Department of Civil Engineering}

- Master's Thesis - Developed a hydrologic computer model to make recommendations for watershed Best Management Practices(BMPs, stormwater management measures) as a part of green stormwater master plan in University of Louisville, funded by Louisville Metropolitan Sewer District

Under supervision of Dr. Rockaway

May 2011 - August 2012

- University of Louisville's green stormwater master plan is aiming to firstly reduce overall storm water flow and second, to reduce flooding during the 25 year storm event in the campus, taking into account the water quality. As a part of this project a hydrologic and water quality simulation model of campus was developed using USEPA's SUSTAIN (US Environmental Protection Agency's System for Urban Stormwater Treatment and Analysis INtegration, a GIS-based hydrologic model) in order to determine the most efficient type, quantities and locations of BMPs necessary to make a measurable difference on the stormwater runoff quantity and quality at the least cost. 
- Prepared a report on utilizing TNM 2.5 (Traffic Noise Model 2.5) for a portion of Interstate 264 in Louisville, to estimate the current and future noise levels for the year 2040 in the area and determine an efficient solution for the reduction of future noise impacts.

Under supervision of Dr.Cohn

April 2012

- Involved in designing, installing and maintaining permeable pavements and monitoring their performance in Louisville, Supervised by USEPA, Louisville MSD, URS Corp. and University of Louisville

December 2011 - August 2012

- Participated in constructing permeable pavements and installing monitoring instruments

- Collecting and analyzing post-construction monitoring data to evaluate the performance of BMPs

- Performing pre- and post-maintenance surface infiltration tests to assess the efficacy of BMP maintenance operations

- Prepared a report on utilizing the QRSII and GNE software to model traffic issues for a portion of the Louisville metro area

Under supervision of Dr.Cohn

December 2011

- Collected socioeconomic data of 10 TAZ's (Traffic Analysis Zones) as well as 5 external zones in order to use QRSIl for predicting system traffic

- Network modeling of the stations were done using GNE software

- Possible shortcomings of these two software were identified and the report included several proposed solutions to these problems.

- Prepared a report for Louisville Metropolitan Sewer District on utilizing USEPA's SUSTAIN to identify suitable locations for installing different types of BMPs in University of Louisville's Belknap Campus.

Under supervision of Dr.Rockaway

November 2011

- Wrote a review of Rigid and Flexible pavement design, Case study: City of Louisville

July 2011

- The traffic loadings were calculated for both rigid and flexible pavement, then the pavement was designed using AASHTO and AL method. The acquired results were compared and analyzed extensively 
- Performed cost analysis for installing BMPs to reduce runoff water in University of Louisville's campus.

Under supervision of Dr.Rockaway

April 2011

- Prepared a review of different applied Intelligent Transportation Systems in Kentucky Under supervision of Dr.Harris

July 2011

\section{Ferdowsi University of Mashhad - Department of Civil Engineering}

- Design of concrete for a five story residential building-Bachelor's thesis project Under Supervision of Prof. Esfahani

- The building was designed using Etabs and SAFE

\section{Spring 2010}

- Design of steel for a three story commercial building- Bachelor's thesis project Under Supervision of Dr. Shahabian

Spring 2010

- The design parameters were calculated using simulation software such as SAP 2000.

- Prepared a review on liquid flow measurement systems Under supervision of Prof. J.Ketabdari

Spring 2009

- Prepared a report on effects of geosynthetics on reduction of reflection cracking in asphalt overlays, Under supervision of Prof. Ziaee

Winter 2009

- Research on the environmental effect of surface water stream's PH. Under supervision of Prof. Shokoohian

Spring 2007

- Prepared a review of traffic flow models, case study example in city of Mashhad-Iran, , Under supervision of PhD. Student H.R. Behnood

Spring 2008

- Prepared a research on Techniques of wastewater treatment with an emphasis on sediment transportation in storm water runoff

Winter 2007 


\section{WORK AND TEACHING}

Internship Sara Commercial Complex- Ferdowsi University of Mashhad

Jan 2010 - May 2010

Under supervision of Prof. M.R. Jafarzadeh

- Assisted engineers in the preparation of plans

- Conduct site visits to perform inspections and to track work progress of the project

- Prepared monthly project progress reports

Construction and project Manager- Number 11 Construction Consultant Mashhad Iran

Jan 2006 - Jan 2008

- Assisted engineers in developing and implementing quality control programs

- Participated in scheduling the project to meet the deadlines

- Prepared budget estimates to complete the project

- Evaluated construction methods and determined cost-effectiveness of plans

Teacher Assistant- Ferdowsi University of Mashhad- Physics 101

Fall and Spring 2007

- Was in charge of tutoring the introductory Physics course

Educational adviser and curriculum planner- Mehregan Toos Educational Institute -Mashhad

October 2004 - June 2005

- Education advisor for university entrance exam candidates

\section{SKILLS}

- Proficient in ArcGIS, QRSII, GNE, SUSTAIN, TNM, Microsoft Office

- Knowledge of contract documentation, estimations, construction practices, proposal preparation and procurement strategies gained from work experience and project management courses

- Adaptable to new softwares

- Proven ability to communicate and coordinate effectively with team members and a wide spectrum of clients 
- Highly motivated and proactive individual with a proven ability to prioritize tasks and work with minimal supervision to meet strict deadlines

\section{GRADUATE COURSES}

- Advanced Hydrology $(B+)$

- Capstone design (A)

- Green Engineering and sustainable design (A)

- Intelligent Transportation Systems (B)

- Pavement Design (A)

- Introduction to GIS (B)

- Transportation plan and design deviation (A)

- Environmental analysis of transportation systems (A)

\section{ACTIVITIES}

- President and VP finance of Ferdowsi university outdoor club : planned and managed several nature camps throughout the year with almost 100 participants

- 8 hours of training in Concrete Day symposium, Mashhad, Iran September 2008

- 10 hours of training in $13^{\text {th }}$ National Conference for civil engineering students, Kerman, Iran

- Former member of Iran concrete Institute

- Hosting committee in Truss Competitions, Ferdowsi University of Mashhad, Iran (Jan 2005 - Jan 2007)

- Participating in "Spaghetti Truss Competition" Kashan,, August 2005

- Swimming and Bodybuilding for more than 10 years

\section{LANGUAGES}

- Persian: Native, English: Fluent, Arabic: Familiar Japanese: Familiar

\section{REFERENCES}

Dr. T. D. Rockaway

Associate Professor - Director, Center for Infrastructure Research

University of Louisville, Kentucky, USA

PHONE: (502) 852 - 3272

E-MAIL: tdrock01@louisville.edu 
Dr. L. F. Cohn

Professor

University of Louisville, Kentucky, USA

PHONE: (502) 852 - 4546

EMAIL:cohn@louisville.edu 